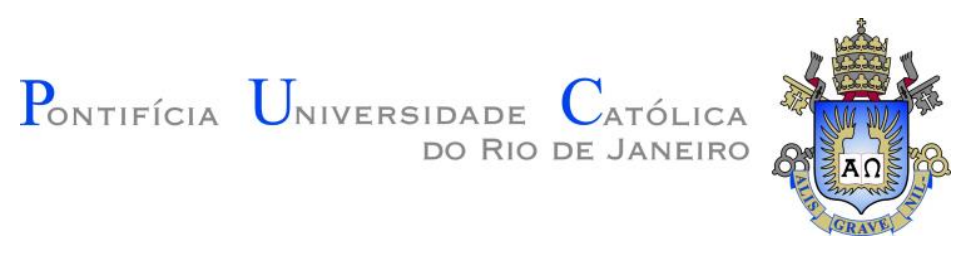

Juan Andres Huang Sam

Numerical implementation of the elastoplastic constitutive model of Lade and Kim for 3D analysis of embankments

\author{
Dissertação de Mestrado
}

Dissertation presented to the Programa de Pós-graduação em Engenharia Civil of PUC-Rio in partial fulfillment of the requirements for the degree of Mestre em Engenharia Civil.

Advisor: Prof. Celso Romanel 


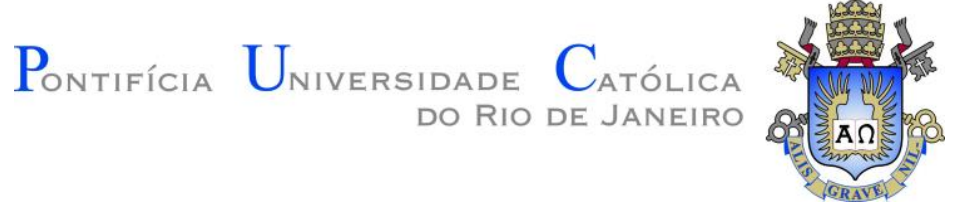

Juan Andres Huang Sam

\section{Numerical implementation of the elastoplastic constitutive model of Lade and Kim for 3D analysis of embankments}

Dissertation presented to the Programa de Pós-graduação em Engenharia Civil of PUC-Rio in partial fulfillment of the requirements for the degree of Mestre em Engenharia Civil. Approved bythe Examination Committee.

Prof. Celso Romanel

Advisor

Departamento de Engenharia Civil e Ambiental- PUC-Rio

Profa. Christianne de Lyra Nogueira Departamento de Engenharia de Minas - UFOP

Prof. Nelson Inoue

Departamento de Engenharia Mecânica-PUC-Rio 
All rights reserved.

\section{Juan Andres Huang Sam}

Majored in Civil Engineering by the Ricardo Palma University (Lima, Peru) in 2016.

Bibliographic data

Huang Sam, Juan Andres

Numerical implementation of the elastoplastic constitutive model of Lade and Kim for 3D analysis of embankments / Juan Andres Huang Sam; advisor: Celso Romanel. - Rio de Janeiro: PUC-Rio, Departamento de Engenharia Civil e Ambiental, 2020.

97 f: il. ; $29,7 \mathrm{~cm}$

Dissertação (mestrado) - Pontifícia Universidade Católica do Rio de Janeiro, Departamento de Engenharia Civil e Ambiental.

Inclui bibliografia

1. Engenharia Civil - Teses. 2. Lade-Kim constitutive model. 3. Embankment. 4. Deformation analysis. I. Romanel, Celso. II. Pontifícia Universidade Católica do Rio de Janeiro. Departamento de Engenharia Civil e Ambiental. III. Título.

CDD: 624 

whom I miss dearly. 


\section{Acknowledgments}

I would like to first thank my advisor, Prof. Celso Romanel, for his advices throughout the master program and the elaboration of this dissertation.

Then I wish to thank my parents, for their sacrifice and support in every single step of my life;

My brother, for caring about me;

Karen, for her love and company during the elaboration of our dissertations;

David, for his friendship, guidance during the program and contributions to this dissertation;

Jackeline, for her friendship, support and advices during my time at the PUC-Rio;

My aunt Sandra, for looking after me;

Mr. Hugo, Ms. Liliana and Anthony, for their support;

The professors of the department of Civil Engineering at PUC-Rio, for their commitment and the lessons taught;

The CNPq, for the financial support;

This study was financed in part by the Coordenação de Aperfeiçoamento de Pessoal de Nível Superior - Brasil (CAPES) - Finance Code 001 


\begin{abstract}
Huang Sam, Juan Andres; Romanel, Celso (Advisor). Numerical implementation of the elastoplastic constitutive model of Lade and Kim for 3D analysis of embankments. Rio de Janeiro, 2020, 97p. Dissertação de Mestrado - Departamento de Engenharia Civil e Ambiental, Pontifícia Universidade Católica do Rio de Janeiro.
\end{abstract}

Geotechnical engineering problems, where the design is mainly influenced by the shear strength, can be successfully analyzed considering a traditional constitutive model; however, advanced constitutive models must be used when the estimative of deformation is an important factor to be considered. Lade and Kim proposed the Lade-Kim model in order to model a granular material stress-strain constitutive relation under different combinations of effective stress and drained or undrained conditions. In this dissertation, this model is implemented and validated in the FLAC3D finite volume program, in order to study the elasto-plastic behavior of embankments. The governing equations of the constitutive model of Lade-Kim are presented and, using an appropriate stress integration algorithm, it is implemented in FLAC3D. This procedure is validated by using experimental results of triaxial tests performed on the sand of the Sacramento River and performing twodimensional deformation analyzes of embankments and comparing the results with the literature. Finally, the Lade-Kim model is used in two-dimensional and threedimensional deformation analyses of embankments in order to analyze the influence of the three-dimensional condition. On the other hand, the same analyzes were carried out using the Mohr- Coulomb constitutive model in order to compare the results and analyze the efficiency of the Lade-Kim constitutive model. Thus, it is concluded that the Lade-Kim constitutive model was successfully implemented and that it provides accurate results regarding modeling geomechanical behavior under different combinations of effective stresses.

\title{
Keywords
}

Lade-Kim constitutive model; embankment; deformation analysis 


\section{Resumo}

Huang Sam, Juan Andres; Romanel, Celso. Implementação numérica do modelo constitutivo elastoplástico de Lade e Kim para análise 3D de aterros. Rio de Janeiro, 2020, 97p. Dissertação de Mestrado - Departamento de Engenharia Civil e Ambiental, Pontifícia Universidade Católica do Rio de Janeiro.

Problemas de engenharia geotécnica onde a resistência ao cisalhamento é fator determinante para o projeto são geralmente avaliados com base no critério de ruptura de Mohr-Coulomb; no entanto, modelos constitutivos avançados são necessários para abordar grande parte de problemas geotécnicos onde estimativas de deformação são necessárias. Lade e Kim propuseram um modelo constitutivo elastoplástico avançado para investigar o comportamento tensão vs. deformação de materiais com atrito, sob condição drenada ou não drenada. Nesta dissertação, este modelo foi implementado no programa computacional de diferenças finitas FLAC3D com o objetivo de estudar o comportamento elasto-plástico de aterros. As equações governantes do modelo constitutivo de Lade-Kim são apresentadas e um algoritmo explícito de integração de tensões foi implementado na presente pesquisa. Os resultados numéricos obtidos com o modelo de Lade e Kim foram comparados com aqueles publicados na literatura, envolvendo ensaios triaxiais de laboratório realizados em areia e análises numéricas 2D do comportamento de barragem. Finalmente, após validação da implementação do modelo, análises do comportamento 2D e 3D de aterros foram executadas, verificando a influência destes tipos de análise nos valores calculados, bem como resultados numéricos foram também comparados com aqueles determinados pelo tradicional modelo elasto-plástico de Mohr-Coulomb.

\section{Palavras-chave}

Modelo constitutivo de Lade-Kim; aterro; análise de deformações 


\section{Table of contents}

1 Introduction 16

$\begin{array}{lll}1.1 & \text { Objectives } & 16\end{array}$

$\begin{array}{lll}1.2 & \text { Dissertation structure } & 17\end{array}$

2 Numerical analysis and modeling in FLAC3D 18

2.1 Formulation of a 3D explicit finite volume model in FLAC3D 18

$\begin{array}{lll}2.1 .1 & \text { Mathematical description } & 18\end{array}$

$\begin{array}{ll}2.1 .2 \text { Numerical formulation } & 19\end{array}$

2.2 Grid discretization 26

2.2.1 Mixed discretization for a hexahedral grid 26

2.2.2 Nodal mixed discretization for a tetrahedral grid 27

2.3 Numerical modeling of embankment dams 28

$\begin{array}{lll}2.3 .1 & \text { Layered analysis } & 28\end{array}$

$\begin{array}{lll}2.3 .2 & \text { Stress paths } & 29\end{array}$

3 Lade-Kim Model 31

$\begin{array}{lll}3.1 & \text { Elastic behavior } & 31\end{array}$

$\begin{array}{lll}3.2 & \text { Failure criterion } & 32\end{array}$

3.3 Plastic potential and flow rule 32

$\begin{array}{lll}3.4 & \text { Yield criterion } & 36\end{array}$

3.4.1 Yield function 36

3.4.2 Hardening/Softening law 38

3.5 Materials with effective cohesion 40

4 Numerical implementation of the Lade-Kim Model 41

$\begin{array}{lll}4.1 & \text { Incremental formulation } & 41\end{array}$

4.1.1 Elasto-plastic stiffness matrix $\quad 41$

4.1.2 Elastic stiffness matrix 42

4.1.3 Derivatives of the plastic potential 42

4.1.4 Derivatives of the yield function 43

4.1.5 Hardening modulus 44

4.2 Stress integration algorithm $\quad 44$

4.2.1 Implementation criteria $\quad 45$

4.2.2 Initial intersection with the yield surface 46

$\begin{array}{lll}\text { 4.2.3 Stress and hardening parameter update } & 49\end{array}$

4.2.4 Forward Euler integration scheme with subincrementation 50 
4.2.5 Modified Forward Euler scheme with error control 54

5 Constitutive model validation $\quad 57$

$\begin{array}{ll}5.1 \text { Parameter determination } & 57\end{array}$

$\begin{array}{lll}5.1 .1 & \text { Elastic parameters } & 57\end{array}$

$\begin{array}{lll}5.1 .2 & \text { Failure criterion } & 58\end{array}$

$\begin{array}{lll}5.1 .3 & \text { Plastic potential } & 59\end{array}$

5.1.4 Hardening/Softening law 60

$\begin{array}{lll}5.1 .5 & \text { Yield criterion } & 61\end{array}$

5.2 Numerical simulation of trixial compression test 62

6 Three-dimensional stress-deformation analysis of an earth dam 67

$\begin{array}{ll}6.1 \text { Beliche dam } & 67\end{array}$

$\begin{array}{lll}6.1 .1 & \text { Introduction } & 67\end{array}$

6.1.2 Description of the dam 68

$\begin{array}{lll}\text { 5.3.3 Numerical analysis } & 70\end{array}$

$\begin{array}{ll}6.2 \text { Roadford dam } & 73\end{array}$

$\begin{array}{lll}6.2 .1 & \text { Introduction } & 73\end{array}$

$\begin{array}{lll}\text { 6.2.2 Description of the dam } & 74\end{array}$

$\begin{array}{lll}6.2 .3 & \text { Numerical analysis } & 75\end{array}$

$\begin{array}{lll}6.3 & \text { Llancopi dam } & 78\end{array}$

6.4 Numerical analysis $\quad 81$

6.4.1 Three-dimensional analysis $\quad 81$

6.4.2 Comparison with two-dimensional analyses 84

6.4.3 Comparison with analyses carried out using the Mohr-Coulomb $\begin{array}{ll}\text { constitutive model } & 88\end{array}$

7 Conclusions and suggestions $\quad 92$

$\begin{array}{lll}7.1 \text { Conclusions } & 92\end{array}$

$\begin{array}{lll}7.2 & \text { Suggestions } & 93\end{array}$

$\begin{array}{ll}\text { Bibliography } & 94\end{array}$ 


\section{List of figures}

Figure 2.1 Tetrahedral shape element (Itasca - FLAC3D, 2017) 20

Figure 2.2 Hexahedral zone with $n_{t}=5$ (Itasca - FLAC3D, 2017) 27

Figure 3.1 Characteristics of failure criterion in stress space (a) Contours in the octahedral plane. (b) Traces in the triaxial plane (Jakobsen, 1999) 32

Figure 3.2 Characteristics of the plastic potential function in stress space. (a) Contours in the octahedral plane (b) Traces in the triaxial plane (Jakobsen, 1999)

Figure 3.3 Directions of incremental plastic strain vectors in triaxial plane for (a) plain concrete and (b) steel fiber reinforced concrete (Lade and Kim, 1988)

Figure 3.4 Combinations of plastic potential and parameter $\mu$ in triaxial plane. (a) Case of positive $g_{p}$ and (b) Case of negative $g_{p}$ (Lade and Kim, 1988)

Figure 3.5 Experimental data points and contours of constant plastic work shown on the octahedral plane for Fujiriver sand (Lade and Kim, 1988a)

Figure 3.6 Characteristics of the yield function in stress space. (a) Contours in the octahedral plane. (b) Traces in the triaxial plane (Jakobsen, 1999) 38

Figure 3.7 Modeling of work hardening and softening (Jakobsen, 1999)

Figure 4.1 Implementation criteria in the (a) stress-strain relation and (b) triaxial plane (Jakobsen and Lade, 2002)

Figure 4.2 Flow chart for the implementation of a constitutive model with a single yield surface

Figure 4.3 Graphical representation of the algorithm to obtain the intersection with the yield surface (Jakobsen and Lade, 2002)

Figure 4.4 Updated stress and hardening parameter when the consistency condition is (a) not fulfilled and (b) is fulfilled (Jakobsen and Lade, 2002)

Figure 5.1 Calibration of parameters $\lambda$ and $M$ (Lade, 2005) 60

Figure 5.2 Calibration of parameters $\eta_{1}$ and $m$ (Lade, 2005) 61

Figure 5.3 Calibration of parameters $\mu$ and $\psi_{2}$ (Lade, 2005) 62

Figure 5.4 Calibration of parameters $C$ and $p$ (Lade, 2005) 63

Figure 5.5 Calibration of parameter $\alpha$ (Lade, 2005) 64

Figure 5.6 Calibration of parameter $k$ (Lade andLiu, 2001) 65

Figure 5.7 Numerical simulations of drained triaxial compression tests on Sacramento river sand (Lade, 2005) 
Figure 5.8 Plan view of the Beliche dam (Naylor, et al., 1986) 67

Figure 5.9 Cross-section of the Beliche dam (Naylor, etal., 1986) 68

Figure 5.10 Stress-strain curves for the dam materials obtained from triaxial compression tests (Adapted from Naylor, et al., 1986) 69

Figure 5.11 Stress-strain curves for the dam materials obtained from isotropic compression tests (Adapted from Naylor, et al., 1986)

Figure 5.12 Intended gradation curves (Naylor, etal., 1986) 70

Figure 5.13 Finite element mesh - Beliche dam (De Melo and Hartl, 1997) 71

Figure 5.14 Finite volume model - Beliche dam 71

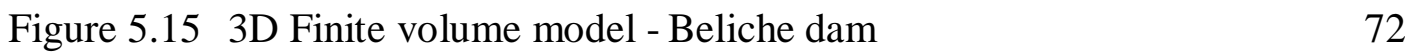

$\begin{array}{ll}\text { Figure 5.16 Vertical displacements (m) - Beliche dam } & 72\end{array}$

Figure 5.17 Vertical displacements at section AA' - Beliche dam 73

Figure 5.18 Cross-section of the Roadford dam(Kovacevic, 1994) 74

Figure 5.19 Cross-section of the Roadford dam(Kovacevic, 1994) 75

Figure 5.20 Comparison of numerical results of triaxial tests on Roadford rockfill 76

Figure 5.21 Finite element mesh - Roadford dam (Kovacevic, 1994) 77

$\begin{array}{lll}\text { Figure 5.22 Finite volume model - Roadford dam } & 78\end{array}$

Figure 5.23 Vertical displacements (m) - Roadford dam 78

Figure 5.24 Vertical displacements at settlement plates $S 1$ and $S 2 \quad 79$

Figure 6.1 Three-dimensional model of the Llancopi dam - longitudinal $\begin{array}{ll}\text { view along the dam axis } & 81\end{array}$

Figure 6.2 Three-dimensional model of the Llancopi dam - plan view 81

Figure 6.3 Three-dimensional model of the Llancopi dam - plan view 82

Figure 6.4 Stress-strain curves obtained from simulating drained triaxial compression tests $\quad 83$

$\begin{array}{lll}\text { Figure 6.5 Three-dimensional finite volume model } & 84\end{array}$

Figure 6.6 Vertical displacements $(m)$ - Llancopi dam 85

$\begin{array}{lll}\text { Figure 6.7 Vertical stresses }(\mathrm{kPa}) \text { - Llancopi dam } & 85\end{array}$

Figure 6.8 Vertical displacements $(m)$ at $\mathrm{x}=79.5 m$-Llancopi dam 86

Figure 6.9 Vertical stresses $(k P a)$ at $\mathrm{x}=79.5 m$ - Llancopi dam 86

Figure 6.10 Vertical displacements $(m)$ at $\mathrm{x}=107.5 m$ - Llancopi dam 87

Figure 6.11 Vertical stresses $(\mathrm{kPa})$ at $\mathrm{x}=107.5 \mathrm{~m}$ - Llancopi dam 87

Figure 6.12 Finite volume model of the tallest cross-section of the Llancopi $\begin{array}{ll}\text { dam } & 88\end{array}$

Figure 6.13 Two-dimensional vertical displacements $(m)$ at $\mathrm{x}=79.5 m$ -

Llancopi dam $\quad 88$

Figure 6.14 Two-dimensional vertical stresses $(k P a)$ at $\mathrm{x}=79.5 m$ - Llancopi 
dam

Figure 6.15 Finite volume model of the shortest cross-section of the Llancopi dam

Figure 6.16 Two-dimensional vertical displacements $(m)$ at $\mathrm{x}=107.5 \mathrm{~m}$ Llancopi dam

Figure 6.17 Two-dimensional vertical stresses $(k P a)$ at $\mathrm{x}=107.5 m$ - Llancopi dam

Figure 6.18 Comparison of vertical displacement profiles obtained in 2D and $3 \mathrm{D}$ analyses

Figure 6.19 Studied cross-sections - longitudinal view along the dam axis

Figure 6.20 Vertical displacements $(m)$ - Llancopi dam, Mohr - Coulomb model 93

Figure 6.21 Vertical stresses $(\mathrm{kPa})$ - Llancopi dam, Mohr - Coulomb model 93

Figure 6.22 Vertical displacements $(m)$ at $\mathrm{x}=79.5 m$ - Llancopi dam, Mohr Coulomb model

Figure 6.23 Vertical stresses $(\mathrm{kPa})$ at $\mathrm{x}=79.5 \mathrm{~m}$ - Llancopi dam, Mohr Coulomb model

Figure 6.24 Vertical displacements $(m)$ at $\mathrm{x}=107.5 m$ - Llancopi dam, Mohr - Coulomb model

Figure 6.25 Vertical stresses $(k P a)$ at $\mathrm{x}=107.5 m$ - Llancopi dam, Mohr Coulomb model

Figure 6.26 Comparison ofconstitutive models 


\section{List of tables}

Table 5.1 Typical parameters for loose Sacramento river sand (Lade, 2005) 66

Table 5.2 Parameters used in the analysis - Beliche dam (De Melo and

Hartl, 1997) 70

Table 5.3 Unit weights used in the analysis - Beliche dam (De Melo and Hartl, 1997)

Table 5.4 Lade and Kim constitutive model parameters for rockfill and sandwaste (Kovacevic, 1994)

Table 5.5 Linear elastic constitutive model parameters used in the analysis (Kovacevic, 1994)

Table 6.1 Properties and parameters of the Llancopi dam material

Table 6.2 Typical parameters for dense Sacramento river sand - dam material (Lade, 2005)

Table 6.3 Mohr-Coulomb model parameters for the dam material

Table 6.4 Linear elastic model parameters of the Llancopi dam foundation 


\section{List of Symbols}

\begin{tabular}{|c|c|}
\hline$a$ & parameter related to the effective cohesion \\
\hline$\overline{\dot{a}}^{p}$ & plastic volumetric stress correction mean value \\
\hline$A$ & softening parameter \\
\hline$\alpha$ & yield function parameter \\
\hline$b_{i}$ & body force per unit mass \\
\hline$B$ & body forces \\
\hline$B$ & softening parameter \\
\hline$C$ & hardening parameter \\
\hline$C^{e}$ & elastic stiffness matrix \\
\hline$C^{p}$ & plastic stiffness matrix \\
\hline$C^{e p}$ & elastoplastic stiffness matrix \\
\hline$\delta$ & Kroenecker's delta \\
\hline$e$ & Euler constant \\
\hline$\dot{e}$ & volumetric strain rate \\
\hline$\overline{\dot{e}}$ & volumetric strain rate mean value \\
\hline$\dot{e}^{p}$ & plastic volumetric strain increment \\
\hline$\eta$ & deviatoric strain-rate tensor \\
\hline$\eta_{1}$ & failure criterion parameter \\
\hline$E$ & external work rate \\
\hline$E^{b}$ & body force contribution to the external work rate \\
\hline$E^{I}$ & inertial force contribution to the external work rate \\
\hline$E_{u r}$ & unloading-reloading elastic modulus \\
\hline$f$ & external work rate done by nodal forces \\
\hline$F$ & equivalent force \\
\hline$f_{n}$ & failure criterion \\
\hline$f_{p}$ & yield function \\
\hline$f_{p}^{l}$ & yield function in terms of stress \\
\hline$f_{p}^{l l}$ & yield function in terms of plastic work \\
\hline$g_{p}$ & plastic potential function \\
\hline$h$ & yield function parameter \\
\hline
\end{tabular}




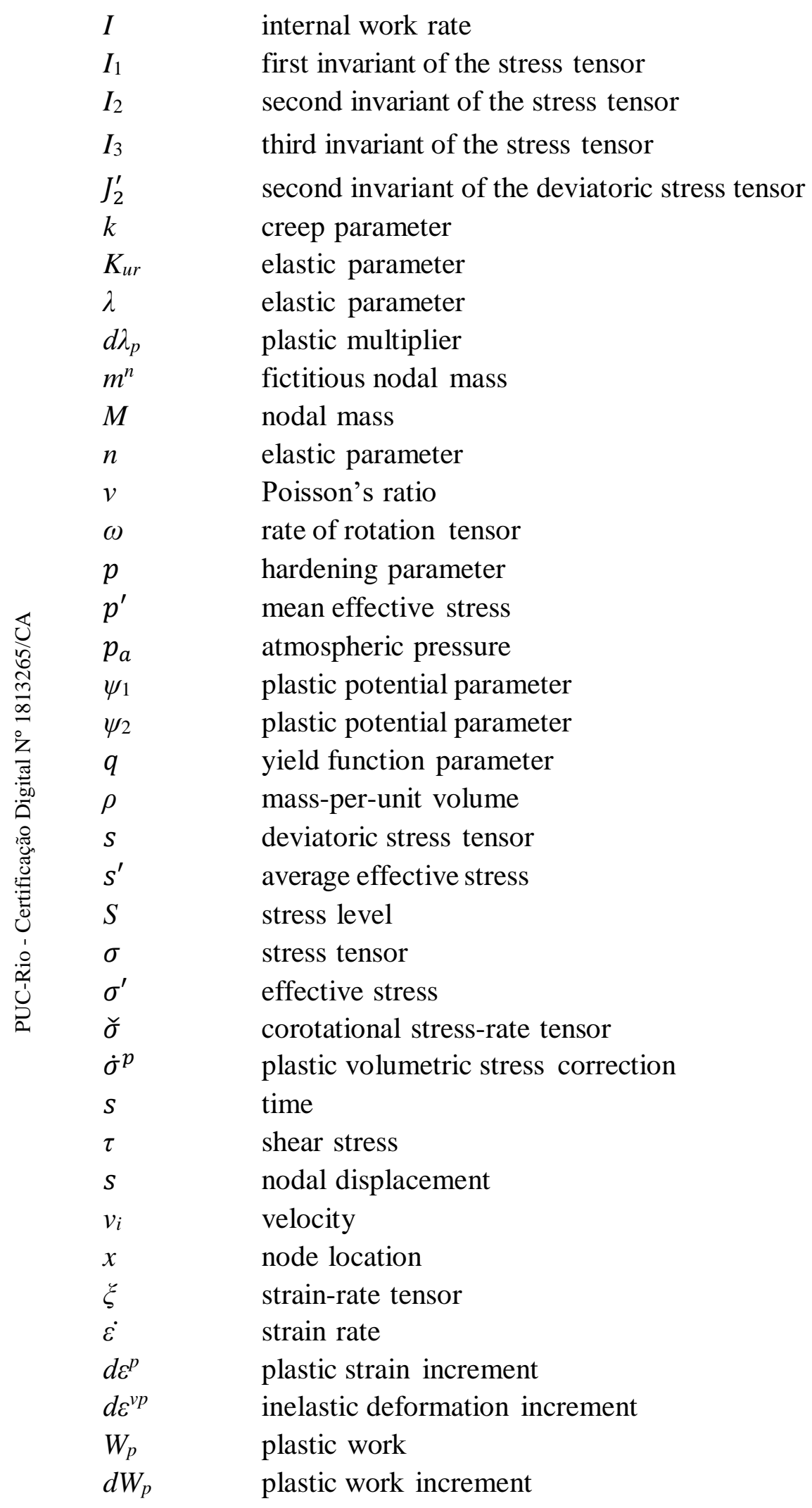




\section{Introduction}

Earth and rockfill dams have been used due to their advantages over masonry dams regarding availability of materials and the cost of construction. Initially, these were designed and monitored considering mainly empirical information based on laboratory and field data and the experience of the engineer. However, the development of theoretical soil mechanics allowed to change the way their design and construction was approached. A better concept regarding constitutive models helped to calculate stresses and displacements due to different boundary conditions during the construction, impounding and posterior operational processes. Simultaneously, numerical methods were developed in order to implement the advanced constitutive models allowing to analyze larger geotechnical projects.

Numerical simulations of earth and rockfill dams are influenced by the parameters obtained from laboratory tests. Hence, representative samples of the materials to be used are needed in order to predict displacements effectively. Moreover, constitutive models capable of modeling the materials stress-strain behavior will enhance the accuracy of numerical simulations. However, conventional constitutive models seem to have problems regarding modeling the elastoplastic behavior before reaching failure resulting in an inefficient prediction. Thus, advanced constitutive models which are able to adequately model geomaterials behavior are needed for a better analysis. On the other side, dam analyses are conventionally carried out considering two-dimensional models and the most critical cross-section although these considerations may not always be accurate. However, the evolution of computational tools based on robust numerical methods has allowed to reach higher expectations regarding geotechnical engineering over time and in a specific manner, these tools have helped to overcome the limitations previously stated.

In previous research works carried out at the Pontifical Catholic University of Rio de Janeiro (PUC-Rio), the Lade-Kim constitutive model was used in order to model geomechanical behavior of construction of embankments, analyze foundations, excavations and even perform numerical analyses of wellbore stability based on the finite element method. This fact motivated the use of the finite volume method and the Lade-Kim model in order to study the three-dimensional behavior of embankments.

\subsection{Objectives}

The general objective of the present dissertation is to provide a theoretical background regarding the formulation of a three-dimensional finite volume model, constitutive models and the numerical modeling of earth dams. Furthermore, a more specific objective is to implement the Lade and Kim constitutive model into the finite volume code FLAC3D by generating a dynamic link library (DLL) written in $\mathrm{C}++$ programming language, in order to carry out a three-dimensional analysis of 
an earth dam and analyze the model efficiency regarding modeling elastoplastic behavior.

\subsection{Dissertation structure}

This dissertation consists of eight chapters including this chapter as the first one and bibliography as the last chapter.

The second chapter provides theoretical background involving the formulation of a three-dimensional finite volume model and the numerical analysis of earth dams.

The third chapter consists of the Lade and Kim constitutive model and its governing equations whereas the fourth chapter describes its incremental form and the stress integration algorithms to be considered during the numerical implementation.

In the fifth chapter, validation cases are presented in order to test the applicability of the implemented model for stress-strain analyses. These involve numerical simulations such as drained triaxial compression tests and twodimensional analyses.

In the sixth chapter, a three-dimensional stress-strain analysis of the Llancopi dam is carried out. Besides, two-dimensional analyses are performed as well in order to compare the two types of analysis. Furthermore, the same analyses are carried out considering the Mohr - Coulomb constitutive model and the results are compared with the Lade and Kim model-based results in order to analyze the model efficiency.

Finally, conclusions that summarize the present work and suggestions for further research are presented in chapter seven. 


\section{Numerical analysis and modeling in FLAC3D}

The software FLAC3D is a code based on the finite volume method with the objective of analyzing the mechanical behavior of a continuous threedimensional medium until it reaches equilibrium condition. In this chapter, theoretical background regarding the finite volume method and its application on a deformation analysis is provided. In a specific manner, a mathematical description as well as the numerical formulation of a three-dimensional finite volume model is presented. Besides, the discretization method adopted by the FLAC3D code is explained. On the other hand, considerations to numerically model the behavior of embankments during construction are provided.

\subsection{Formulation of a 3D explicit finite volume model in FLAC3D}

\subsubsection{Mathematical description}

The medium behavior is influenced by the governing equations (equations of motion and equilibrium) and the defined constitutive relation. Based on these, a mathematical expression involving a set of partial differential equations, mechanical variables such as stress and kinematic variables such as velocity is obtained. Thus, the expression is solved considering the medium geometry, boundary conditions and an initial state.

The governing equations that the software FLAC3D is based on are defined as the Cauchy's equations of motion and are stated as:

$$
\sigma_{i j, j}+\rho b_{i}=\rho \frac{d v_{i}}{d t}
$$

where $\rho$ is the mass-per-unit volume of the medium, $[b]$ is the body force per unit mass and $d[v] / d t$ is the material derivative of the velocity.

These are the equations that govern the motion of the medium due to applied forces. It can be deduced that in the case of equilibrium state, the acceleration $d[v] / d t$ becomes equal to zero and the governing equations are reduced to:

$$
\sigma_{i j, j}+\rho b_{i}=0
$$

Constitutive equations are the other factor in which the behavior of the medium is based on besides of the governing equations. These usually describe the relation between a strain-rate tensor $\xi_{i j}$ and a stress tensor $\sigma_{i j}$.

Considering constant strain elements, the strain-rate tensor can be defined as follows:

$$
\xi_{i j}=\frac{1}{2}\left(v_{i, j}+v_{j, i}\right)
$$


where the partial derivatives are calculated with respect to components of the current position vector $[x]$ and considering that $[v]$ is the velocity vector of the nodes of the medium.

\subsubsection{Numerical formulation}

The FLAC3D code solution procedure relies on three different approaches which involve a finite volume, a discrete-model and a dynamic-solution approach. In the first one, first-order time and space derivatives of a variable are obtained by considering finite volumes and assuming linear variations of the variable over finite time and space intervals respectively. In the second case, a discrete representative model is used in order to represent the continuous medium in which all conditions are applied on the nodes of the grid used in the model. In the third one, the inertial terms in the equations of motion are considered as numerical means in order to reach equilibrium condition of the studied model.

Based on the defined approaches the FLAC3D code relies on, the equations of motion are transformed into discrete forms of Newton's law at the nodes. Then, the obtained ordinary differential equations system is resolved by using an explicit finite difference approach in time.

\subsubsection{Finite volume approximation to space derivatives}

Approximation of space derivatives are needed since they appear in the definition of strain-rates in term of velocities as previously defined. The FLAC3D code implemented a discretization procedure where tetrahedral shape elements with constant strain-rate are used in order to represent the continuous medium and define velocity variations and corresponding space intervals, as shown in figure 2.1.

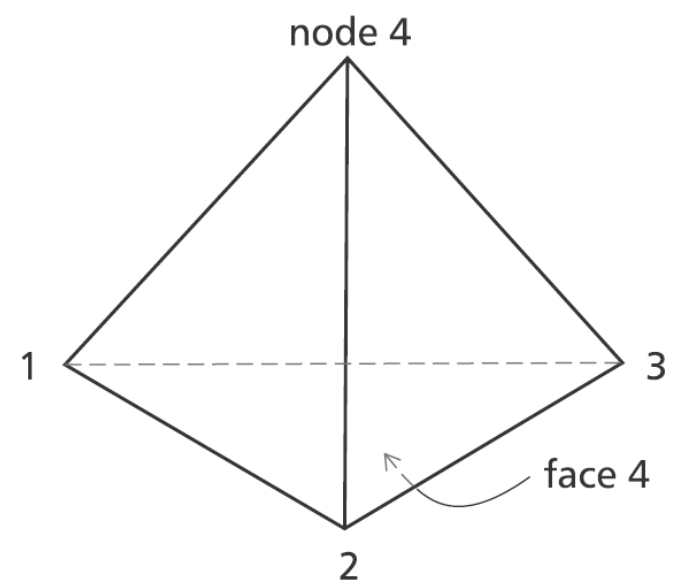

Figure 2.1: Tetrahedral shape element (Itasca - FLAC3D, 2017) 
The strain-rate tensor previously defined can be numerically derived based on the tetrahedral shaped element shown in figure 2.1 and considering the local number convention in order to derive the nodal formulation of the equations of motion later on.

Thus, the Gauss divergence theorem can be applied to the tetrahedral shape element in order to obtain:

$$
\int_{V} v_{i, j} d V=\int_{S} v_{i} n_{j} d S
$$

where the integral taken over volume is equal to the one taken over the surface of the tetrahedral element and $[n]$ is the exterior unit vector normal to each surface.

Since the tetrahedral element has a constant strain-rate, the velocity field is linear and $[n]$ is constant over the surface of each face. Thus, the previous expression can be reduced to:

$$
V v_{i, j}=\sum_{f=1}^{4} \bar{v}_{i}^{(f)} n_{j}^{(f)} S^{(f)}
$$

where $\bar{v}_{i}$ is the average value of velocity component $i$ and the superscript $(f)$ is related to the value of the associated variable on face $f$.

Moreover, considering a linear velocity variation, the following expression can be derived:

$$
\bar{v}_{i}(f)=\frac{1}{3} \sum_{l=1, l \neq f}^{4} v_{i}^{l}
$$

where the superscript $(l)$ is related to the value at node $l$.

Taking into account both previous equations, the following expression can be obtained after rearranging terms by node contribution:

$$
V v_{i, j}=\frac{1}{3} \sum_{l=1}^{4} v_{i}^{l} \sum_{f=1, f \neq l}^{4} n_{j}^{(f)} S^{(f)}
$$

The following equation is obtained when replacing $v_{i}$ with 1 in equation 27 and by applying the divergence theorem:

$$
\sum_{f=1}^{4} n_{j}^{(f)} S^{(f)}=0
$$


Considering the previous expression and by diving equation 2-10 by $V$, the expression below is defined:

$$
v_{i, j}=-\frac{1}{3 V} \sum_{l=1}^{4} v_{i}^{l} n_{j}^{(l)} S^{(l)}
$$

allowing to obtain the components of the strain-rate tensor components as shown in the following expression:

$$
\xi_{i j}=-\frac{1}{6 V} \sum_{l=1}^{4}\left(v_{i}^{l} n_{j}^{(l)}+v_{j}^{l} n_{i}^{(l)}\right) S^{(l)}
$$

\subsubsection{Nodal formulation of the equations of motion}

The derivation of the nodal formulation of the equations of motion is needed in order to study the equilibrium state of the representative model. Thus, the theorem of virtual work is applied at any instant time to an equivalent static problem to derive the nodal formulation.

The derivation procedure is started by considering a fixed time $t$ and an equivalent static problem governed by the equations of equilibrium shown below at any instant in time.

$$
\sigma_{i j, j}+\rho B_{i}=0
$$

where $B_{i}$ represent the body forces and is defined as:

$$
B_{i}=\rho\left(b_{i}-\frac{d v_{i}}{d t}\right)
$$

As previously stated, the FLAC3D code relies on three different approaches. In a specific manner, the code is based on using a representative model which can be defined as a continuous assembly of constant-strain tetrahedral elements that is object of body forces $[B]$. However, nodal forces $[f]^{n}$ where $n=1,2,3$ and 4 that act on the tetrahedral element in "static" equilibrium with the tetrahedron stresses and equivalent body forces are needed in this approach. Thus, the theorem of virtual work is considered and the following procedure is applied.

First, a virtual nodal velocity $\delta[v]^{n}$ is applied, generating a linear velocity field $\delta[v]$ and a constant strain-rate $\delta[\xi]$ inside the tetrahedral element. Then, the external work rate done by the nodal forces $[f]^{n}$ and body forces $[B]$ and the internal rate of work done by the stresses $\sigma_{i j}$ under the applied velocity are equalized. The external work rate may be expressed as follows, considering that the superscript is related tot he nodal value of a variable and the Einstein summation 
convention on indices $i$ and $j$ :

$$
E=\sum_{n=1}^{4} \delta v_{i}^{n} f_{i}^{n}+\int_{V} \delta B_{i} d V
$$

whereas the internal work rate is expressed as:

$$
I=\int_{V} \delta \xi_{i j} \sigma_{i j} d V
$$

However, for a constant strain-rate tetrahedral element, the internal work rate can be expressed as shown below after considering the components of the strain-rate tensor shown in equation 2-13:

$$
I=-\frac{1}{6} \sum_{l=1}^{4}\left(\delta v_{i}^{l} \sigma_{i j} n_{j}^{(l)}+\delta v_{j}^{l} \sigma_{i j} n_{i}^{(l)}\right) S^{(l)}
$$

Considering that the stress tensor is symmetric, this expression can be reduced by defining the vector $T^{l}$ as:

$$
T_{i}^{l}=\sigma_{i j} n_{j}^{(l)} S^{(l)}
$$

allowing to obtain the expression:

$$
I=-\frac{1}{3} \sum_{l=1}^{4} \delta v_{i}^{l} T_{i}^{l}
$$

The contributions of the body forces $\rho b_{i}$ and inertial forces to the external work rate can be obtained after substituting the body forces definition shown in equation 2-15 into the definition of the external work rate. Thus, the following expression is yielded:

$$
E=\sum_{n=1}^{4} \delta v_{i}^{n} f_{i}^{n}+E^{b}+E^{I}
$$

where $E^{b}$ and $E^{I}$ represent the body forces and inertial forces contributions, respectively. In a specific manner, the body forces contribution for a constant-body force inside the tetrahedral element can be expressed as:

$$
E^{b}=\rho b_{i} \int_{V} \delta v_{i} d V
$$

whereas the inertial force contribution can be expressed as:

$$
E^{I}=-\int_{V} \rho \delta v_{i} \frac{d v_{i}}{d t} d V
$$


As stated previously, the velocity field varies linearly inside a tetrahedral element that has a constant strain-rate and in order to define it, local axes $x_{1}^{\prime}, x_{2}^{\prime}, x^{\prime}{ }_{3}$ with origin at the centroid of the tetrahedral element is considered. Thus, the following expression is yielded:

$$
\delta v_{i}=\sum_{n=1}^{4} \delta v_{i}^{n} N^{n}
$$

where $N^{n}$ are linear functions defined as:

$$
N^{n}=c_{0}^{n}+c_{1}^{n} x_{1}^{\prime}+c_{2}^{n} x^{\prime 2}+c_{3}^{n} x^{\prime}{ }_{3}
$$

and $c_{0}^{n}, c_{1}^{n}, c_{2}^{n}, c_{3}^{n}(n=1,2,3,4)$ are constants that can be calculated by solving the following equation systems:

$$
N^{n}\left(x_{1}^{\prime j}, x_{2}^{\prime j}, x_{3}^{\prime j}\right)=\delta_{n j}
$$

where $\delta_{n j}$ represents the Kroenecker delta. Considering the expressions above and the fact that all integral of the form $\int_{V} x_{j}^{\prime} d V$ are equal to zero due to the definition of the centroid, the external work rate contribution of the body forces can be expressed as:

$$
E^{b}=\rho b_{i} \sum_{n=1}^{4} \delta v_{i}^{n} c_{0}^{n} V
$$

Moreover, Cramer's rule allows to solve equation systems 2-6 by taking into account the properties of the centroid in order to obtain:

$$
c_{0}^{n}=\frac{1}{4}
$$

Thus, after considering the description of the velocity field, the contribution of the body forces is reduced to:

$$
E^{b}=\sum_{n=1}^{4} \delta v_{i}^{n} \frac{\rho b_{i} V}{4}
$$

whereas, after applying the same procedure to the inertial forces term, its contribution is reduced to:

$$
E^{I}=-\sum_{n=1}^{4} \delta v_{i}^{n} \int_{V} \rho N^{n} \frac{d v_{i}}{d t} d V
$$

This expressions can be substituted into equation 2-21 in order to yield: 


$$
E=\sum_{n=1}^{4} \delta v_{i}^{n}\left[f_{i}^{n}+\frac{\rho b_{i} V}{4}-\int_{V} \rho N^{n} \frac{d v_{i}}{d t} d V\right]
$$

Regarding the equilibrium condition for a tetrahedral element of the representative model, the external and internal work rate have the same value for any virtual velocity. Thus, by equalizing equations 2-31 and 2-20 and regrouping terms, the following expression is obtained:

$$
-f_{i}^{n}=\frac{T_{i}^{n}}{3}+\frac{\rho b_{i} V}{4}-\int_{V} \rho N^{n} \frac{d v_{i}}{d t} d V
$$

where the last term can be defined after considering the case of small spatial variations of the acceleration field around an average value inside the element as:

$$
\left.\int_{V} \rho N^{n} \frac{d v_{i}}{d t} d V=\frac{d v_{i}}{d t}\right)^{n} \int_{V} \rho N^{n} d V
$$

Besides, considering constant values of $\rho$ inside the element and the properties of the centroid, the same expression can be reduced to:

$$
\left.\int_{V} \rho N^{n} \frac{d v_{i}}{d t} d V=\frac{\rho V}{4} \frac{d v_{i}}{d t}\right)^{n}
$$

Taking into account the approaches FLAC3D relies on, numerical stability of the representative model must be guaranteed when reaching equilibrium state. In order to achieve this, the term $\rho V / 4$ is replaced by a fictitious nodal mass $m^{n}$ in this analysis. Thus, equation 2-34 is expressed:

$$
\left.\int_{V} \rho N^{n} \frac{d v_{i}}{d t} d V=m^{n} \frac{d v_{i}}{d t}\right)^{n}
$$

whereas equation 2-32 becomes:

$$
\left.-f_{i}^{n}=\frac{T_{i}^{n}}{3}+\frac{\rho b_{i} V}{4}-m^{n} \frac{d v_{i}}{d t}\right)^{n}
$$

Equilibrium state is numerically achieved when the sum of the statically equivalent forces $-[f]$ of all the contributing tetrahedral elements in addition to the nodal contributions $[P]$ of applied loads and concentrated forces at each node is equal to zero. In order to analyze the representative model behavior until reaching equilibrium conditions, Newton's law is considered:

$$
\left.F_{i}^{<l>}=M^{<l>} \frac{d v_{i}}{d t}\right)^{<l>} \quad l=1, n_{n}
$$

where the superscript $\langle l\rangle$ is the node label in the global node numbering. 
Thus, a variable with the superscript $\langle l\rangle$ is related to the value of the variable at a node with the same label. The term $n_{n}$ is the total number of nodes of the representative model, $M^{<l>}$ is the nodal mass, which is defined as:

$$
M^{<l>}=[[m]]^{<l>}
$$

where the notation $[[\cdot]]^{<l>}$ represents the sum of the contributions of all tetrahedral elements involved at global node $l$ and $[F]^{<l>}$ is a force that depends on the equilibrium state of the representative medium since it is equal to zero when equilibrium stated is achieved. It is called the out-of-balance force and is calculated by the following expression:

$$
F_{i}^{<l>}=\left[\left[\frac{T_{i}}{3}+\frac{\rho b_{i} V}{4}\right]\right]^{<l>}+P_{i}^{<l>}
$$

\subsubsection{Explicit finite difference approximation to time derivatives}

Previously, the nodal formulation of the equations of motion was derived in order to numerically analyze the equilibrium state of the representative medium. However, numerical methods are required in order to find a solution. Thus, taking into consideration the constitutive relations shown in equation 2-3 and the components of the strain-rate tensor shown in equation 2-13, the definition of the out-of-balance force shown in equation 2-37 can be written as a system of ordinary differential equations as follows:

$$
\frac{d v_{i}^{<l>}}{d t}=\frac{1}{M^{<l>}} F_{i}^{<l>}\left(t,\left\{v_{i}^{<1>}, v_{i}^{<2>}, v_{i}^{<3>}, \ldots, v_{i}^{<p>}\right\}^{<l>}, k\right) \quad l=1, n_{n}
$$

where the symbol \{\}$^{<l>}$ refers to the subset of nodal velocity values involved in the analysis at global node $l$.

In order to solve the equations system, a explicit finite difference formulation in time is adopted by the FLAC3D code where the velocity of the representative medium nodes are assumed to vary linearly over a time interval $\Delta t$. Moreover, the derivative $\left(d v_{i} / d t\right)^{<l>}$ is calculated using central finite differences. Thus, the nodal velocities are obtained under the following expression:

$$
\left.\left.v_{i}^{<l>} t+\frac{\Delta t}{2}\right)=v_{i}^{<l>} t-\frac{\Delta t}{2}\right)+\frac{\Delta t}{M^{<l>}} F_{i}^{<l>}\left(t,\left\{v_{i}^{<1>}, v_{i}^{<2>}, v_{i}^{<3>}, \ldots, v_{i}^{<p>}\right\}^{<l>}, k\right)
$$

whereas the node location is obtained by using the central difference 
approximation in order to obtain the following relation:

$$
\left.x_{i}^{<l>}(t+\Delta t)=x_{i}^{<l>}(t)+\Delta t v_{i}^{<l>} t+\frac{\Delta t}{2}\right)
$$

Similarly, the nodal displacements are computed under the following expression:

$$
\left.u_{i}^{<l>}(t+\Delta t)=u_{i}^{<l>}(t)+\Delta t v_{i}^{<l>} t+\frac{\Delta t}{2}\right)
$$

where,

$$
u_{i}^{<l>}(0)=0
$$

\subsection{Grid discretization}

The second approach adopted by the FLAC3D code is related to a discrete representative model that is used to model the geomechanical behavior of the continuous medium and is based on a grid that is conformed by nodes and zones. However, two types of primary discretization are available in FLAC3D. The model may be discretizated considering hexahedral or tetrahedral and, based on the chosen type, a mixed discretization technique is applied in order to give more volumetric flexibility to the element.

\subsubsection{Mixed discretization for a hexahedral grid}

Marti and Cundall (1982) introduced an approach that involved a coarser discretization in zones superposed to a tetrahedral discretization, where the first strain-rate invariant of one tetrahedron is calculated as the volumetric-average value considering all the tetrahedra in the zone. For a hexahedral grid, FLAC3D adopts hexahedral zones conformed by $n_{t}$ tetrahedra and two overlays as shown in figure 2.2 .

In this type of discretization, each tetrahedron inside the hexahedral zone is analyzed individually in order to obtain analyze the zone as a unit. Regarding one tetrahedron locally labeled $l$ in the zone, the strain-rate tensor is initially estimated and divided as follows:

$$
\xi_{i j}^{[l]}=\eta_{i j}^{[l]}+\frac{\xi^{[l]}}{3} \delta_{i j}
$$

where $\eta^{[l]}$ is the deviatoric strain-rate tensor and $\xi^{[l]}$ is the strain-rate first invariant. 

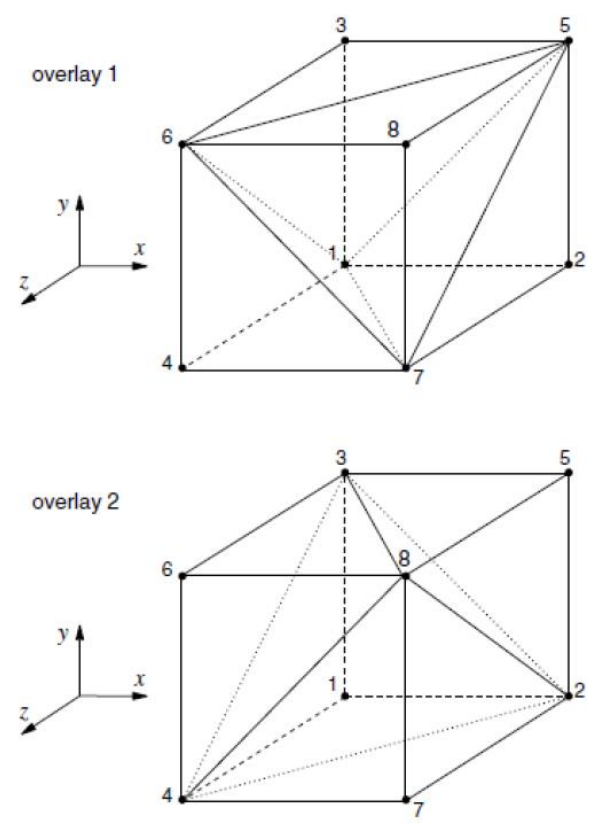

Figure 2.2: Hexahedral zone with $n_{t}=5$ (Itasca - FLAC3D, 2017)

Considering the hexahedral zone, the strain-rate first invariant is computed as the volumetric average value of the strain-rate first invariant of all the tetrahedra conforming the zone as shown in the following expression:

$$
\xi^{[z]}=\frac{\sum_{k=1}^{n_{t}} \xi^{[k]} V^{[k]}}{\sum_{k=1}^{n_{t}} V^{[k]}}
$$

where $V^{[k]}$ is the volume of tetrahedron $k$. Thus, the strain-rate tensor components of each tetrahedron is computed from:

$$
\xi_{i j}^{[l]}=\eta_{i j}^{[l]}+\frac{\xi^{[z]}}{3} \delta_{i j}
$$

\subsubsection{Nodal mixed discretization for a tetrahedral grid}

By default, FLAC3D adopts a hexahedral grid during the discretization procedure; however, tetrahedral grid may be used as well. In this case, a nodal mixed discretization (NMD) is applied. The principal difference between this approach and the mixed discretization for a hexahedral grid is based on the averaging procedure since it is carried out on a node instead of the zone.

In a similar manner as in the mixed discretization technique for a hexahedral grid, the strain rate $\dot{\varepsilon}$ is first estimated from nodal velocities and divided as follows:

$$
\dot{\varepsilon}_{i j}=\dot{e}_{i j}+\dot{e} \delta_{i j}
$$

where $\dot{e}_{i j}$ is the deviatoric component, $\dot{e}$ is the volumetric component and 
$\delta_{i j}$ is the Kroenecker delta. Then, a nodal volumetric strain rate is computed considering the surrounding elements of the node as shown in the following equation:

$$
\dot{e}_{n}=\frac{\sum_{e=1}^{m_{n}} \dot{e}_{e} V_{e}}{\sum_{e=1}^{m_{n}} V_{e}}
$$

where $m_{n}$ are the elements surrounding node $n$ and $V_{e}$ is the volume of element $e$. After that, a mean value for the element $\overline{\dot{e}}$ is computed by averaging the values of each node in order to recalculate the element strain rate $\dot{\varepsilon}_{i j}$ as shown below:

$$
\dot{\varepsilon}_{i j}=\dot{e}_{i j}+\bar{e} \delta_{i j}
$$

\subsection{Numerical modeling of embankment dams}

Embankment dams behavior during construction, first impounding and subsequent operation has been object of study in order to monitor its performance. Over time, numerical and computational tools have evolved resulting in more accurate geomechanical behavior predictions. Moreover, different aspects regarding modeling of embankment dams have been taken into account in order to reproduce different geotechnical conditions and, therefore, improve numerical results. As presented by Naylor (1991b), these aspects involve layered analysis and typical stress in embankment dams.

\subsubsection{Layered analysis}

In the field, an embankment dam is constructed sequentially where thin layers are placed above the previous one until the dam is finished. Due to this procedure, each layer is deformed by the following one and the dam becomes stiffer. It is important to note that Naylor and Jones (1973) defined this deformation as the cumulative movement of a marker placed on the surface of the fill due to compression of the underlying material by the weight of the material added above.

After acknowledging the importance of simulating the construction of layers, Cloud and Woodward (1969) first carried out a finite element analysis of an embankment dam. Since then, many finite element analysis have been carried out with the idea of modeling the larger number of layers in order to obtain improved results. However, Hamza (1976) as well as Naylor and Mattar (1988) stated that modeling all construction layers would result computationally expensive since considering as few as five layers was enough to expect acceptable results regarding 
dam behavior.

Observations made by different authors as well as the method proposed by the Imperial College Finite Element Program is taken into account in order to simulate the construction sequence. These involve considering construction layers with an average thickness that allows to obtain a smooth settlement profile and applying a gravity loading. In a specific manner, the construction sequence is modeled by adding the corresponding group of zones until finishing the dam. It is important to note that equilibrium state must be reached before adding the following construction layer since a gravity load is applied. Moreover, each constructed layer maintains the involved stresses, nodal forces and corresponding parameters depending of the adopted constitutive model; however, displacements and strains are set to zero between each construction phase.

\subsubsection{Stress paths}

Soil behavior is strongly influenced by the stress path it is subject of, the adopted constitutive model and its respective parameters; specifically, the soil deformation response. Due to this fact, typical stress paths and the adequate constitutive model must be considered in the stress-strain analysis of an embankment dam.

Different authors carried out researches in order to analyze typical stress paths during construction and first impounding. Charles (1976) performed elastic finite element analyses considering three different types of rockfill dams and concluded that, generally, a large increase in mean effective stress $p^{\prime}=\left(\sigma_{1}^{\prime}+\right.$ $\left.\sigma_{2}^{\prime}+\sigma_{3}^{\prime}\right) / 3$ and gradual changes in principal stress ratio $\sigma_{1}^{\prime} / \sigma_{3}^{\prime}$. Moreover, Charles (1976) noted that the vertical stress remained as the major principal stress on the center of the dam whereas principal stresses rotations incremented near the slopes. On the other hand, typical stress paths related to the first impounding of the dam with an upstream impermeable membrane are characterized by an increase of the mean effective stress $p^{\prime}$, a reduction of the principal stress ratio $R$ and an important principal stresses rotation along the impermeable membrane.

A more particular case that involved a rockfill dam with a clay core was presented by Veiga Pinto and Maranha Das Neves (1985). They stated that during construction phase, the maximum shear stress $\tau=\left(\sigma_{1}-\sigma_{3}\right) / 2$ increased following a nearly constant principal stress ratio $R$. During first impounding, the behavior tended to be more complex since transition zones were subject of different kind of stress paths. Generally, a decrease in maximum shear stress $\tau$ is presented, 
with an increase of the average effective stress $s^{\prime}=\left(\sigma_{1}^{\prime}+\sigma_{3}^{\prime}\right) / 2$ in the downstream part and a decrease of it in the upstream part.

Different stress paths are involved during construction and first impounding of a dam representing a challenge when laboratory tests are needed. However, its a common practice to rely on standard laboratory tests due to the acceptable results obtained by different authors. In FLAC3D, stress paths are accommodated in order to apply the constitutive model properly and obtain a reasonable solution. 


\section{Lade-Kim Model}

The Lade-Kim constitutive model was developed by Lade and Kim (1988, 1988a, 1988b) in order to calculate deformations under any combinations of effective stresses during primary loading, neutral loading, unloading and reloading in drained or undrained conditions. In 1975, Lade and Duncan proposed a formulation based on the experimental data obtained by cubical triaxial tests performed in sand during 1972 and 1973; however, it only considered one conical yield surface. In 1977, Lade modified the Lade-Duncan constitutive model by introducing curved meridians and a second yield surface known as yield caps. This modification allowed to describe the behavior of granular materials under isotropic compression or proportional loading $\left(\sigma_{1} / \sigma_{3}=c t e\right)$ in a more appropriate way. Then, Lade (1979) extended this formulation in order to include the behavior of normally consolidated clay based on experimental observations. Finally, the new model was proposed by Lade and Kim (1988, 1988a, 1988b).

\subsection{Elastic behavior}

The elastic strain increments are calculated using Hooke's law. Lade and Kim (1988b) used the unloading-loading elastic modulus in order to obtain the elastic increments, defined as follows:

$$
\left.E_{u r}=K_{u r} p_{a} \frac{\sigma_{3}}{p_{a}}\right)^{n}
$$

where the constants $K_{u r}$ and $n$ are dimensionless, $\sigma_{3}$ is the actual confining pressure and $p_{a}$ is the atmospheric pressure. Constants $K_{u r}$ and $n$ are obtained from triaxial compression tests under different confining pressures.

Lade and Jakobsen (2002) calculated Young's modulus considering a nonlinear variation with stress state, defined as:

$$
E=M p_{a}\left[\left(\frac{I_{1}{ }^{2}}{p_{a}}\right)+6\left(\frac{1+v}{1-2 v}\right) \frac{J^{\prime}{ }_{2}}{p_{a}}\right]^{\lambda}
$$

where the modulus number $M$ and the constant $\lambda$ are dimensionless, $v$ is the Poisson's ratio, $I_{1}$ is the first invariant of the stress tensor and $J^{\prime}{ }_{2}$ is the second invariant of the deviatoric stress tensor, which are defined as: 


$$
\begin{gathered}
I_{1}=\sigma_{x}+\sigma_{y}+\sigma_{z} \\
J_{2}^{\prime}=\frac{1}{6}\left[\left(\sigma_{x}-\sigma_{y}\right)^{2}+\left(\sigma_{y}-\sigma_{z}\right)^{2}+\left(\sigma_{z}-\sigma_{x}\right)^{2}\right]+\sigma_{x y}^{2}+\sigma_{y z}^{2}+\sigma_{z x}^{2}
\end{gathered}
$$

\subsection{Failure criterion}

The failure criterion of the Lade-Kim model is described as a general, threedimensional criterion developed for soils, concrete and rock by Lade and Kim (1988, 1988a, 1988b). This criterion is expressed in terms of the stress invariants of the stress tensor and is defined below.

$$
f_{n}=\left(\frac{I_{1}^{3}}{I_{3}}-27\right)\left(\frac{I_{1}}{p_{a}}\right)^{m}
$$

where $I_{1}$ has already been defined and

$$
I_{3}=\sigma_{x} \sigma_{y} \sigma_{z}+\tau_{x y} \tau_{y z} \tau_{z x}+\tau_{y x} \tau_{z y} \tau_{x z}-\left(\sigma_{x} \tau_{y z} \tau_{z y}+\sigma_{y} \tau_{z x} \tau_{x z}+\sigma_{z} \tau_{x y} \tau_{y z}\right)
$$

The value of $f_{n}$ is equal to $\eta_{1}$ at failure and depends on parameter $m$ besides the stress invariants. These parameters are constant dimensionless numbers that affect the shape of the failure criterion as shown in figure 3.1. Failure criterion is shaped as an asymmetric bullet by Lade and Kim (1988b) with the pointed apex at the origin of the stress axes and is influenced by the parameters $\eta_{1}$ and $m$.

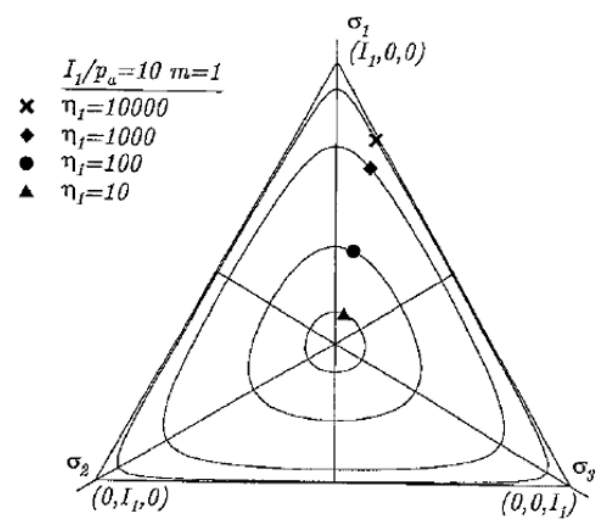

(a)

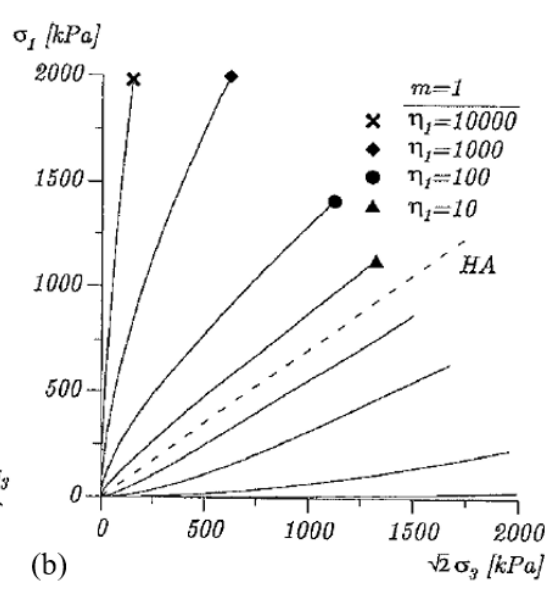

Figure 3.1: Characteristics of failure criterion in stress space (a) Contours in the octahedral plane. (b) Traces in the triaxial plane (Jakobsen, 1999)

\subsection{Plastic potential and flow rule}

Saint Venant (1870) proposed that the principal stress axes coincide with the corresponding principal axes of the incremental plastic strain during stresses 
rotation; however, not with those of total plastic strain. Based on this proposal, the suggestion of determining the plastic strain increments from a plastic potential function was made. Thus, the following plastic flow rule was made by Melan (1938).

$$
d \varepsilon^{p}=d \lambda_{p} \frac{\partial g_{p}}{\partial \sigma}
$$

where $d \varepsilon^{p}$ represents the plastic strain increments, $g_{p}$ is the plastic potential function and $d \lambda_{p}$ is a positive constant of proportionality known as plastic multiplier.

Lade and Kim (1988) based on experimental data in order to propose a plastic potential function that could successfully describe granular materials behavior. This function was expressed in terms of the stress invariants of the stress tensor as:

$$
\left.g_{p}=\psi_{1} \frac{I_{1}^{3}}{I_{3}}-\frac{I_{1}^{2}}{I_{2}}+\psi_{2}\right)\left(\frac{I_{1}}{p_{a}}\right)^{\mu}
$$

where $I_{1}$ and $I_{3}$ have already been defined and

$$
I_{2}=-\left(\sigma_{11} \sigma_{22}+\sigma_{22} \sigma_{33}+\sigma_{11} \sigma_{33}\right)+\sigma_{12}^{2}+\sigma_{23}^{2}+\sigma_{13}^{2}
$$

The parameters $\psi_{1}, \psi_{2}$ and $\mu$ are dimensionless constant numbers such that $\psi_{1}$ is a weighting factor between the triangular and circular shape of the plastic function in the octahedral plane, $\psi_{2}$ controls where this function will intercept the hydrostatic axis and $\mu$ models the curvature of the meridians. Thus, the characteristics of the plastic potential function in the stress space can be observed in figure 3.2 .

The parameter $\psi_{1}$ can be determined using an empirical relation proposed by Lade and Kim (1988), which was based on many triaxial tests data. The expression below, relates the parameter $\psi_{1}$ with the failure criterion parameter $m$.

$$
\psi_{1}=0.00155 m^{-1.27}
$$




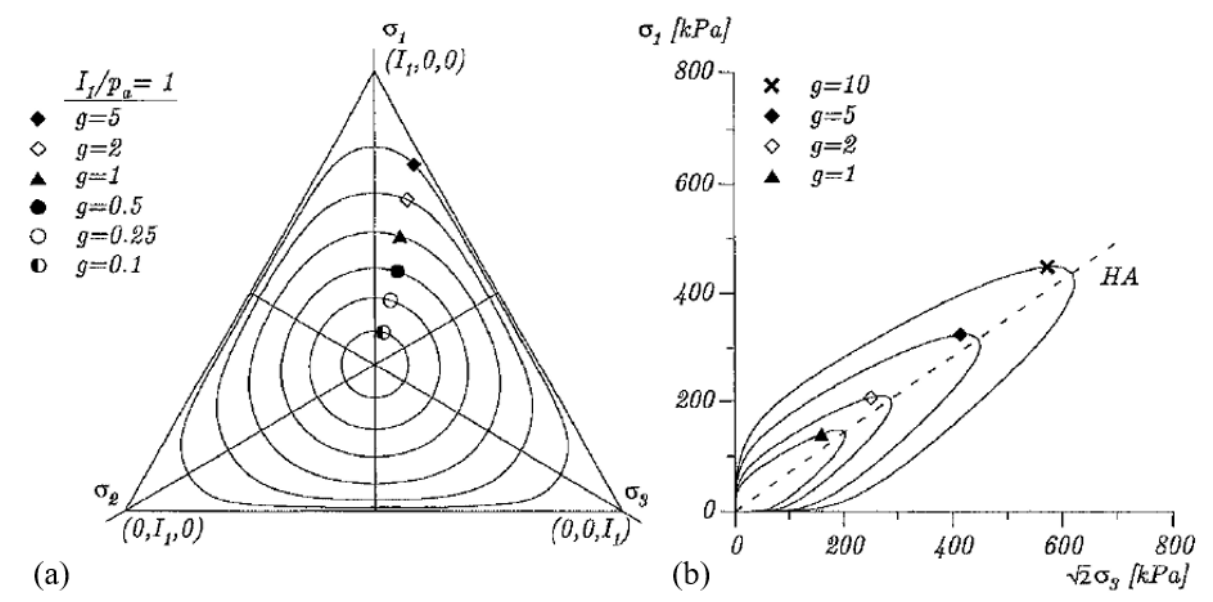

Figure 3.2: Characteristics of the plastic potential function in stress space. (a) Contours in the octahedral plane (b) Traces in the triaxial plane (Jakobsen, 1999)

Replacing equation 3-8 into equation 3-7, is possible to calculate the plastic strain increments as follows:

$$
\left\{\begin{array}{l}
d \varepsilon_{x x}^{p} \\
d \varepsilon_{y y}^{p} \\
d \varepsilon_{z z}^{p} \\
d \gamma_{y z}^{p} \\
d \gamma_{x z}^{p} \\
d \gamma_{x y}^{p}
\end{array}\right\}=d \lambda_{p}\left(\frac{I_{1}}{p_{a}}\right)^{\mu}\left\{\begin{array}{l}
G-\left(\sigma_{22}+\sigma_{33}\right) \frac{I_{1}^{2}}{I_{2}^{2}}-\psi_{1}\left(\sigma_{22}-\sigma_{33}-\sigma_{23}^{2}\right) \frac{I_{1}^{3}}{I_{3}^{2}} \\
G-\left(\sigma_{11}+\sigma_{33}\right) \frac{I_{1}^{2}}{I_{2}^{2}}-\psi_{1}\left(\sigma_{11}-\sigma_{33}-\sigma_{13}^{2}\right) \frac{I_{1}^{3}}{I_{3}^{2}} \\
2 \sigma_{23} \frac{I_{1}^{2}}{I_{2}^{2}}-2 \psi_{1}\left(\sigma_{12} \sigma_{13}-\sigma_{11} \sigma_{23}\right) \frac{I_{1}^{2}}{I_{2}^{2}}-\psi_{1}\left(\sigma_{11}-\sigma_{22}-\sigma_{12}^{2}\right) \frac{I_{1}^{3}}{I_{3}^{2}} \\
2 \sigma_{13} \frac{I_{1}^{2}}{I_{2}^{2}}-2 \psi_{1}\left(\sigma_{12} \sigma_{23}-\sigma_{22} \sigma_{13}\right) \frac{I_{1}^{3}}{I_{3}^{2}} \\
2 \sigma_{12} \frac{I_{1}^{2}}{I_{2}^{2}}-2 \psi_{1}\left(\sigma_{23} \sigma_{13}-\sigma_{33} \sigma_{12}\right) \frac{I_{1}^{3}}{I_{3}^{2}}
\end{array}\right\}
$$

where

$$
G=\psi_{1}(\mu+3) \frac{I_{1}^{2}}{I_{3}}-(\mu+2) \frac{I_{1}}{I_{2}}+\psi_{2} \mu \frac{1}{I_{1}}
$$

It is crucial to define the irreversibility condition in order to properly model the behavior of materials. Prager (1949) stated that with the objective of fulfilling this condition, the plastic work must be equal or greater than zero each time plastic deformation occurs. Thus, the following condition has to be taken into account.

$$
d W_{p}=\sigma d \varepsilon^{p}=\sigma d \lambda_{p} \frac{\partial g_{p}}{\partial \sigma} \geq 0
$$




$$
d W_{p}=\mu g_{p} d \lambda_{p} \geq 0
$$

Considering Euler's theorem for homogeneous functions, equation 3-13 can be transformed into equation 3-14 since the plastic potential function is homogeneous and of the order of $\mu$. Thus, knowing that $\mathrm{d} \lambda_{p}$ is positive, the following relation is derived.

$$
\mu g_{p} \geq 0
$$

As shown in figure 3.3, the incremental plastic strain vectors are directed outside the plastic potential function. In order to comply with this experimental data and the irreversibility condition, Lade and Kim (1988) analyzed two cases: (a) case of positive $g_{p}$ and (b) case of negative $g_{p}$.

Figure 3.4 shows that for the case of positive $g_{p}$ the incremental plastic strain vectors are directed in the correct way. Moreover, since $I_{1}^{3} / I_{3} \geq 27$, $-I_{1}^{2} / I_{2} \geq 3$ and $I_{1} / p_{a}$ is always positive; the irreversibility condition is defined below:

$$
\begin{gathered}
\mu>0 \\
g_{p} \geq 0 \\
\psi_{2}>-\left(27 \psi_{1}+3\right)
\end{gathered}
$$
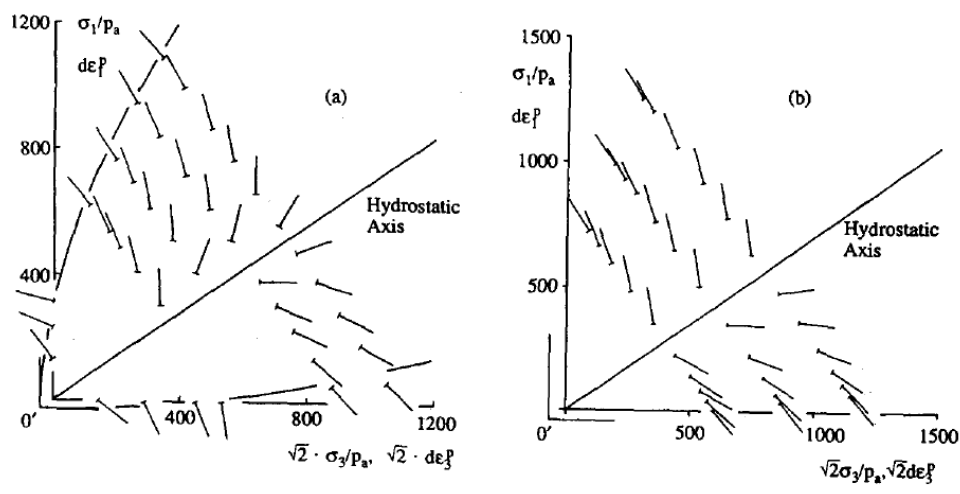

Figure 3.3: Directions of incremental plastic strain vectors in triaxial plane for (a)plain concrete and (b) steel fiber reinforced concrete (Lade and Kim, 1988) 
(a) $\mathrm{g}_{\mathrm{p}}>0$
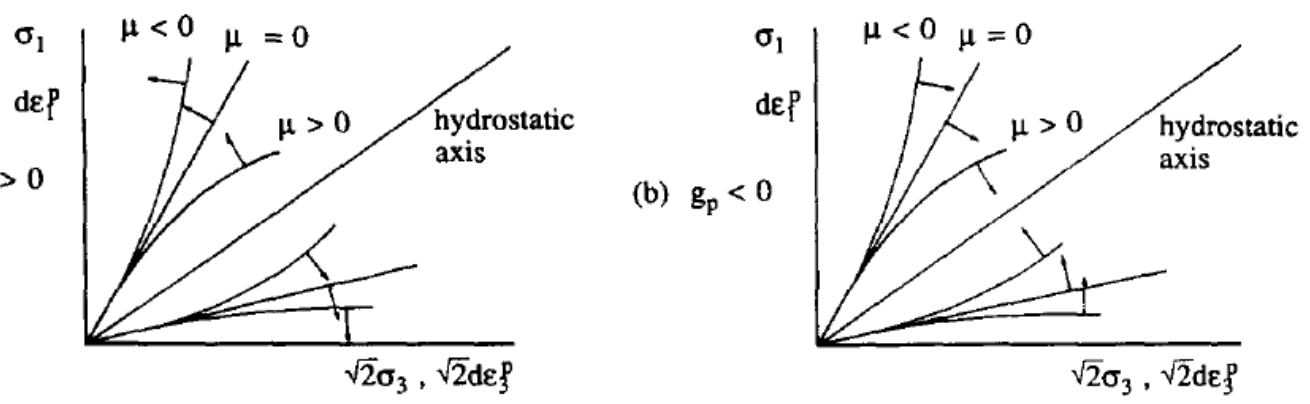

Figure 3.4: Combinations of plastic potential and parameter $\mu$ in triaxial plane.

(a) Case of positive $g_{p}$ and (b) Case of negative $g_{p}$ (Lade and Kim, 1988)

\subsection{Yield criterion}

Taking into account that a yield criterion should be associated with the hardening and softening characteristics of the material, developing one that is capable of describing a yield surface in order to model the deformation of frictional materials effectively represents a challenge. Investigating this kind of behavior under different types of loading conditions is not simple, for this reason Lade and Kim (1988a) proposed a yield function based on the plastic work contours obtained during triaxial tests which used the plastic work as the hardening parameter.

Based on the theory of plasticity, the stress space is divided into an elastic domain and an elasto-plastic domain where elastic and plastic deformations occur. The yield criterion, which describes a yield surface in the stress space, divides these domains and is defined below, consisting of a stress dependent term $f^{\prime}{ }_{p}(\sigma)$ and a hardening/softening term $f^{\prime \prime}\left(W_{p}\right)$.

$$
f_{p}=f^{\prime}{ }_{p}(\sigma)-f^{\prime \prime}{ }_{p}\left(W_{p}\right) \leq 0
$$

\subsubsection{Yield function}

Studying the yield behavior of materials is not an easy task because of the identification of yield points. On the other side, using plastic work contours has advantages like avoiding using tests with complicated stress-paths and capturing the yield behavior of the material.

Generally, the plastic work contours and yield surfaces have similar shapes. Figure 3.5 shows contours for constant plastic work for Fuji river sand that were described by Lade and Kim (1988a) with a yield function defined as: 


$$
\left.f^{\prime}{ }_{p}=\psi_{1} \frac{I_{1}^{3}}{I_{3}}-\frac{I_{1}^{2}}{I_{2}}\right)\left(\frac{I_{1}}{p_{a}}\right)^{h} e^{q}
$$

where $I_{1}, I_{2}$ and $I_{3}$ are the first, second and third stress invariant of the stress tensor respectively.

The yield function depends on the failure parameters $h$ and $q$, where $h$ is a material constant and $q$ is a variable that depends on the stress level according to the following expression:

$$
q=\frac{\alpha S}{1-(1-\alpha) S}
$$

where $\alpha$ is a material constant parameter and $S$ represents the stress level, varying from zero at the hydrostatic axis to unity at the failure surface. Thus, it can be concluded that:

$$
\left.S=\frac{f_{n}}{\eta_{1}}=\frac{1}{\eta_{1}} \frac{I_{1}^{3}}{I_{3}}-27\right)\left(\frac{I_{1}}{p_{a}}\right)^{m}
$$

$$
\begin{gathered}
q=0 \text { during isotropic compression } \\
0<q<1 \quad \text { during hardening } \\
0<q<1 \quad \text { during hardening }
\end{gathered}
$$

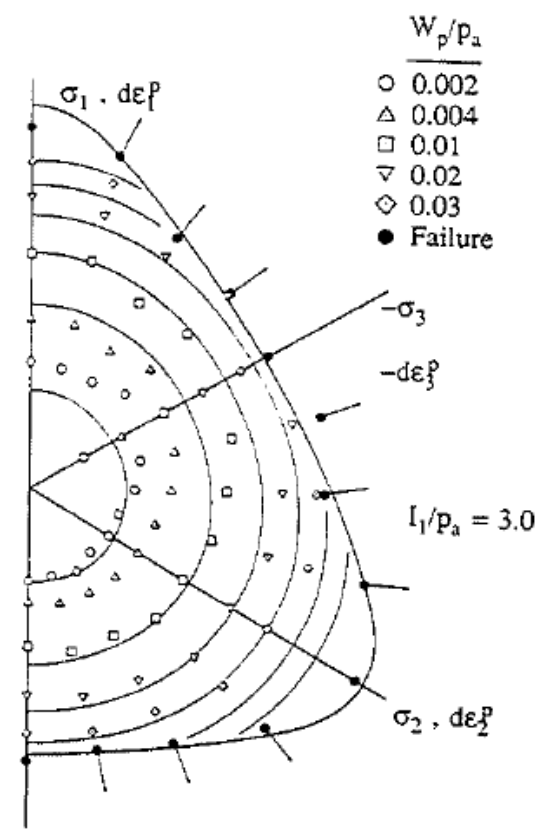

Figure 3.5: Experimental data points and contours of constant plastic work shown on the octahedral plane for Fuji river sand (Lade and Kim, 1988a) 
The described yield criterion simulates yield surfaces with the shape of an asymmetric tear drop, such as shown in figure 3.6. The yield surface expands as the plastic work increases due to loading conditions, until reaching failure surface eventually.

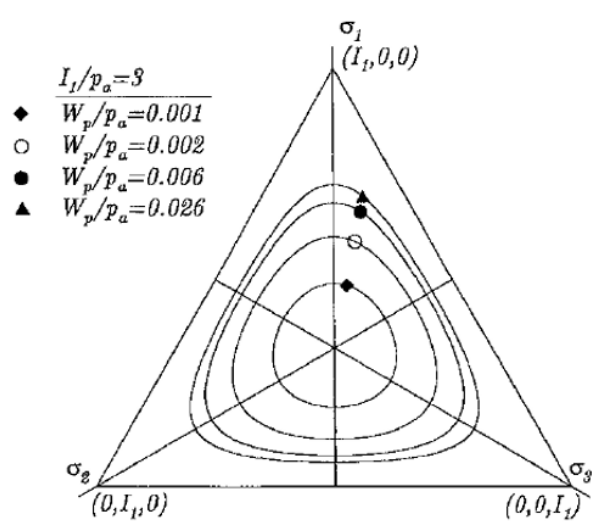

(a)

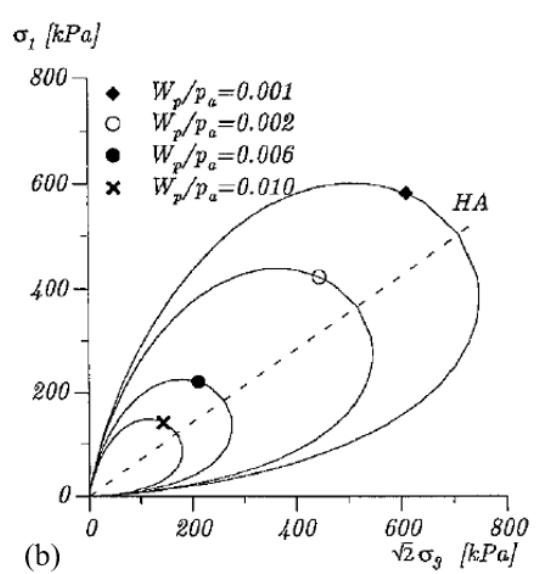

(b)

Figure 3.6: Characteristics of the yield function in stress space. (a)Contours in the octahedral plane. (b) Traces in the triaxial plane (Jakobsen, 1999)

\subsubsection{Hardening/Softening law}

Lade and Kim (1988a) used the plastic work as the hardening parameter, which is calculated and continuously updated each time plastic deformations occur. Thus, plastic work can be defined generally as:

$$
W_{p}=\int \sigma d \varepsilon^{p}
$$

A convenient option to study plastic work is to perform isotropic compression tests due to the simple stress path where the normal stresses are the same in all directions and the experimental data that these provide, which can be used to plot plastic work contours. The plastic work in an isotropic compression test can be calculated with the following expression:

$$
W_{p}=C p_{a}\left[\frac{I_{1}}{p_{a}}\right]^{p}
$$

where $I_{1}$ is the first stress invariant of the stress tensor, $p_{a}$ is the atmospheric pressure, $C$ and $p$ are the hardening/softening parameters. Thus, equation 3-27 can be generalized as:

$$
W_{p}=p_{a} D\left(f^{\prime}\right)^{\rho}
$$


Where

$$
D=\frac{C}{\left(27 \psi_{1}+3\right)^{\rho}} \quad \rho=p / h
$$

The hardening/softening term of the yield criterion depends on the accumulated plastic work that occurs due to plastic deformations; however, depends on the material having a hardening or softening behavior. Regarding hardening behavior, this term is defined as:

$$
\left.f^{\prime \prime}{ }_{p}=\left(\frac{1}{D}\right)^{1 / \rho} \frac{W_{p}}{p_{a}}\right)^{1 / \rho}
$$

Regarding softening behavior, Lade and Kim (1988a) proposed a softening law that could simulate the curve shown in figure 3.7. Thus, an isotropic softening behavior was adopted due to its simplicity and the expression below was defined:

$$
f^{\prime \prime}{ }_{p}=A e^{-B W_{p} / p_{a}}
$$

where

$$
\begin{aligned}
& A=\left[f^{\prime \prime}{ }_{p} e^{B W_{p} / p_{a}}\right]_{S=1} \\
& B=\left[b \frac{d{f^{\prime \prime}}_{p}}{d\left(\frac{W_{p}}{p_{a}}\right)} \frac{1}{\left.f^{\prime \prime}\right]_{S=1}}\right]_{S}
\end{aligned}
$$

This law can be described as an exponential decay function, where $A$ and $B$ are positive constants derived from the slope of the hardening curve when $S=$ 1. At this point, a sudden transition from hardening to softening behavior occurs and the yield surface starts to reduce.

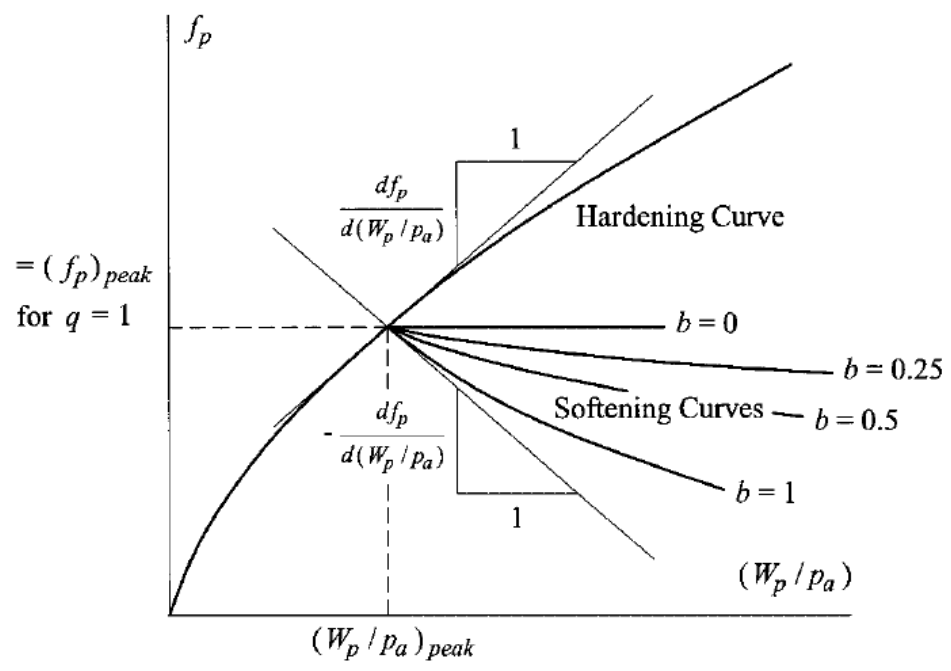

Figure 3.7: Modeling of work hardening and softening (Jakobsen, 1999) 


\subsection{Materials with effective cohesion}

Lade and Kim (1988, 1988a, 1988b) developed the Lade-Kim model for granular materials, which could be used to model the behavior of materials with effective cohesion and tension strength such as concrete or rock. This can be achieved by translating the principal stress axis along the hydrostatic axis by adding a constant stress to the normal stresses before performing any calculations. Thus, the following expression was proposed:

$$
\sigma_{a}=\sigma+a p_{a} I
$$

where $a$ is a dimensionless constant, $p_{a}$ is the atmospheric pressure and $I$ is the identity matrix. The product $a p_{a}$ represents the true cohesion of the material and can be obtained from laboratory tests such as a triaxial compression test. 


\section{Numerical implementation of the Lade-Kim Model}

Many difficulties are found in numerical solution schemes during the implementation of a constitutive model. These difficulties include path dependency and highly nonlinear behavior. Any numerical solution scheme must anticipate these difficulties in order to model the behavior of geo-materials properly. The FLAC3D software is an explicit, dynamic solution scheme that approaches the difficulties and provides a tool to implement extremely nonlinear constitutive model.

\subsection{Incremental formulation}

The numerical implementation of an elasto-plastic model into a finite volume program, such as FLAC3D, through the generation of a dynamic link library (DLL), requires its incremental form. In order simplify the constitutive model implementation procedure for future authors, Lade and Jakobsen (2002) presented the incremental form as follows.

\subsubsection{Elasto-plastic stiffness matrix}

The incremental form of a constitutive model with a single yield surface allows to express the stress increments in terms of the total strains increments and the elasto-plastic stiffness matrix, as it is shown in the following:

$$
d \sigma=C^{e p} d \varepsilon=\left(C^{e}-C^{p}\right) d \varepsilon
$$

where $C^{e p}$ is the elasto-plastic stiffness matrix, $C^{e}$ is the elastic stiffness matrix and $C^{p}$ is the plastic stiffness matrix.

Many authors, such as Zienkiewicz and Taylor (1991), Smith and Griffiths (1988), Chen and Mizuno (1990), Lade and Nelson (1984), described an incrementalization procedure in order to define the elasto-plastic stiffness matrix. Thus, the expression below was obtained:

$$
C^{p}=\left[\frac{C^{e}\left(\frac{\partial g_{p}}{\partial \sigma}\right)\left(\frac{\partial f_{p}}{\partial \sigma}\right)^{T} C^{e}}{\left(\frac{\partial f_{p}}{\partial \sigma}\right)^{T} C^{e}\left(\frac{\partial g_{p}}{\partial \sigma}\right)+H}\right]
$$

Replacing equation 4-2 into equation 4-1, it is obtained the incremental form of a single yield surface constitutive model: 


$$
d \sigma=\left[C^{e}-\frac{C^{e}\left(\frac{\partial g_{p}}{\partial \sigma}\right)\left(\frac{\partial f_{p}}{\partial \sigma}\right)^{T} C^{e}}{\left(\frac{\partial f_{p}}{\partial \sigma}\right)^{T} C^{e}\left(\frac{\partial g_{p}}{\partial \sigma}\right)+H}\right] d \varepsilon
$$

where $g_{p}$ is the plastic potential function, $f_{p}$ is the yield function and $H$ is the hardening modulus.

Initially, if the stress point is inside the elastic domain, the defined $C^{e p}$ becomes equal to $C^{e}$. After that, while being in the elasto-plastic domain, the defined $C^{e p}$ becomes equal to $C^{p}$. Moreover, based on the theory of plasticity, it is possible to obtain the plastic multiplier from equation 4-3:

$$
d \lambda_{p}=\left[\frac{C^{e}\left(\frac{\partial f_{p}}{\partial \sigma}\right)^{T}}{\left(\frac{\partial f_{p}}{\partial \sigma}\right)^{T} C^{e}\left(\frac{\partial g_{p}}{\partial \sigma}\right)+H}\right] d \varepsilon
$$

\subsubsection{Elastic stiffness matrix}

The elastic stiffness matrix is defined as:

$$
C^{e}=\frac{E}{(1+v)(1-2 v)}\left[\begin{array}{llllll}
1-v & v & v & 0 & 0 & 0 \\
v & 1-v & v & 0 & 0 & 0 \\
v & v & 1-v & 0 & 0 & 0 \\
0 & 0 & 0 & 1-2 v & 0 & 0 \\
0 & 0 & 0 & 0 & 1-2 v & 0 \\
0 & 0 & 0 & 0 & 0 & 1-2 v
\end{array}\right]
$$

where $E$ is Young's modulus and $v$ is Poisson's ratio, which was assumed constant in this approach.

\subsubsection{Derivatives of the plastic potential}

The derivatives of the plastic potential function $g_{p}$ are obtained on the basis of the chain rule since $g_{p}$ is expressed in terms of the stress invariants. Thus, the following expression is defined:

$$
\frac{\partial g_{p}}{\partial \sigma}=\frac{\partial g_{p}}{\partial I_{1}} \frac{\partial I_{1}}{\partial \sigma}+\frac{\partial g_{p}}{\partial I_{2}} \frac{\partial I_{2}}{\partial \sigma}+\frac{\partial g_{p}}{\partial I_{3}} \frac{\partial I_{3}}{\partial \sigma}
$$

where the derivatives of the plastic potential with respect to the stress invariants are

$$
\frac{\partial g_{p}}{\partial I_{1}}=\left(\psi_{1}(\mu+3) \frac{I_{1}^{2}}{I_{3}}-(\mu+2) \frac{I_{1}}{I_{2}}+\frac{\mu \psi_{2}}{I_{1}}\right)\left(\frac{I_{1}}{p_{a}}\right)^{\mu}
$$




$$
\begin{gathered}
\frac{\partial g_{p}}{\partial I_{2}}=\frac{I_{1}^{2}}{I_{2}^{2}}\left(\frac{I_{1}}{p_{a}}\right)^{\mu} \\
\frac{\partial g_{p}}{\partial I_{3}}=-\psi_{1} \frac{I_{1}^{3}}{I_{3}^{2}}\left(\frac{I_{1}}{p_{a}}\right)^{\mu}
\end{gathered}
$$

and the derivatives with respect to stresses are

$$
\begin{gathered}
\frac{\partial I_{1}}{\partial \sigma}=\left[\begin{array}{l}
1 \\
1 \\
1 \\
0 \\
0 \\
0
\end{array}\right] \\
\frac{\partial I_{2}}{\partial \sigma}=\left[\begin{array}{l}
-\left(\sigma_{22}+\sigma_{33}\right) \\
-\left(\sigma_{33}+\sigma_{11}\right) \\
-\left(\sigma_{11}+\sigma_{22}\right) \\
2 \sigma_{23} \\
2 \sigma_{31} \\
2 \sigma_{12}
\end{array}\right] \\
\frac{\partial I_{3}}{\partial \sigma}=\left[\begin{array}{l}
\sigma_{22} \sigma_{33}-\sigma_{23}^{2} \\
\sigma_{33} \sigma_{11}-\sigma_{31}^{2} \\
\sigma_{11} \sigma_{22}-\sigma_{12}^{2} \\
2\left(\sigma_{12} \sigma_{31}-\sigma_{11} \sigma_{23}\right) \\
2\left(\sigma_{23} \sigma_{12}-\sigma_{22} \sigma_{31}\right) \\
2\left(\sigma_{31} \sigma_{23}-\sigma_{33} \sigma_{12}\right)
\end{array}\right]
\end{gathered}
$$

\subsubsection{Derivatives of the yield function}

The yield function is expressed in terms of the stress invariants as well as the plastic potential. Then, the derivatives can be obtained in a similar way:

$$
\frac{\partial f_{p}^{\prime}}{\partial \sigma}=\frac{\partial f_{p}^{\prime}}{\partial I_{1}} \frac{\partial I_{1}}{\partial \sigma}+\frac{\partial f_{p}^{\prime}}{\partial I_{2}} \frac{\partial I_{2}}{\partial \sigma}+\frac{\partial f_{p}^{\prime}}{\partial I_{3}} \frac{\partial I_{3}}{\partial \sigma}
$$

where the derivatives of the yield function with respect to the stress invariants are

$$
\begin{gathered}
\frac{\partial f^{\prime}{ }_{p}}{\partial I_{1}}=\left(\frac{3+h}{I_{1}}+\frac{\partial q}{\partial I_{1}}\right) f^{\prime}{ }_{p}+\frac{I_{1}}{I_{2}}\left(\frac{I_{1}}{p_{a}}\right)^{h} e^{q} \\
\frac{\partial f^{\prime}{ }_{p}}{\partial I_{2}}=\frac{I_{1}^{2}}{I_{2}^{2}}\left(\frac{I_{1}}{p_{a}}\right)^{h} e^{q}
\end{gathered}
$$




$$
\frac{\partial f^{\prime} p}{\partial I_{3}}=f^{\prime}{ }_{p} \frac{\partial q}{\partial I_{3}}-\psi_{1} \frac{I_{1}^{3}}{I_{3}^{2}}\left(\frac{I_{1}}{p_{a}}\right)^{h} e^{q}
$$

and the derivatives of $q$, which is a function of the stress level $S$, with respect to the stress invariants are

$$
\begin{gathered}
\frac{\partial q}{\partial I_{1}}=\frac{\alpha}{\eta_{1}(1-(1-\alpha) S)^{2}}\left(\frac{m S \eta_{1}}{I_{1}}+\frac{3 I_{1}^{2}}{I_{3}}\left(\frac{I_{1}}{p_{a}}\right)^{m}\right) \\
\frac{\partial q}{\partial I_{3}}=-\frac{\alpha}{\eta_{1}(1-(1-\alpha) S)^{2}} \frac{I_{1}^{3}}{I_{3}^{2}}\left(\frac{I_{1}}{p_{a}}\right)^{m}
\end{gathered}
$$

\subsubsection{Hardening modulus}

The hardening modulus is expressed in terms of the actual stress and the derivatives of the plastic potential; however, on the basis of Euler's theorem for homogeneous functions, the hardening modulus can be expressed in terms of the plastic potential and the parameter $\mu$, since $g_{p}$ is homogeneous and of the order $\mu$. Thus, the following expression is obtained:

$$
H=\frac{\partial f^{\prime \prime} p}{\partial W_{p}} \sigma^{T} \frac{\partial g_{p}}{\partial \sigma}=\frac{\partial f^{\prime \prime} p}{\partial W_{p}} \mu g
$$

where the derivative of the yield function with respect to the plastic work depends on the hardening or softening behavior of the material.

Thus, the derivative is described as:

$$
\begin{gathered}
\text { Hardening: } \frac{\partial f_{p}}{\partial W_{p}}=\frac{\partial f_{p}^{\prime \prime}}{\partial W_{p}}=\frac{1}{\rho\left(D p_{a}\right)^{1 / \rho}} W_{p}^{\frac{1}{\rho}-1} \\
\text { Softening: } \frac{\partial f_{p}}{\partial W_{p}}=\frac{\partial f^{\prime \prime} p}{\partial W_{p}}=-\frac{A B}{p_{a}} e^{-B W_{p} / p_{a}}
\end{gathered}
$$

\subsection{Stress integration algorithm}

A stress integration algorithm is needed in order to obtain the updated state of stress and hardening parameter caused by a strain increment, being the forward Euler scheme the most common for elastoplastic stress-strain relations. This integration scheme is an explicit integration scheme that can be successfully used for the implementation of an advanced constitutive model into FLAC3D software due to the explicit, dynamic solution scheme it relies on. 


\subsubsection{Implementation criteria}

The incremental form of the Lade-Kim model is used to define the evolution of stress in computer codes; however, an implementation criteria must be used as well in order to model the behavior of a material (Borja, 2013). This criteria is based on the theory of plasticity and is illustrated in figure 4.1 .

(a)

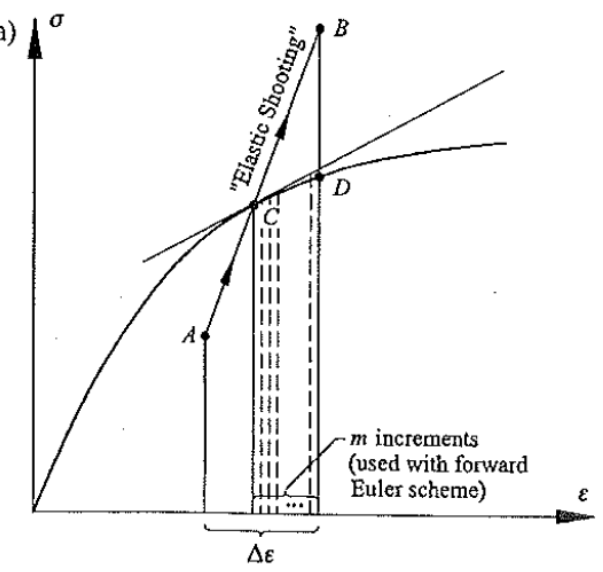

(b) ${ }^{\sigma}$

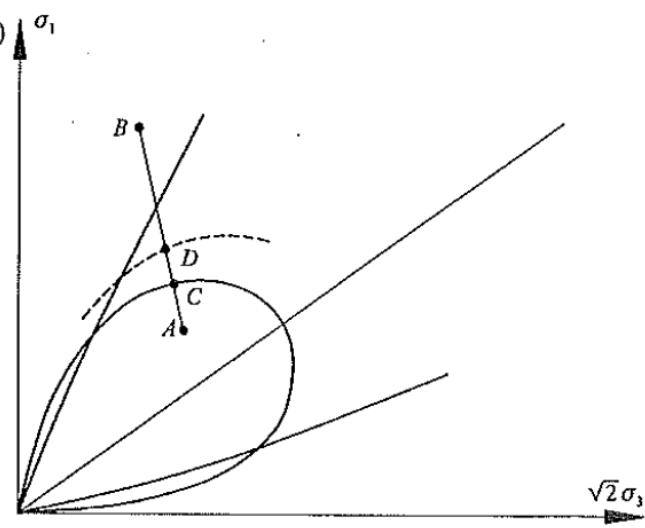

Figure 4.1: Implementation criteria in the (a) stress-strain relation and (b) triaxial plane (Jakobsen and Lade, 2002)

In figure 4.1, point $A$ is the current stress located in the stress-strain relation and the triaxial plane. After a strain increment $\Delta \varepsilon$ occurs, a new stress point is obtained by assuming that all of the strain increment is purely elastic. However, it is needed to verify this assumption by checking the consistency condition. First, the value of the yield function $f_{p}$ is obtained considering the stress point $B$. Then, it is calculated the value of $\left(f^{\prime}{ }_{p}-f^{\prime \prime}{ }_{p}\right)$ taking into account the value of $f^{\prime \prime}{ }_{p}$, which was obtained considering the maximum plastic work $W_{p}$. The next step depends on the value of $\left(f^{\prime}{ }_{p}-f^{\prime \prime}{ }_{p}\right)$. If the difference is equal or less than zero, the stress point $B$ is located inside the yield surface and the total strain increment corresponds is purely elastic; if the difference is greater than zero, the stress point $B$ is located outside the yield surface and the total strain increment has a plastic part.

Considering the case when stress point $B$ is located outside the current yield function, stress point $A$ could be located either inside or on the yield function. Thus, considering the previous value of $f^{\prime \prime}{ }_{p}$ and by calculating $f^{\prime}{ }_{p}$ using stress point $A$, is possible to calculate $\left(f^{\prime}{ }_{p}-f^{\prime \prime}{ }_{p}\right)$. If the difference is equal to zero, then is concluded that point $A$ and point $C$ are the same. However, if the difference is less than zero, then is concluded that point $A$ is located inside the yield surface and 
the total strain increment consists of an elastic and a plastic part. It is important to calculate the purely elastic portion in order to model the material behavior; hence, is needed to calculate the ratio $\alpha=A C / A B$ in figure 4.1.

Finally, a stress integration scheme is used in order to calculate the corresponding stresses and hardening parameter after determining which portion of the total strain increment is purely elastic and which one develops elastic and plastic strain increments. As shown in figure 4.2, Lade and Jakobsen (2002) presented a flow chart for the implementation of a constitutive model with a single yield surface.

\subsubsection{Initial intersection with the yield surface}

Many materials can be found in a presheared or overconsolidated state, where the current stress state is located inside the yield surface. This situation is illustrated in figure 4.1, where stress point $A$ is located in the elastic domain and stress point $B$ is located outside the yield surface due to a strain increment. In this cases, stress point $C$ needs to be determined in order to divide the total strain increment into purely and non-purely elastic strain increment. Thus, it can be established that the value of the yield function $f_{p}$ corresponding to stress point $A$ is defined as:

$$
f\left(\sigma_{A}, W_{p, A}\right)=f_{A}<0
$$

Then, stress point $B$ is calculated by assuming that the total strain increment is purely elastic and on the basis of Hooke's law; however, the yield criterion may not be fulfilled since stress point $B$ is located in the elastoplastic domain, as shown in equation 4-23.

$$
f\left(\sigma_{A}+\alpha \Delta \sigma^{e}, W_{p, C}\right)=f\left(\sigma_{B}, W_{p, C}\right)=f_{B}>0
$$

It is necessary to obtain stress point $C$ in order to determine the purely elastic portion of the total strain increment; hence, the ratio $\alpha$ must be calculated to fulfill the consistency condition.

$$
f\left(\sigma_{A}+\alpha \Delta \sigma^{e}, W_{p, C}\right)=f\left(\sigma_{C}, W_{p, C}\right)=f_{C}=0
$$




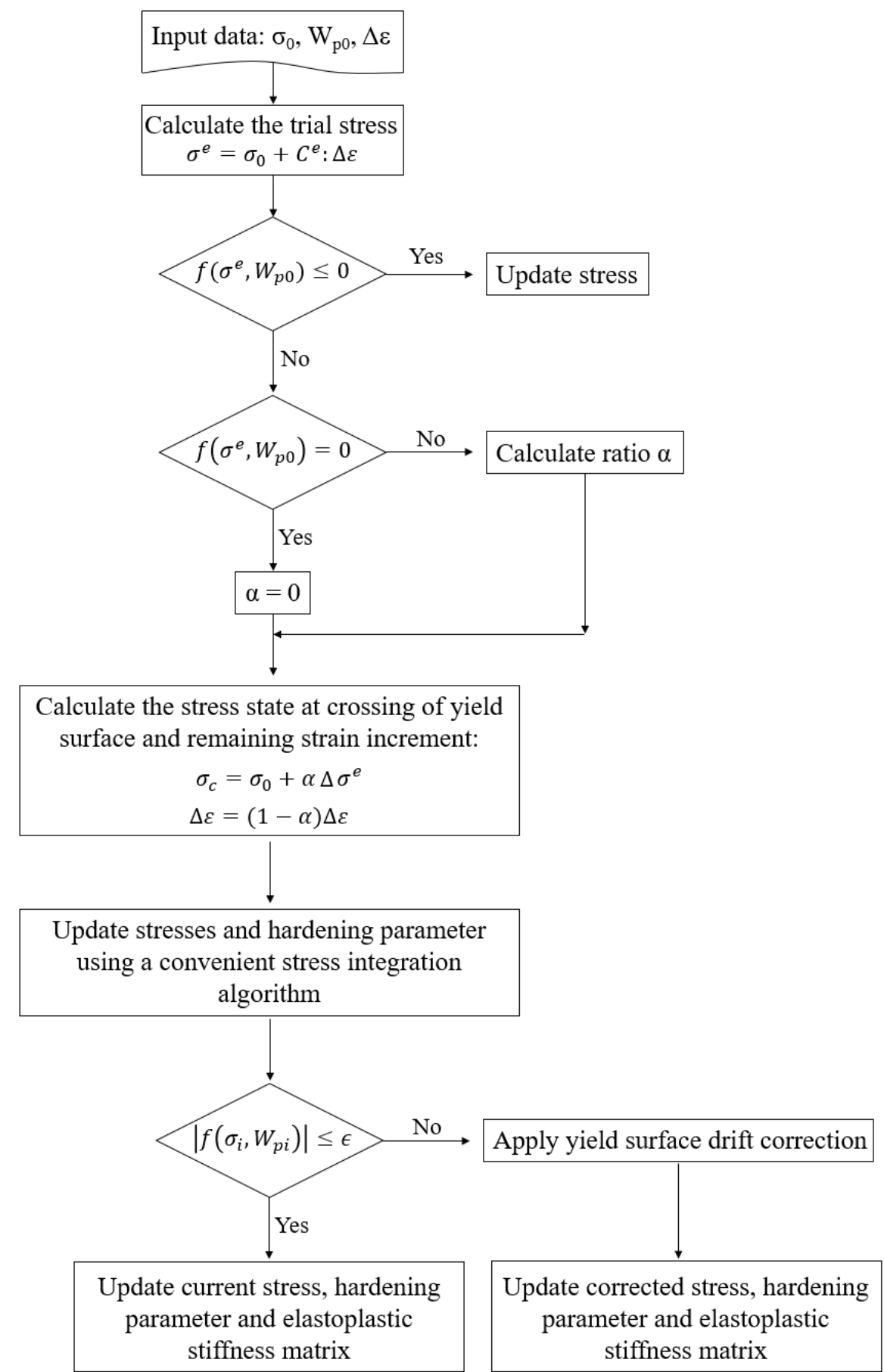

Figure 4.2: Flow chart for the implementation of a constitutive model with a single yield surface (adapted from Jakobsen and Lade, 2002)

Lade and Jakobsen (2002) used a Taylor series expansion to propose an estimate of ratio $\alpha$, such that:

$$
\alpha=\alpha_{0}-\frac{f_{E}}{\left(\partial f / \partial\left(\sigma_{A}+\alpha_{0} \Delta \sigma^{e}\right)^{T}\right) \Delta \sigma^{e}}
$$

where $\alpha_{0}$ is a first estimate defined as: 


$$
\alpha_{0}=-\frac{f_{A}}{f_{B}-f_{A}}
$$

and $f_{E}$ is the value of the yield function calculated by using the first estimate $\alpha_{0}$, which is defined as follows:

$$
f\left(\sigma_{A}+\alpha_{0} \Delta \sigma^{e}, W_{p, C}\right)=f\left(\sigma_{E}, W_{p, C}\right)=f_{E} \neq 0
$$

The described mathematical procedure allows to determine the purely elastic portion of the total strain increments and stress point $C$. This formulation is accurate for small strains only, therefore it is suitable for the FLAC3D software due to the use of small strain increments.

Lade and Jakobsen (2002) proposed an algorithm, which is expressed below, in order to determine stress point $C$, in other words, the initial intersection with the yield surface. This algorithm is based on the Newton-Raphson iterative method. The procedure starts by considering the first estimate ratio $\alpha_{0}$ and the iteration continues until an error tolerance is reached. In the end of this procedure, the purely elastic stress increment is calculated as $\alpha \Delta \sigma^{e}$ corresponding to an elastic strain increment of $\alpha \Delta \varepsilon$ and the remaining portion as $(1-\alpha) \Delta \varepsilon$.

$$
\begin{gathered}
\text { Input: } \sigma_{0}, W_{p, 0} \\
\text { If } \quad f\left(\sigma_{0}, W_{p, 0}\right)>0 \\
\alpha_{0}=-\frac{f_{A}}{f_{B}-f_{A}} \\
\text { Iterations } \quad i=1,2, \ldots, i_{\text {max }} \\
\sigma_{i}=\sigma_{i-1}+\alpha_{i-1} \Delta \sigma^{e} \\
\sigma_{i}=\sigma_{i-1}+\alpha_{i-1} \Delta \sigma^{e} \\
\Delta \alpha_{i}=-\frac{f\left(\sigma_{i}, W_{p}\right)}{\left(\partial f / \partial \sigma_{i}\right)^{T} \Delta \sigma^{e}} \\
\alpha_{i}=\alpha_{i-1}+\Delta \alpha_{i} \\
\text { iteration } \quad \text { when } \quad \| \sigma_{i} \\
-\sigma_{i-1}\|/\| \sigma_{i-1} \| \leq \epsilon \\
\text { Output: } \quad \sigma_{c}=\sigma_{i}, \alpha_{c}=\alpha_{i}
\end{gathered}
$$

The presented algorithm can also be expressed graphically, as shown in 
figure 4.3. Here, starting from stress point $A$, stress point $B$ is obtained by the first assumption where the total strain increment is purely elastic. Then, in the case where stress point $B$ belongs to the elastoplastic domain, stress point $E$ is determined by using equation 4-26 in order to obtain the first estimate of $\alpha$. Finally, a more accurate value of $\alpha$ is calculated by using a Taylor series expansion as shown in the algorithm previously presented and a correct estimate of stress point $C$ is established.

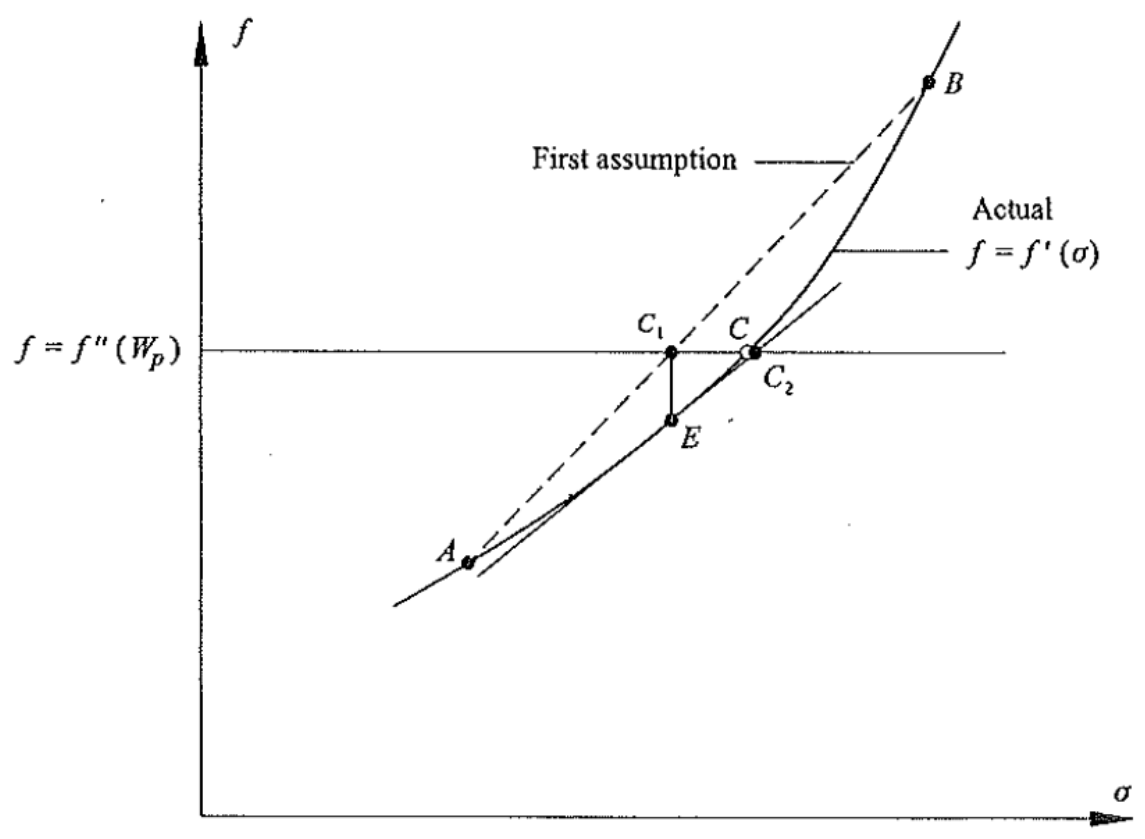

Figure 4.3: Graphical representation of the algorithm to obtain the intersection with the yield surface (Jakobsen and Lade, 2002)

\subsubsection{Stress and hardening parameter update}

The implementation of a constitutive model in a numerical solution scheme allows to determine the updated stress and hardening parameter that result from a total strain increment. Thus, a suitable integration scheme must be chosen based on the advantages and disadvantages it may have. Generally, an implicit or an explicit scheme (Sloan, 1987; Ortiz \& Simo, 1986; Abbo \& Sloan, 1993) is used to update the stress tensor and the hardening parameter.

The backward Euler or implicit algorithm scheme has advantages regarding the initial intersection with the yield surface. This algorithm scheme allows to neglect the calculation of the initial intersection if the stress is updated from a purely 
elastic domain to an elastoplastic one, being this characteristic the main advantage. Lade and Jakobsen (2002) define this scheme as an elastic predictor and plastic corrector type method, where this plastic correction is computed by solving a an iterative method as defined by Crisfield (1991). Thus, the consistency condition is fulfilled in a range of tolerance.

On the other side, the disadvantage involves convergence problems for highly non-linear constitutive models since establishing the equations system may present difficulties. Besides, this scheme has not been used widely in the implementation of advanced constitutive models.

An explicit integration algorithm is more widely used in the implementation of advanced constitutive models. In contrast with the implicit integration schemes, the initial intersection with the yield surface must be determined as stated in subsection 4.2.2 for explicit integration schemes. Moreover, it is necessary to check if the consistency condition has been fulfilled after computing the updated stress and hardening parameter since it is not guaranteed with this type of method. However, this disadvantages are compensated by the advantages.

This scheme has a relatively easier implementation procedure for advanced constitutive models in comparison with an implicit method. Besides, the accuracy of this scheme can be improved in order to obtain better results.

\subsubsection{Forward Euler integration scheme with subincrementation}

There are different explicit schemes that allow the integration of the stress along a strain increment, each one with advantages and disadvantages. For example, the forward Euler integration scheme is only accurate for small strain increments. Initially, this scheme was proposed in order to update stresses and hardening parameters; however, a consistent accuracy was not always achieved mainly due to strain increment size. It was concluded that strain increment could be subdivided in order to improve the scheme accuracy. Thus, the forward Euler integration scheme with subincrementations was presented. Besides, a correction for the yield surface drift can be performed to make it even more accurate.

Following the implementation criteria described in subsection 4.2.1, the forward Euler integration scheme with subincrementation is used after determining the initial intersection with the yield surface if needed. Thus, the updated stress is obtained by the following expression:

$$
\Delta \sigma=C^{e p}\left(\sigma_{0}, W_{p, 0}\right) \Delta \varepsilon
$$


As already stated, this explicit integration scheme improves its accuracy significantly when the strain increments are subdivided. Thus,

$$
\delta \varepsilon=\Delta T \Delta \varepsilon=\frac{\Delta \varepsilon}{m}
$$

where, $\Delta T$ is a dimensionless timestep of fixed size and $m$ is the number of divisions the strain increment will be subjected to. Each strain subincrement is treated as forward Euler step in order to determine the updated stress and hardening parameter for each strain subincrement, as shown in the following expression:

$$
\begin{gathered}
\delta \sigma_{i}=C^{e p}\left(\sigma_{0}+\Delta \sigma_{i-1}, W_{p, 0}+\Delta W_{p, i-1}\right) \delta \varepsilon \\
\delta W_{p, i}=\delta \lambda_{p}\left(\sigma_{0}+\Delta \sigma_{i-1}, W_{p, 0}+\Delta W_{p, i-1}, \delta \varepsilon\right)\left(\sigma_{0}+\Delta \sigma_{i-1}\right) \frac{\partial g}{\partial\left(\sigma_{0}+\Delta \sigma_{i-1}\right)}
\end{gathered}
$$

where,

$$
\begin{aligned}
\Delta \sigma_{i-1} & =\sum_{j=1}^{i-1} \delta \sigma_{j} \\
\Delta W_{p, i-1} & =\sum_{j=1}^{i-1} \delta W_{p, j}
\end{aligned}
$$

This procedure can be summarized in an implementation algorithm, as shown below.

The hardening parameter, initial stress state, strain increment and subincrement conform the input data required to determine the elastoplastic stiffness matrix as described in subsection 1 . The output data is conformed by the updated stress, hardening parameter and the elastoplastic stiffness matrix.

$$
\begin{gathered}
\text { Input: } \sigma_{0}, W_{p, 0}, \Delta \varepsilon, \delta \varepsilon=\Delta \varepsilon / m \\
\text { Strain } \quad \text { subincrements } i=1,2, \ldots, m \\
\delta \sigma_{i}=C^{e p}\left(\sigma_{i-1}, W_{p, i-1}\right) \delta \varepsilon \\
\delta W_{p, i}=\delta \lambda_{p}\left(\sigma_{i-1}, W_{p, i-1}, \delta \varepsilon\right) \sigma_{i-1} \frac{\partial g}{\partial \sigma_{i-1}} \\
\sigma_{i}=\sigma_{i-1}+\delta \sigma_{i}
\end{gathered}
$$




$$
\begin{gathered}
W_{p, i}=W_{p, i-1}+\delta W_{p, i} \\
\text { Stop subincrementation } \quad \text { when } \quad i=m \\
\text { Output: } \sigma_{i}, W_{p, i}, C^{e p}\left(\sigma_{i}, W_{p, i}\right)
\end{gathered}
$$

The forward Euler integration scheme has the advantage of being easier to implement than other integration schemes; however, it may be computational expensive to use subincrements of fixed size and the consistency condition may not be fulfilled after each step. For this reason, a correction is needed in order to ensure that the updated stress is located on the yield surface, known as correction for the yield surface drift and it can be expressed graphically in figure 4.4.
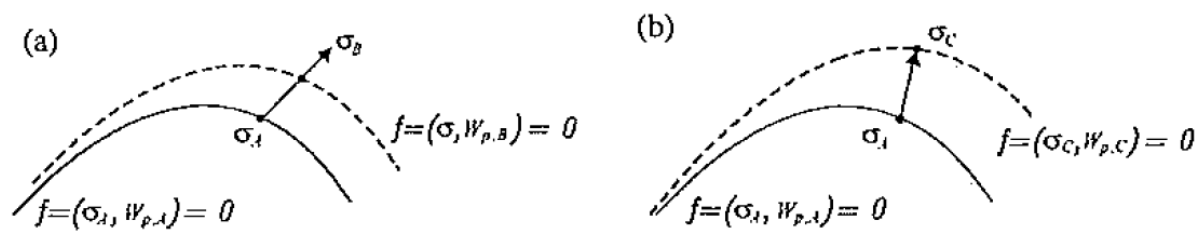

Figure 4.4: Updated stress and hardening parameter when the consistency condition is (a) not fulfilled and (b)is fulfilled (Jakobsen and Lade, 2002)

The correction procedure, proposed by Potts and Gens (1985), consists of maintaining the total strain increment constant, meaning that elastic and plastic strains will be modified with equal but opposite changes. Thus, this condition can be expressed as:

$$
d \varepsilon^{p}=-d \varepsilon^{e}=-C^{e^{-1}}\left(\sigma_{C}-\sigma_{B}\right)
$$

where the plastic strain increment can be expressed in function of the gradient of the plastic potential as follows:

$$
d \varepsilon^{p}=\beta \frac{\partial g}{\partial \sigma}
$$

Then, by substituting equation 4-35 into equation 4-34, the following expression is obtained:

$$
\sigma_{C}=\sigma_{B}-\beta C^{e} \frac{\partial g}{\partial \sigma_{B}}
$$

where $\sigma_{C}$ is the updated stress after the correction for the yield surface drift. The hardening parameter will be subjected to change as well since it depends on the stress state. Thus, 


$$
W_{p, C}=W_{p, B}+\Delta W_{p}
$$

where the hardening parameter variation determined by:

$$
\Delta W_{p}=\beta\left(\frac{\partial g}{\partial \sigma_{B}}\right)^{T} \sigma_{B}
$$

Considering the corrected stress state and hardening parameter, the consistency condition must be fulfilled. This can be mathematically expressed as:

$$
f\left(\sigma_{c}, W_{p, c}\right)=f\left(\sigma_{B}-\beta C^{e} \frac{\partial g}{\partial \sigma_{B}}, W_{p, \beta}+\beta\left(\frac{\partial g}{\partial \sigma_{B}}\right)^{T} \sigma_{B}\right)=0
$$

where the scalar $\beta$ can be obtained by using a Taylor series expansion:

$$
\beta=\frac{f\left(\sigma_{B}, W_{p, B}\right)}{\left(\frac{\partial f}{\partial \sigma_{B}}\right)^{T} C^{e}\left(\frac{\partial g}{\partial \sigma_{B}}\right)-\left(\frac{\partial f}{\partial W_{p, B}}\right)\left(\frac{\partial g}{\partial \sigma_{B}}\right)^{T} \sigma_{B}}
$$

The described procedure for the correction for the yield surface drift allows, at the end of each forward euler step, the consistency condition to be fulfilled within a specified tolerance. Thus, the following algorithm is presented in order to be applied after the forward Euler integration scheme.

$$
\begin{gathered}
\text { Input: } \sigma_{0}, W_{p, 0} \\
\text { If } \quad\left|f\left(\sigma_{0}, W_{p, 0}\right)\right|>\epsilon \\
\text { Iterations } \quad i=1,2, \ldots, i_{\text {max }} \\
\beta_{i-1}=\frac{f\left(\sigma_{i-1}, W_{p, i-1}\right)}{\left(\frac{\partial f}{\partial \sigma_{i-1}}\right)^{T} C^{e}\left(\frac{\partial g}{\partial \sigma_{i-1}}\right)-\left(\frac{\partial f}{\partial W_{p, i-1}}\right)\left(\frac{\partial g}{\partial \sigma_{i-1}}\right)^{T} \sigma_{i-1}} \\
\sigma_{i}=\sigma_{i-1}-\beta_{i-1} C^{e} \frac{\partial g}{\partial \sigma_{i-1}} \\
\Delta W_{p, i-1}=\beta_{i-1} \sigma_{i-1} \frac{\partial g}{\partial \sigma_{i-1}} \\
\text { Stop } \quad \text { when } \quad\left|f\left(\sigma_{i}, W_{p, i}\right)\right| \leq \epsilon \\
\text { Output: } \quad \sigma_{c}=\sigma_{i}, W_{p, c}=W_{p, i}
\end{gathered}
$$




\subsubsection{Modified Forward Euler scheme with error control}

Using subdivisions notably enhances the forward Euler integration scheme; however, is computationally more expensive because the solution takes longer to converge due to the fixed sized strain increments the scheme uses. For this reason, other algorithms were developed in order to reduce the computational cost and the necessary correction for the yield surface drift.

Thus, a modified forward Euler scheme with error control was developed by Sloan (1987). The major advantage of this scheme is the variable sized strain subincrements, which considerably reduces the computational cost. Besides, due to the error control, the correction of the yield surface drift is no longer needed.

The procedure consists of estimating the updated stress state and hardening parameter considering a first and second order Euler formulas in order to estimate the error produced when using the forward Euler integration scheme after each strain subincrement. A first estimate of the updated stress and hardening parameter is made considering the following expressions:

$$
\begin{gathered}
\sigma=\sigma_{0}+\delta \sigma^{I} \\
W_{p}=W_{p, 0}+\delta W_{p}^{I}
\end{gathered}
$$

where

$$
\begin{gathered}
\delta \sigma^{I}=C^{e p}\left(\sigma_{0}, W_{p, 0}\right) \delta \varepsilon \\
\delta W_{p}^{I}=\delta \lambda_{p}\left(\sigma_{0}, W_{p, 0}, \delta \varepsilon\right) \sigma_{0} \frac{\partial g}{\partial \sigma_{0}}
\end{gathered}
$$

The first estimate can be enhanced by using the following expressions,

$$
\begin{gathered}
\hat{\sigma}=\sigma_{0}+\frac{1}{2}\left(\delta \sigma^{I}+\delta \sigma^{I I}\right) \\
\widehat{W}_{p}=W_{p, 0}+\frac{1}{2}\left(\delta W_{p}^{I}+\delta W_{p}^{I I}\right)
\end{gathered}
$$

where

$$
\begin{gathered}
\delta \sigma^{I I}=C^{e p}\left(\sigma_{0}+\delta \sigma^{I}, W_{p, 0}+\delta W_{p, 0}^{I}\right) \delta \varepsilon \\
\delta W_{p}^{I I}=\delta \lambda_{p}\left(\sigma_{0}+\delta \sigma^{I}, W_{p, 0}+\delta W_{p, 0}^{I}, \delta \varepsilon\right)\left(\sigma_{0}+\delta \sigma^{I}\right) \frac{\partial g}{\partial\left(\sigma_{0}+\delta \sigma^{I}\right)}
\end{gathered}
$$

The modified Euler integration scheme with error control seeks to estimate the size of the next strain increment on the basis of the local error, which can be 
estimated by:

$$
\delta \sigma^{I-I I} \approx \hat{\sigma}-\sigma=\frac{1}{2}\left(\delta \sigma^{I I}-\delta \sigma^{I}\right)
$$

This expression allows to determine the size of the next timestep. Besides, it avoids specifying the number of subincrements, making the modified forward Euler scheme less computational expensive than the forward Euler scheme, since the number of subincrements needed is calculated.

The local error during the integration along the strain increment serves as the stopping criteria for the algorithm and is defined as:

$$
\xi=\frac{\left\|\delta \sigma^{I-I I}\right\|}{\|\hat{\sigma}\|}
$$

The algorithm stops when the local error becomes less than a specified value, considering $\hat{\sigma}$ as the updated stress and $\widehat{W}_{p}$ as the hardening parameter when the stopping criteria is reached.

Considering the case where this criteria has not been reached yet, the timestep is reduced by multiplying it by a parameter $q$ as follows:

$$
\Delta T=q \Delta T
$$

where $q$ has a value inside the limits 0.01 and 2 in order to control the size of the next strain increment. The value of $q$ is defined as:

$$
q=0.9\left(\frac{\epsilon}{\xi}\right)^{1 / 2}
$$

Considering the definitions described above and the procedure to calculated the updated stress and hardening parameter for each strain increment, an algorithm is presented in order to computationally facilitate the integration of stress along a strain increment:

$$
\begin{gathered}
\text { Input: } \sigma_{0}, W_{p, 0}, \Delta \varepsilon, \delta \varepsilon_{0}=\Delta \varepsilon, q=1 \\
\text { Strain increment } \quad i=1,2, \ldots, n \\
\delta \varepsilon_{i}=\min \left[q \delta \varepsilon_{i-1}, 1-\sum_{j=1}^{i-1} \delta \varepsilon_{j}\right] \\
d o \\
\delta \sigma_{i}^{I}=C^{e p}\left(\sigma_{i-1}, W_{p, i-1}\right) \delta \varepsilon_{i}
\end{gathered}
$$




$$
\begin{gathered}
\delta W_{p, i}^{I}=\delta \lambda_{p}\left(\sigma_{i-1}, W_{p, i-1}, \delta \varepsilon_{i}\right) \sigma_{i-1} \frac{\partial g}{\partial \sigma} \\
\delta \sigma_{i}^{I I}=C^{e p}\left(\sigma_{i-1}+\delta \sigma_{i}^{I}, W_{p, i-1}+\delta W_{p, i}^{I}\right) \delta \varepsilon_{i} \\
\delta W_{p, i}^{I I}=\delta \lambda_{p}\left(\sigma_{i-1}+\delta \sigma_{i}^{I}, W_{p, i-1}+\delta W_{p, i}^{I}, \delta \varepsilon_{i}\right)\left(\sigma_{i-1}+\delta \sigma_{i}^{I}\right) \frac{\partial g}{\partial \sigma} \\
\delta \sigma_{i}^{I-I I}=\frac{1}{2}\left(\delta \sigma_{i}^{I I}-\delta \sigma_{i}^{I}\right) \\
\hat{\sigma}_{i}=\sigma_{i-1}+\frac{1}{2}\left(\delta \sigma_{i}^{I}+\delta \sigma_{i}^{I I}\right) \\
\widehat{W}_{p, i}=W_{p, i-1}+\frac{1}{2}\left(\delta W_{p, i}^{I}+\delta W_{p, i}^{I I}\right) \\
\xi_{i}=\frac{\left\|\delta \sigma_{i}^{I-I I}\right\|}{\left\|\hat{\sigma}_{i}\right\|}
\end{gathered}
$$

$$
\text { If } \xi_{i}>\epsilon \quad \text { then } \quad q=\max \left[0.9\left(\frac{\epsilon}{\xi}\right)^{\frac{1}{2}}, 0.01\right] ; \delta \varepsilon_{i}=q \delta \varepsilon_{i}
$$

$$
\text { Until } \quad \xi_{i} \leq \epsilon
$$

$$
q=\min \left[0.9\left(\frac{\epsilon}{\xi}\right)^{\frac{1}{2}}, 2\right]
$$

Stop strain incrementation $\sum_{i=1}^{n} \delta \varepsilon_{i}=\Delta \varepsilon$

$$
\text { Output: } \quad \hat{\sigma}_{i}, \widehat{W}_{p, i}, C^{e p}\left(\hat{\sigma}_{i}, \widehat{W}_{p, i}\right)
$$

The modified forward Euler integration scheme with error control is an enhanced version of the forward Euler scheme since it reduces the disadvantages presented by the traditional one, improving the validity of the numerical solution. Considering this aspect, the fact that FLAC3D uses already small strain increments and the recommendations made by Lade and Jakobsen (2002), the modified forward Euler scheme is used to implement the Lade-Kim model. 


\section{Constitutive model validation}

In this chapter the validation of the implementation procedure is carried out. Thus, in order to perform it, the determination of the Lade and Kim constitutive model parameters is explained in first place. Later, three different validation cases are studied. These involve numerical simulation of conventional triaxial tests on Sacramento river sand and two-dimensional stress-deformation analyses of earth dams during construction.

\subsection{Parameter determination}

In previous chapters, the formulation of the Lade and Kim constitutive model was presented by identifying the model parameters and the governing functions. These parameters can be determined from results of laboratory tests, such as triaxial and isotropic compression tests.

\subsubsection{Elastic parameters}

The elastic behavior can be modeled using either the formulation used by Lade and Jakobsen (2002), which involves parameters $\lambda$ and $M$, or the one used by Lade and Kim (1988), which involves parameters $K_{u r}$ and $n$. Regardless the case, experimental results such as stress-deformation curves are needed.

For the first case, dimensionless parameters $M$ and $\lambda$ can be calibrated considering the following expression:

$$
\log \left(E / p_{a}\right)=\log (M)+\lambda \log \left[\left(\frac{J^{\prime} 1 \sigma}{p_{a}}\right)^{2}+6\left(\frac{1+v}{1-2 v}\right) \frac{J^{\prime \prime 2}{ }_{D}}{p_{a}^{2}}\right]
$$

where $E$ is Young's modulus and can be obtained from stress-deformation curves, $p_{a}$ is the atmospheric pressure, $J^{\prime}{ }_{1 \sigma}$ is the first invariant of the stress tensor, $J_{2 D}$ is the second invariant of the deviatoric stress tensor, $v$ is the Poisson's ratio and $\lambda$ and $M$ are dimensionless parameters. This expression is plotted in figure 5.1 in a logarithmic scale, where $\lambda$ is the slope of the straight line and $M$ is the interception.

Poisson's ratio can be determined considering a volumetric strain $\varepsilon_{v}$ vs axial strain $\varepsilon_{1}$ plane. Thus, regarding the initial slope of the curve, the following expression can be used in order to calculate the Poisson's ratio.

$$
v=-\frac{\Delta \varepsilon_{3}}{\Delta \varepsilon_{1}}=\frac{1}{2}\left(1-\frac{\Delta \varepsilon_{v}}{\Delta \varepsilon_{1}}\right)
$$

For the second case, calibration of corresponding parameters can be realized 
based on the formulation of Duncan and Chang (1970) in a similar way as the first case. Thus, based on a linear regression, the following expression allows to determine the required parameters:

$$
\log \left(E_{u r} / p_{a}\right)=\log K_{u r}+n \log \left(\sigma_{3} / p_{a}\right)
$$

where $E_{u r}$ is the unloading-reloading elastic modulus and can be obtained from stress-deformation curves where unloading-reloading conditions are simulated, $\sigma_{3}$ is the confining pressure, $p_{a}$ is the atmospheric pressure and $K_{u r}$ and $n$ are dimensional parameters.

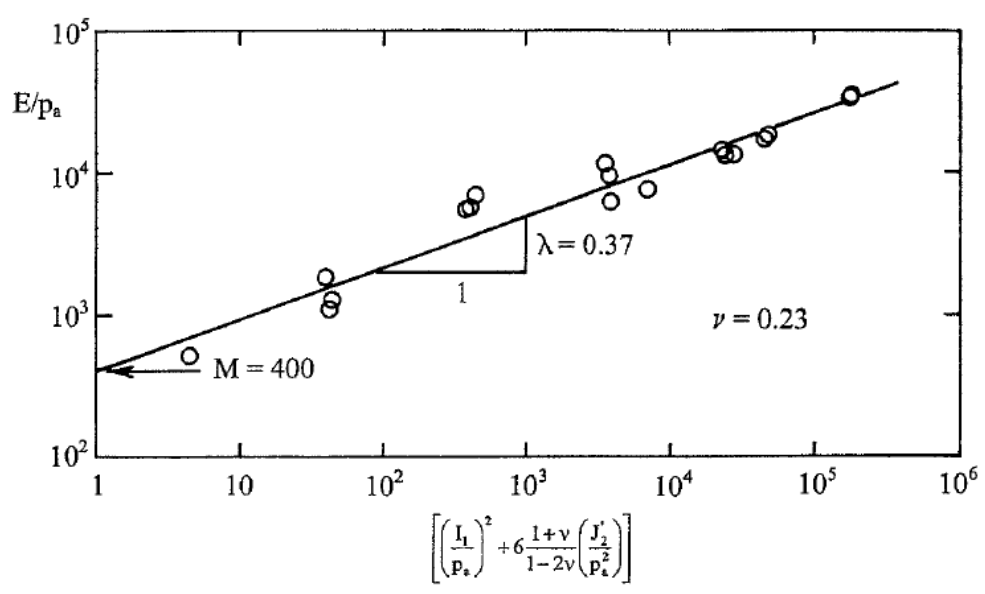

Figure 5.1: Calibration of parameters $\lambda$ and $M$ (Lade, 2005)

\subsubsection{Failure criterion}

Lade (2005) expressed the failure criterion function in order to estimate parameters $\eta_{1}$ and $m$ according to figure 5.2. Thus, the expression

$$
\log \left(\frac{I_{1}^{3}}{I_{3}}-27\right)=\log \eta_{1}+m \log \left(\frac{p_{a}}{I_{1}}\right)
$$

where $I_{1}$ and $I_{3}$ are the first and third invariants of the stress tensor allows to estimate the corresponding parameters by calculating the slope of the straight line and the value of $\left(I_{1}^{3} / I_{3}-27\right)$ that corresponds to $p_{a} / I_{1}=1$. 


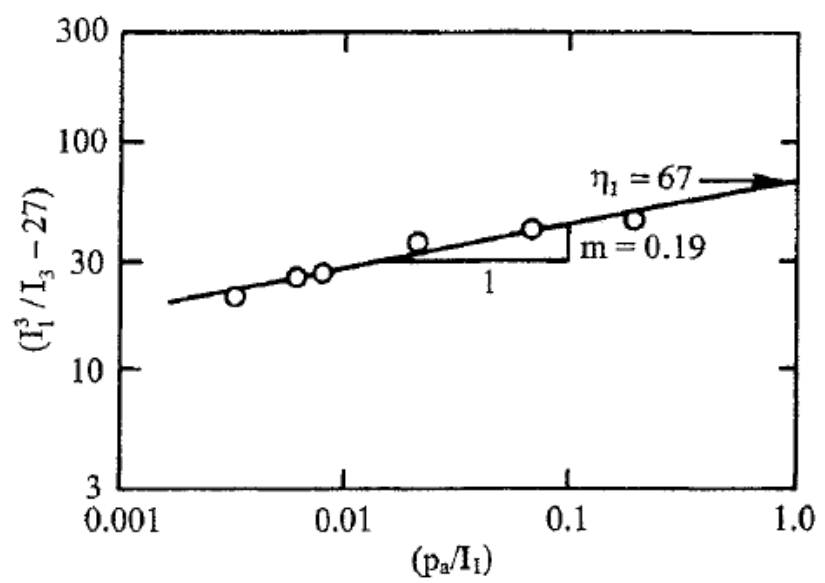

Figure 5.2: Calibration of parameters $\eta_{1}$ and $m$ (Lade, 2005)

\subsubsection{Plastic potential}

The plastic potential parameters are calibrated by plotting the results of a triaxial compression test into a $\xi_{y}$ vs $\xi_{x}$ plane and fitting a straight line. Its slope corresponds to the value of $1 / \mu$ while the interception with the vertical axis corresponds to $-\psi_{2}$, as shown in figure 5.3. Thus, the equation of the line is:

$$
\xi_{y}=\frac{1}{\mu} \xi_{x}-\psi_{2}
$$

where

$$
\xi_{x}=\frac{1}{1+v_{p}}\left[\frac{I_{1}^{3}}{I_{2}^{2}}\left(\sigma_{1}+\sigma_{3}+2 v_{p} \sigma_{3}\right)+\psi_{1} \frac{I_{1}^{4}}{I_{3}^{2}}\left(\sigma_{1} \sigma_{3}+v_{p} \sigma_{3}^{2}\right)\right]-3 \psi_{1} \frac{I_{1}^{3}}{I_{3}}+2 \frac{I_{1}^{2}}{I_{2}}
$$

and

$$
\xi_{y}=\psi_{1} \frac{I_{1}^{3}}{I_{3}}-\frac{I_{1}^{2}}{I_{2}}
$$

Parameter $\psi_{1}$ is calculated in previous chapters and $v_{p}$ is defined as:

$$
v_{p}=-\frac{d \varepsilon_{3}^{p}}{d \varepsilon_{1}^{p}}
$$

where $d \varepsilon_{3}^{p}$ and $d \varepsilon_{1}^{p}$ are the plastic strain increments obtained during a triaxial compression test. These can be calculated considering that the elastic strain increments plus the plastic strain increments is equal to the measured strain increments during the test. 


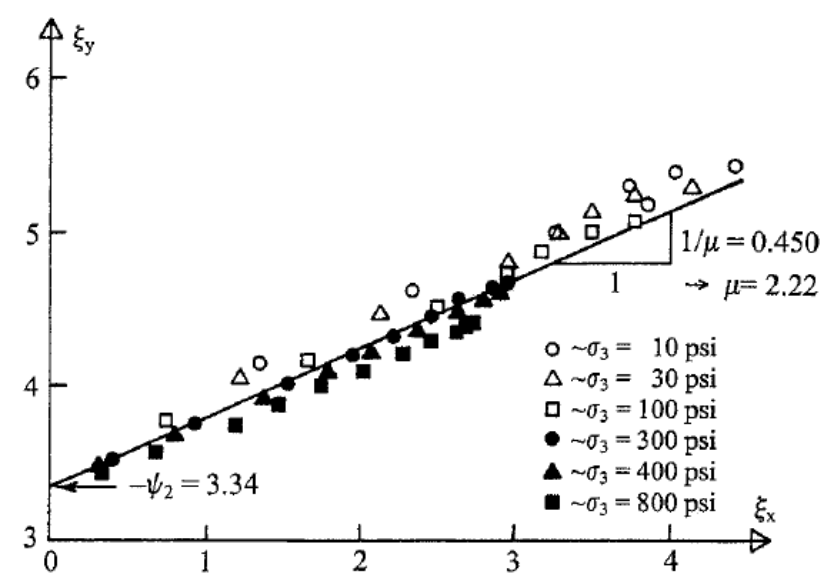

Figure 5.3: Calibration of parameters $\mu$ and $\psi_{2}$ (Lade, 2005)

\subsubsection{Hardening/Softening law}

Parameters required for the hardening/softening law are calibrated considering the results from a isotropic compression test. These results are plotted into a $W_{p} / p_{a}$ vs $I_{1} / p_{a}$ plane in logarithmic scale as shown in figure 5.4.

The plastic work along the hydrostatic axis $W_{p}$ is generally defined as:

$$
W_{p}=\int\left\{\sigma_{i j}\right\}^{T}\left\{d \varepsilon_{i j}^{p}\right\}
$$

However, this expression can be reduced for an isotropic compression test to:

$$
W_{p}=\int \sigma_{3} d \varepsilon_{v}^{p}
$$

where $\sigma_{3}$ is the confining pressure and $d \varepsilon_{v}^{p}$ is the plastic volumetric strain increment, which can be obtained by subtracting the elastic part form the measured strain increments.

Thus, parameter $C$ is calibrated by fitting a straight line and calculating the interception with the vertical, whereas parameter $p$ is obtained by calculating the slope of the line. 


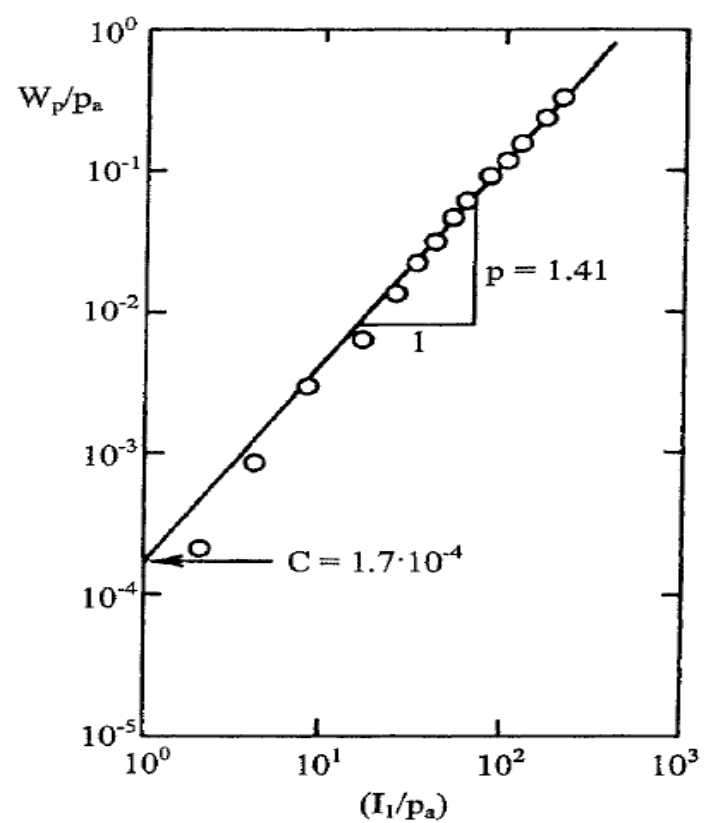

Figure 5.4: Calibration of parameters $C$ and $p$ (Lade, 2005)

\subsubsection{Yield criterion}

Hardening/softening law parameters are needed in order to calculate parameters $h$ and $\alpha$. Lade and Kim (1988b) determined the value of $h$ considering that the plastic work remains constant in a yield surface. Then, considering that stress points $A$ and $B$ are located in the same plastic work contour, these points belong to the same yield surface.

Thus, the following expression can be derived:

$$
\left(\psi_{1} \frac{I_{1 A}^{3}}{I_{3 A}}-\frac{I_{1 A}^{2}}{I_{2 A}}\right)\left(\frac{I_{1 A}}{p_{a}}\right) e^{q_{A}}=\left(\psi_{1} \frac{I_{1 B}^{3}}{I_{3 B}}-\frac{I_{1 B}^{2}}{I_{2 B}}\right)\left(\frac{I_{1 B}}{p_{a}}\right) e^{q_{B}}
$$

where $\psi_{1}$ is known, $e$ is the base of natural logarithms, $q$ is a stress dependent variable and $I_{1}$ and $I_{3}$ are the first and third invariant of the stress tensor of the respective stress point.

Considering that stress point $A$ is on the hydrostatic axis and stress point $B$ is on the failure surface, is concluded that $q_{A}=0$ whereas $q_{B}=1$. Thus, the expression above can be rearranged in order to estimate parameter $h$ :

$$
h=\frac{\frac{\ln \left(\psi_{1} \frac{I_{1 B}^{3}}{I_{3 B}}-\frac{I_{1 B}}{I_{2 B}}\right) e}{27 \psi_{1}+3}}{\ln \frac{I_{1 A}}{I_{1 B}}}
$$


Lade (2005) rearranged the yield criterion function expressed in previous chapters in order to define variable $q$.

Thus, the following expression is presented:

$$
q=\ln \frac{\left(\frac{W_{p}}{D \cdot p_{a}}\right)^{\frac{1}{\rho}}}{\left(\psi_{1} \frac{I_{1}^{3}}{I_{3}}-\frac{I_{1}^{2}}{I_{2}}\right)\left(\frac{I_{1}}{p_{a}}\right)^{h}}
$$

Finally, parameter $\alpha$ is estimated considering the following expression, where $S$ is the stress level:

$$
q=\frac{\alpha S}{1-(1-\alpha) S}
$$

and the curve that best fits the laboratory data as shown in figure 5.5.

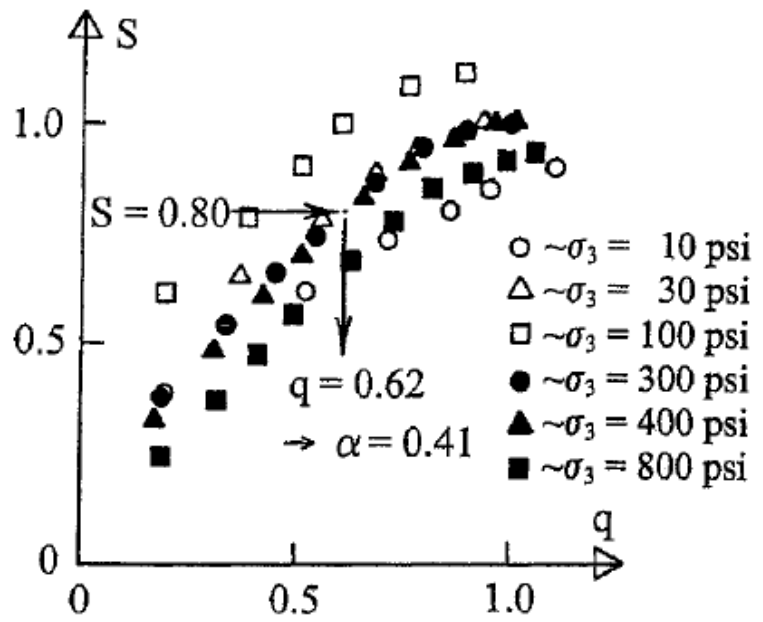

Figure 5.5: Calibration of parameter $\alpha$ (Lade, 2005)

\subsection{Numerical simulation of trixial compression test}

Numerical simulations of triaxial compression tests are performed in order to validate the implemented constitutive model. The simulations are carried out using a single zone considering unit dimensions as shown in figure 5.6, where the boundary conditions consisted of a constant lateral confining pressure in $\mathrm{x}$ - and $\mathrm{y}$ directions, an initial stress in all directions equal to the confining pressure and a velocity boundary condition in z-direction. 


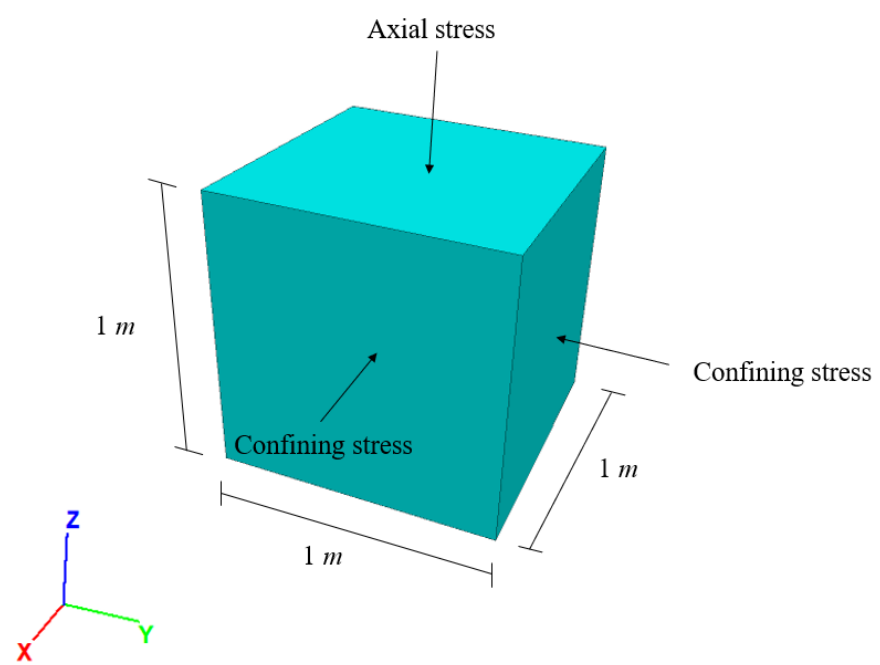

Figure 5.6: Simulation of a compression test

For a first validation case, typical parameters for loose Sacramento river sand provided by Lade (2005) are taken into consideration with the objective of comparing the numerical triaxial compression test results with experimental results found in the literature. Thus, the parameters adopted for the validation are shown in Table 5.1.

The numerical results regarding the deviatoric stress and axial deformation relation are shown in figure 5.7, where it is observed that the implemented constitutive model provides results that show strong agreement with the experimental ones. Besides, acceptable results regarding the volumetric strain and axial deformation relation are shown in figure 5.8.

Table 5.1: Typical parameters for loose Sacramento river sand (Lade, 2005)

\begin{tabular}{|c|c|c|c|c|}
\hline Model component & Parameter names & \multicolumn{3}{|c|}{ Parameter values } \\
\hline Elastic properties & $M, \lambda, v$ & 510 & 0.28 & 0.20 \\
\hline Failure criterion & $m, \eta_{1}, a$ & 0.093 & 28 & 0 \\
\hline Plastic potential & $\psi_{2}, \mu$ & -3.72 & 2.36 & - \\
\hline Yield criterion & $h, \alpha$ & 0.534 & 0.794 & - \\
\hline Hardening/Softening law & $C, p, b$ & 0.000127 & 1.65 & - \\
\hline
\end{tabular}




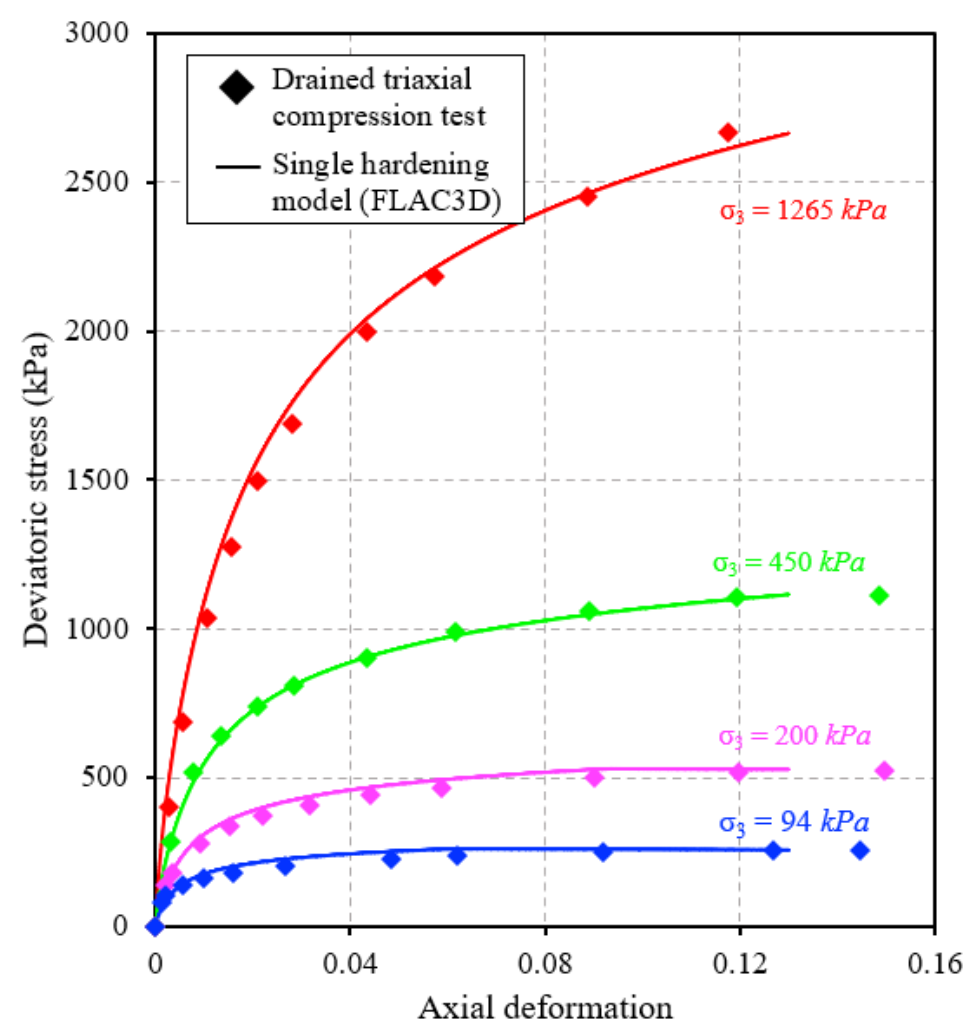

Figure 5.7: Deviatoric stress vs axial deformation curves - Loose Sacramento river sand

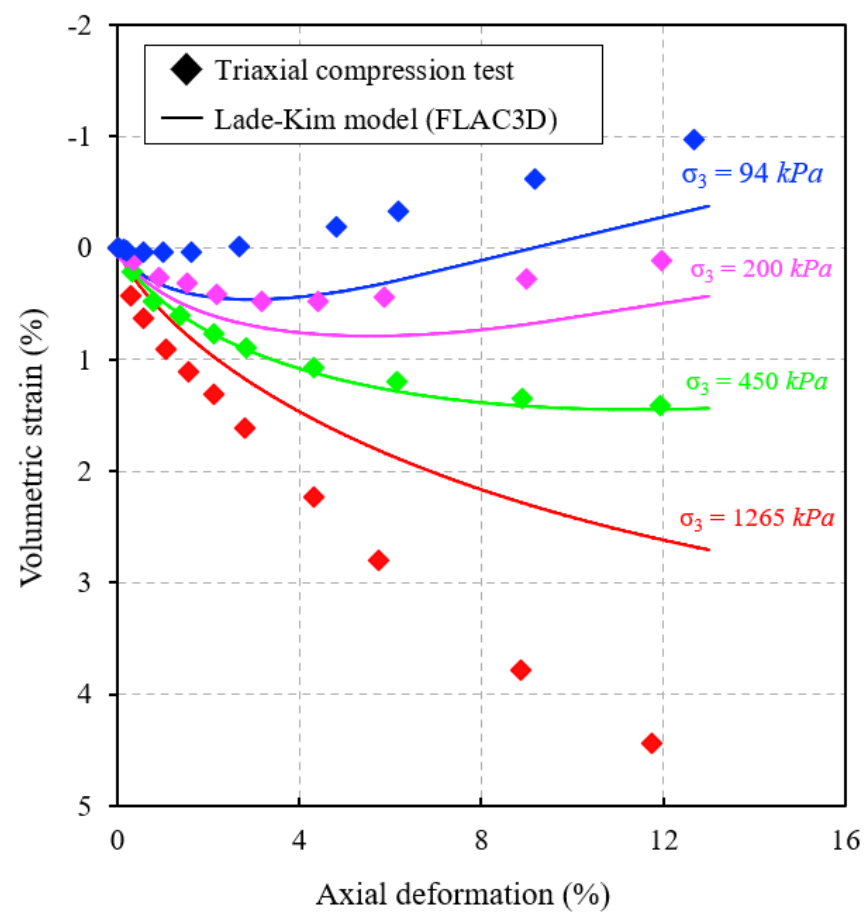

Figure 5.8: Volumetric strain vs axial deformation curves - Loose Sacramento river sand 
Kovacevic (1994) obtained Lade-Kim constitutive model parameters from experimental results shown in Table 5.2 and performed numerical simulations of triaxial compression tests for different confining stresses considering the rockfill material. A second validation case involves reproducing the same conditions Kovacevic (1994) adopted in order to simulate the triaxial compression tests. The corresponding results are shown in figure 5.9 and 5.10, allowing to conclude that strong agreement is obtained between experimental and numerical results.

Table 5.2: Lade and Kim constitutive model parameters for rockfill and sandwaste (Kovacevic, 1994)

\begin{tabular}{|c|c|c|}
\hline Parameter & Rockfill & Sandwaste \\
\hline$K_{u r}$ & 300 & 1200 \\
\hline$n$ & 0.50 & 0.45 \\
\hline$v$ & 0.20 & 0.20 \\
\hline$\eta_{1}$ & 260.0 & 45.0 \\
\hline$m$ & 0.65 & 0.10 \\
\hline$\psi_{2}$ & -3.00 & -3.40 \\
\hline$\mu$ & 2.70 & 2.15 \\
\hline$c$ & 0.000105 & 0.000090 \\
\hline$p$ & 1.80 & 1.65 \\
\hline$h$ & 0.875 & 0.650 \\
\hline$\alpha$ & 0.175 & 0.450 \\
\hline$b$ & 1.0 & 1.0 \\
\hline
\end{tabular}




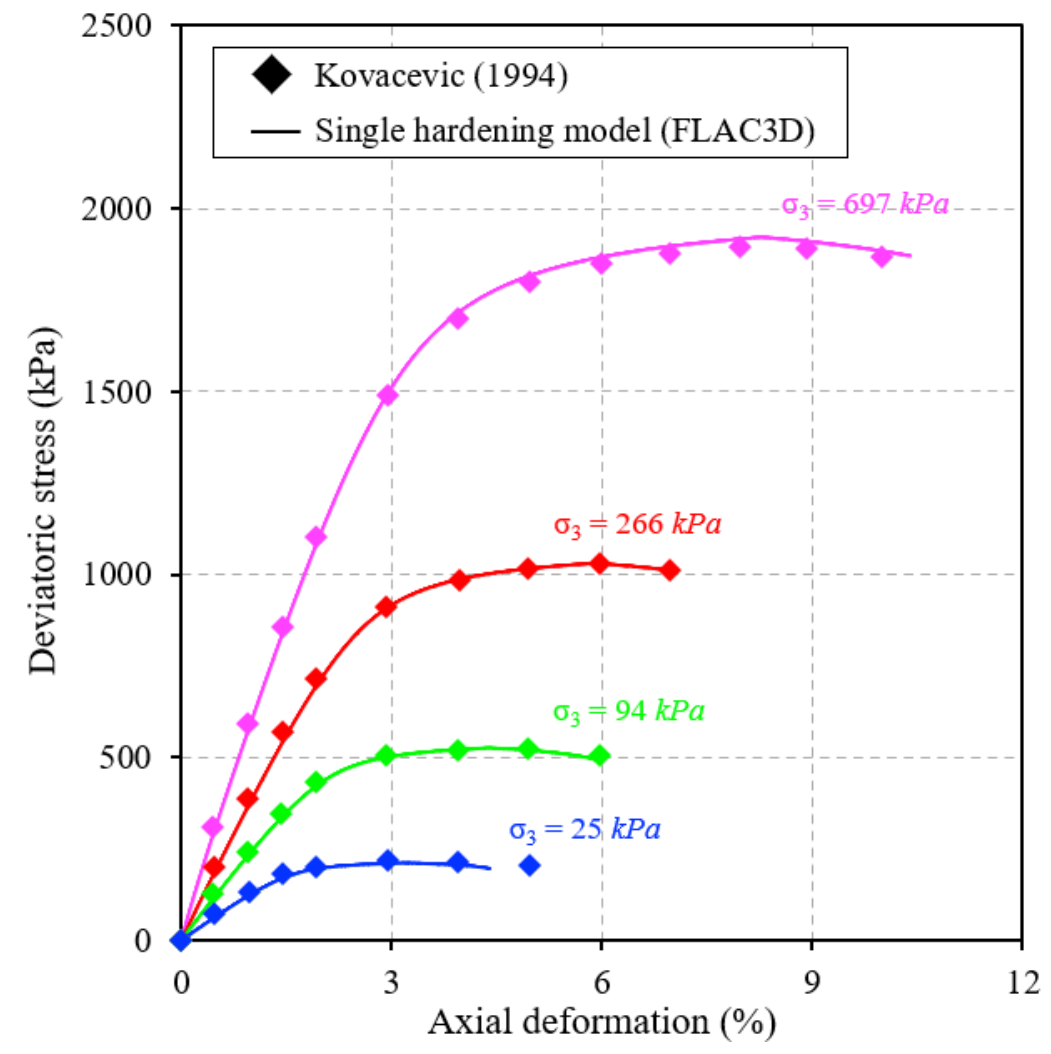

Figure 5.9: Deviatoric stress vs axial deformation - Roadford rockfill

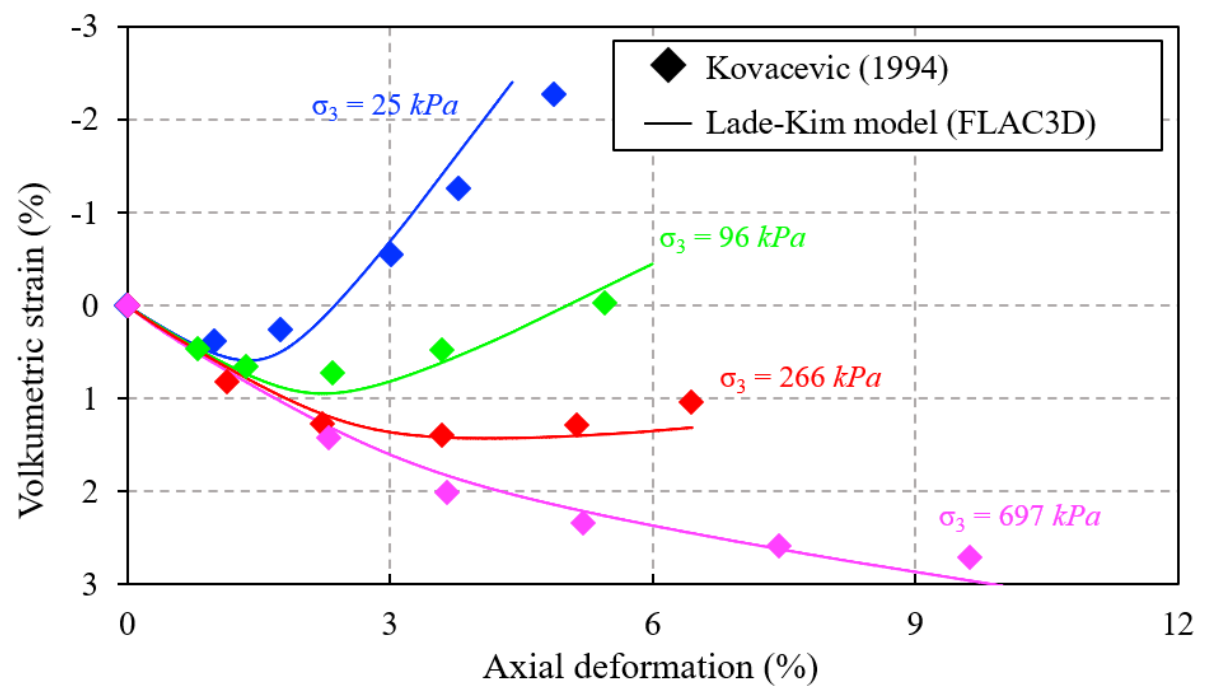

Figure 5.10: Volumetric strain vs axial deformation - Roadford rockfill 


\section{Three-dimensional stress-deformation analysis of an earth dam}

In previous chapters, the Lade and Kim constitutive model was fully described by presenting the failure criterion, yield function, plastic potential function, hardening/softening law and equations regarding the elastic part. Moreover, the incremental form of the model as well as the implementation procedure was also stated. After that, the constitutive model applicability was tested with a validation procedure that involved the numerical simulation of triaxial compression tests, which allowed to conclude that elastoplastic behavior could be successfully modeled.

Two-dimensional deformation analyses are commonly performed when displacement prediction is needed in geotechnical problems. During this type of analyses, assumptions are made for simplicity. For example, assuming that the embankment has a constant cross-section, which usually corresponds to the tallest one in order to obtain conservative results. Nevertheless, this assumption is not always suitable for cases were embankments are situated on a $\mathrm{V}$-shaped valley. For these cases, a three-dimensional analysis is needed since stresses and displacements may vary significantly along the dam.

In this chapter, three cases of study are presented. The first one corresponds to the Beliche dam, where a two-dimensional deformation analysis is involved. The second one corresponds to a two-dimensional analysis of the construction of the Roadford dam. In these cases, previous numerical simulations are available in the literature allowing to compare the numerical results obtained when using the LadeKim model. A third case corresponds to a three-dimensional deformation analysis during construction of the Llancopi dam. The analysis has the objective of predicting stresses and deformations due to gravity loading considering the LadeKim constitutive model.

Furthermore, two-dimensional analyses are performed considering the tallest and shortest cross-section, to study the influence of the assumptions made during a twodimensional analysis. On the other hand, the same analyses are carried out using the Mohr-Coulomb constitutive model in order to compare the results with the previously obtained and analyze the impact the constitutive model has in the analyses.

\subsection{Beliche dam}

\subsubsection{Introduction}

In 1982, the construction of the Beliche dam started and finished in 1985. The dam was constructed with the objective of being used as a water supply and irrigation reservoir. Thus, laboratory investigations were carried out by the Laboratório Nacional de Engenharia Civil in Lisbon (LNEC) in order to test the materials that would be used during the dam construction. Moreover, stress- 
deformation analyses were performed by Naylor et al. (1986) considering the K-G constitutive model and a model partly based on the hyperbolic model of Duncan and Chang (1970). On the other side, Melo and Hartl (1997) performed a similar analysis considering the Lade and Kim constitutive model after identifying the material parameters based on the experimental results provided by the LNEC, in order to predict the stress and deformation behavior of the dam.

\subsubsection{Description of the dam}

The Beliche dam is a rockfill dam with a central clay core with low plasticity. Its principal function consists of water supplying the south-east of Algarve, Portugal. The geometry of the dam is shown in figures 6.1 and 6.2, being the plan view and cross-section at the valley center respectively. Consisting of 54 $m$ of height, a $522 \mathrm{~m}$ long crest and a curved axis as shown in the plan view, the reservoir reaches a maximum volume of 48 million $\mathrm{m}^{3}$.

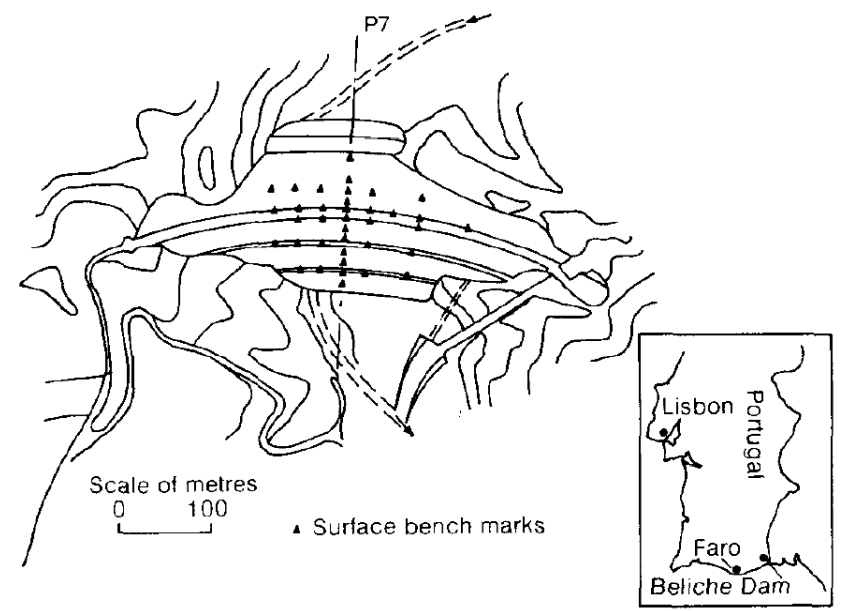

Figure 6.1: Plan view of the Beliche dam (Naylor, et al., 1986)

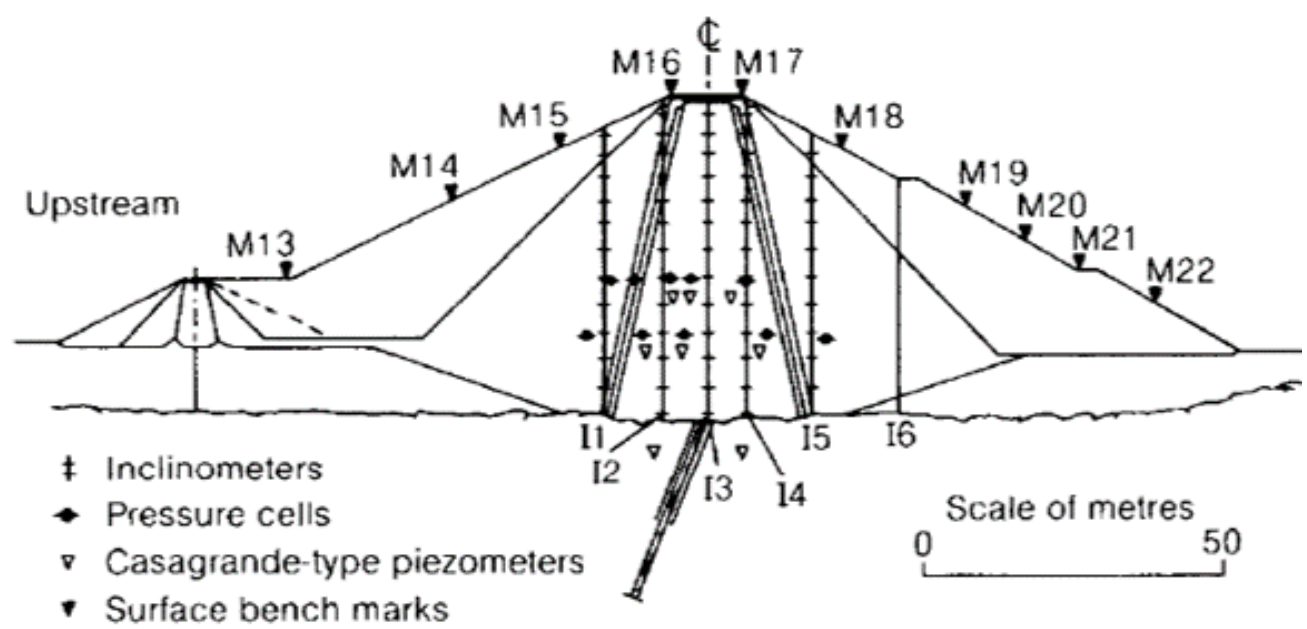

Figure 6.2: Cross-section of the Beliche dam (Naylor, et al., 1986) 
The Beliche dam is mainly conformed by two material types, which are low permeability clay and rockfill. Furthermore, two types of rockfill can be distinguished: hard rockfill, intended to be used for the outer shell composed primarily by greywackes and a fractured rockfill for the inner shell composed by schists and fines. Considering that the dam is on alluvial foundation and that a coarse filter is employed, five different material types are used for the analysis.

Geotechnical investigations were needed in order to calibrate parameters required by the constitutive models. Thus, triaxial compression tests considering a confining pressure of $300 \mathrm{kPa}$ allowed to obtain the stress-strain curves from figure 6.3, whereas isotropic compression tests allowed to obtain stress-strain curves from figure 6.4. Besides, regarding figure 6.5, Naylor et al. (1986) provided the intended gradation curves for each dam material.

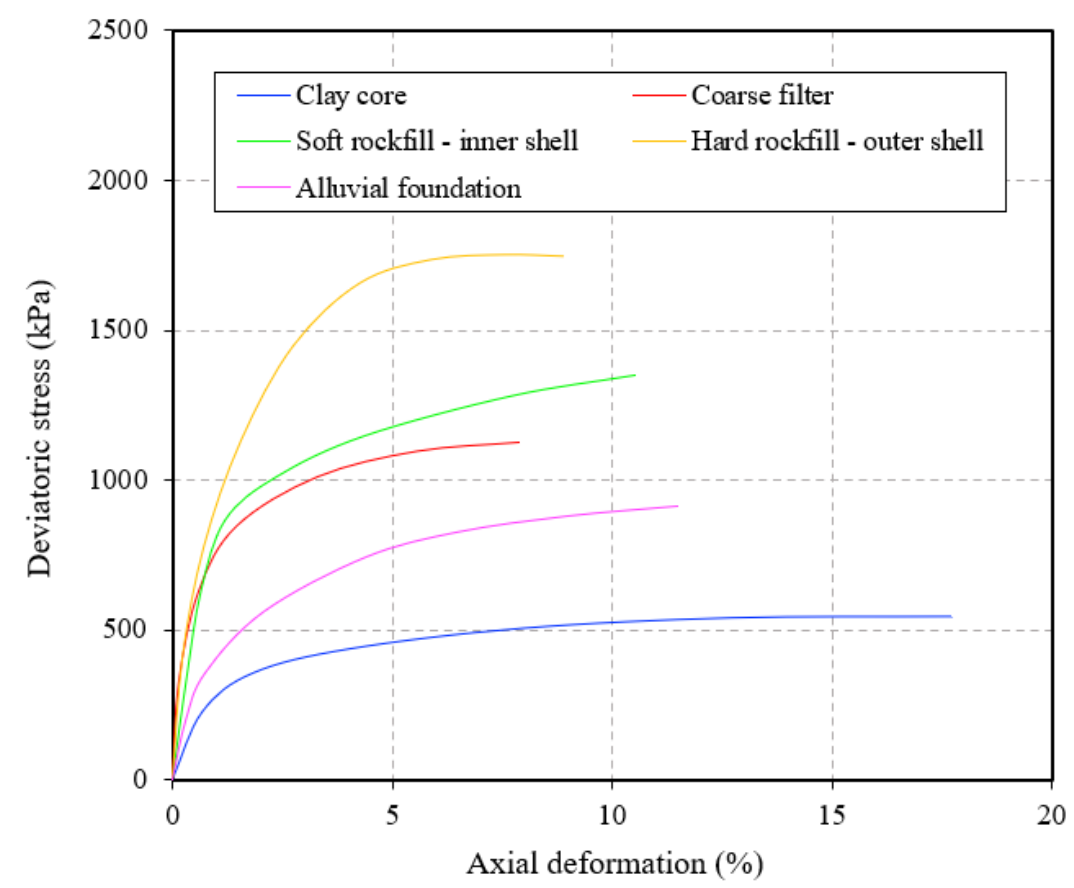

Figure 6.3: Stress-strain curves for the dam materials obtained from triaxial compression tests (Adapted from Naylor, et al., 1986) 


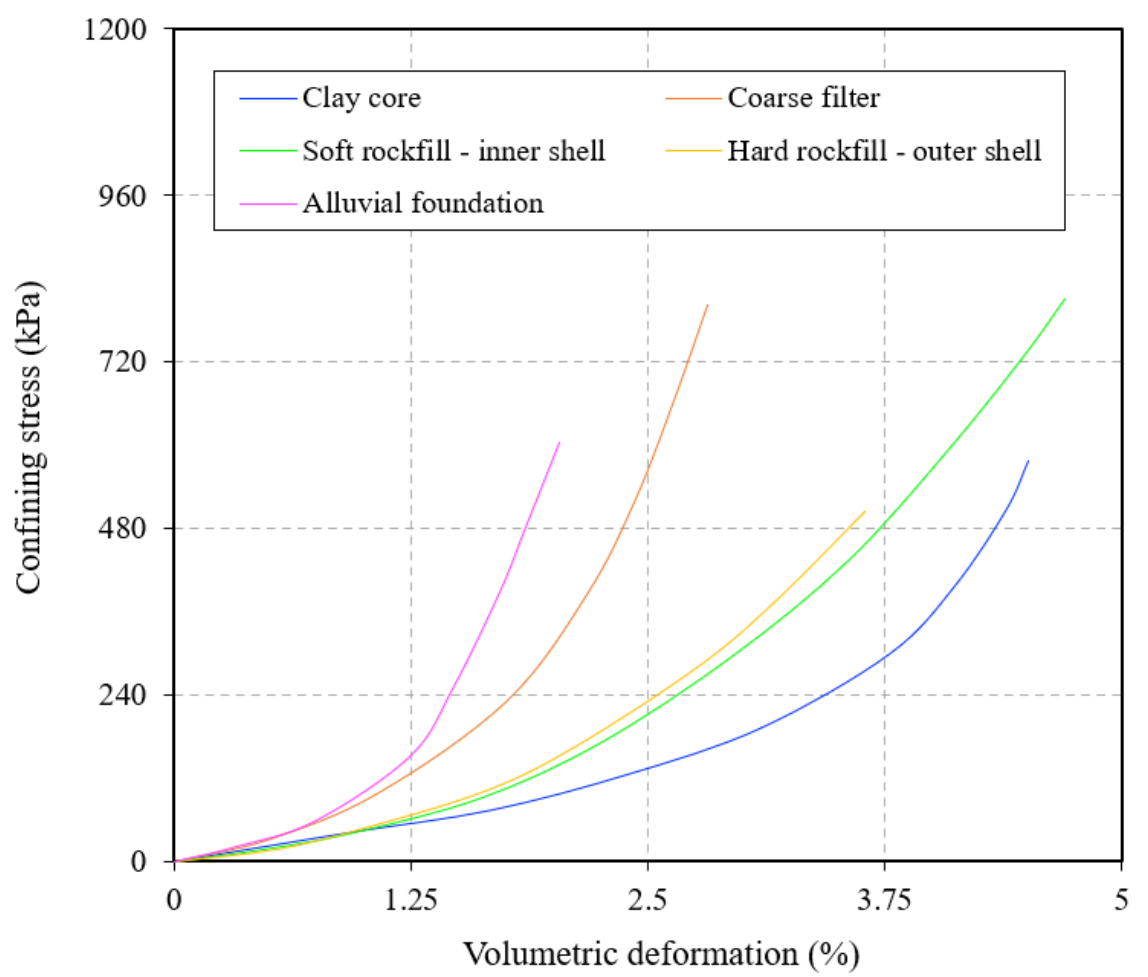

Figure 6.4: Stress-strain curves for the dam materials obtained from isotropic compression tests (Adapted from Naylor, et al., 1986)

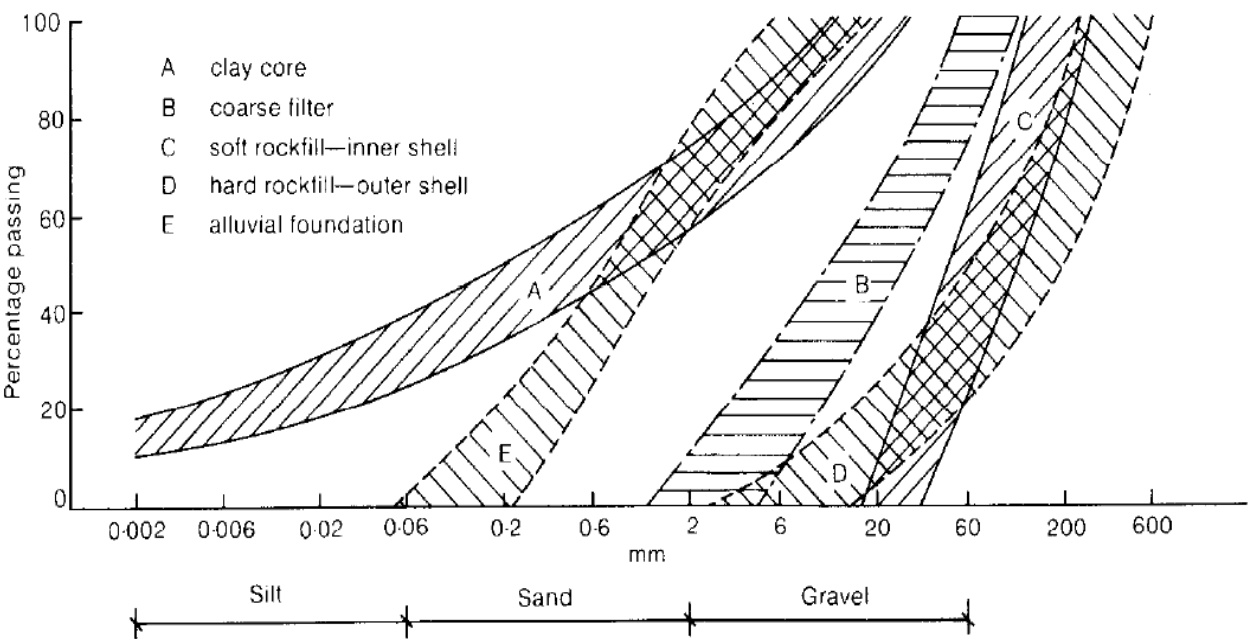

Figure 6.5: Intended gradation curves (Naylor, et al., 1986)

\subsubsection{Numerical analysis}

Melo and Hartl (1997) performed a two-dimensional stress-strain analysis of the Beliche dam in order to predict the elastoplastic behavior of the dam during its construction. The Lade and Kim constitutive model was used during the analysis 
and the required parameters were based on laboratory test results presented by Naylor et al. (1986). Thus, the parameters used for the analysis are shown in Table 6.1, whereas Table 6.2 shows the unit weights of the dam materials.

Table 6.1: Parameters used in the analysis - Beliche dam (De Melo and Hartl, 1997)

\begin{tabular}{|c|c|c|c|c|c|c|c|c|c|c|}
\cline { 2 - 10 } \multicolumn{1}{c|}{} & $K_{u r}$ & $n$ & $m$ & $\eta_{1}$ & $c$ & $p$ & $\psi_{2}$ & $\mu$ & $h$ & $\alpha$ \\
\hline Outer shell & 2000 & 0.10 & 0.81 & 1154 & 0.000092 & 1.99 & -2.75 & 3.74 & 1.12 & 0.33 \\
\hline Inner shell & 10000 & 0.10 & 0.64 & 385 & 0.000067 & 2.44 & -2.96 & 3.11 & 1.63 & 0.40 \\
\hline Filter & 10000 & 0.10 & 0.40 & 146 & 0.00245 & 1.27 & -2.91 & 2.76 & 1.58 & 0.16 \\
\hline Core & 256 & 0.64 & 0.85 & 150 & 0.00048 & 1.69 & -3.02 & 2.09 & 0.51 & 1.19 \\
\hline Foundation & 2000 & 0.10 & 0.25 & 61 & 0.00094 & 1.68 & -2.88 & 2.29 & 1.08 & 0.35 \\
\hline
\end{tabular}

Table 6.2: Unit weights used in the analysis - Beliche dam (De Melo and Hartl, 1997)

\begin{tabular}{|c|c|c|c|c|c|}
\cline { 2 - 6 } \multicolumn{1}{c|}{} & Outer shell & Inner shell & Filter & Core & Foundation \\
\hline$\gamma\left(\mathrm{kN} / \mathrm{m}^{3}\right)$ & 20.5 & 18.2 & 21.7 & 21.8 & 17.9 \\
\hline
\end{tabular}

Melo and Hartl (1997) based their research on the finite element method, using 116 eight-node quadrilateral elements, as shown in figure 6.6. Regarding boundary conditions, the bottom of the grid was fixed in $\mathrm{x}$ - and $\mathrm{y}$-directions, the foundation lateral boundaries were fixed in $\mathrm{x}$-direction and a gravity load was applied.

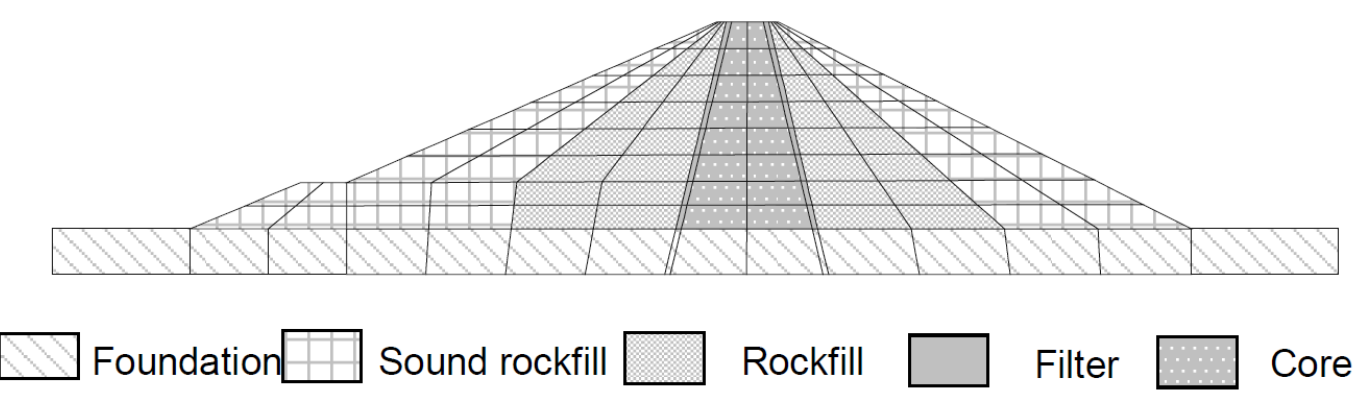

Figure 6.6: Finite element mesh - Beliche dam (De Melo and Hartl, 1997)

The procedure consists of performing a two-dimensional stress-analysis of the Beliche dam and comparing the results with those provided by de Melo and Hartl (1997). Thus, a finite volume model was created in order to predict the displacements of the Beliche dam due to gravity loading during construction. The tetrahedral grid used for the analysis, which consisted of 3761 zones, is shown in 
figure 6.7. Although this model was created as a three-dimensional model, a unit thickness was considered and displacement was restricted in y-direction. Besides, similar boundary conditions to the conditions applied by Melo and Hartl were considered when the finite volume model was modeled.

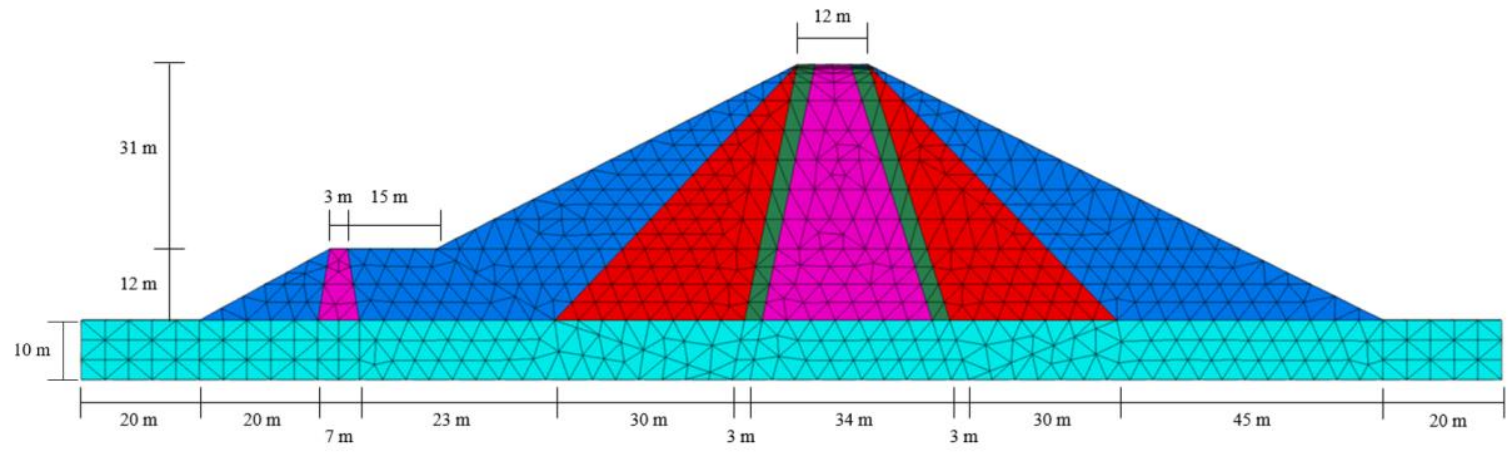

Figure 6.7: Finite volume model - Beliche dam

The construction sequence adopted for the analysis was based on the layered analysis previously described. Initially, the foundation was modeled. Then, construction layers with an average thickness of $4 \mathrm{~m}$ were added. It is worth to mention that layers with low thickness were added at the top of the embankment in order to have low vertical displacements at the top, as expected in field. Thus, vertical displacements due to gravity loading were obtained as shown in figure 6.8.

By comparing results with the literature, it is concluded that the applied process is very consistent. The vertical displacements along section AA' were obtained to validate the numerical implementation, see figure 6.9. The procedure shows strong agreement with the results provided by Melo and Hartl (1997).
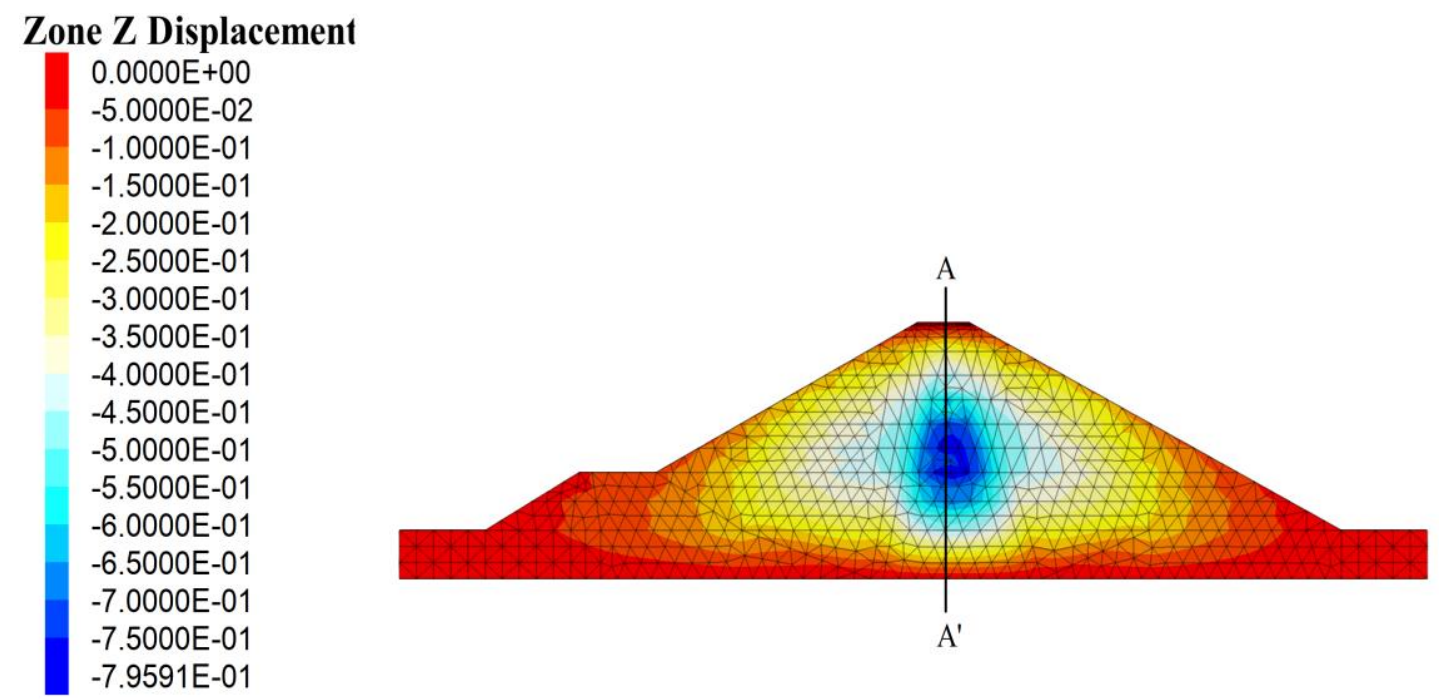

Figure 6.8: Vertical displacements (m) - Beliche dam 


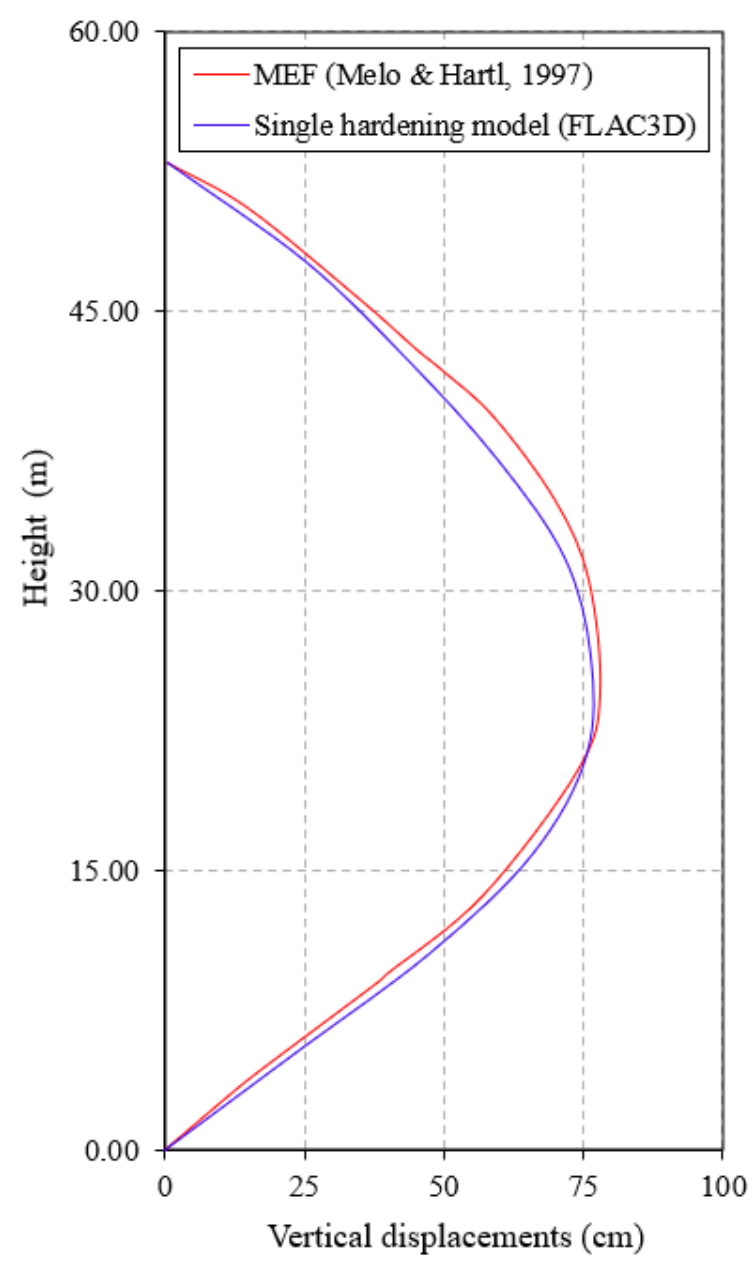

Figure 6.9: Vertical displacements at section AA' - Beliche dam

\subsection{Roadford dam}

\subsubsection{Introduction}

Geotechnical investigations were carried out in 1975 and 1977 in order to analyze the site suitability for the construction of a dam, which allowed to start with preliminary designs; however, more extensive investigations were performed in 1983. These provided information about the geology at the dam site and borrow quarry, which involved sedimentary rocks of the Cracking formation such as sandstones, mudstones and siltstones. Furthermore, the investigations evaluated the applicability of the materials for the dam construction. It was concluded that only the less weathered material would be suitable for use to construct the dam. According to Wilson and Evans (1991), this material could be obtained from depths greater that $4 \mathrm{~m}$ below the original ground level.

Wilson and Evans (1991) stated that in 1987, the construction of the Roadford dam started with a maximum construction period of 3.5 years; however, an agreement that consisted of reaching the goal that allowed to start impounding 
before winter of 1989. Thus, the construction of the dam started in June and finished by the end of October.

\subsubsection{Description of the dam}

The Roadford dam is a rockfill dam with an asphaltic concrete membrane on its upstream that provides impermeability located in the United Kingdom and it was constructed to reduce water deficiencies in Plymouth, South West and North Devon. The dam dimensions consist of $41 \mathrm{~m}$ height, $430 \mathrm{~m}$ long with a crosssection as shown in figure 6.10, a 1:2.227 upstream slope and a 1:2.25 downstream slope that assured an accepted factor of security. It is made of 1 million $\mathrm{m}^{3}$ of lowgrade rockfill made of mudstone, sandstone and siltstone and was founded on weathered sedimentary rocks.

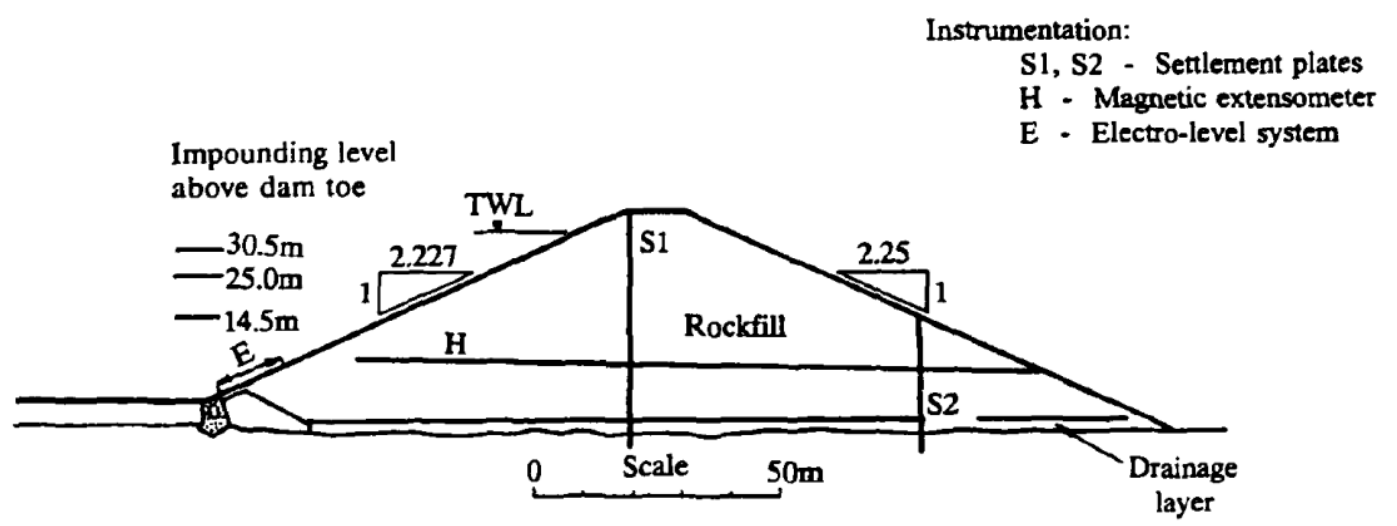

Figure 6.10: Cross-section of the Roadford dam (Kovacevic, 1994)

The Roadford dam could be considered a homogeneous dam since is made mainly of low-grade rockfill. Wilson and Evans (1991) provided many construction details about the Roadford dam, which consisted of a drainage layer at the bottom of the dam, a cut-off structure at the upstream toe of the dam and stiffer sandwaste fill as shown in figure 6.11, besides of the asphaltic concrete membrane.

Geotechnical investigations were carried out in order to calibrate parameters for the low-grade rockfill and the sandwaste fill. These involved oedometer and drained triaxial compression tests. Kovacevic (1994) determined parameters for the Lade-Kim constitutive model based on these experimental results in order to perform a stress-strain analysis considering the finite element method. These parameters are shown in table 5.2. Thus, Kovacevic (1994) performed numerical simulations of triaxial compression tests for different confining pressures. 


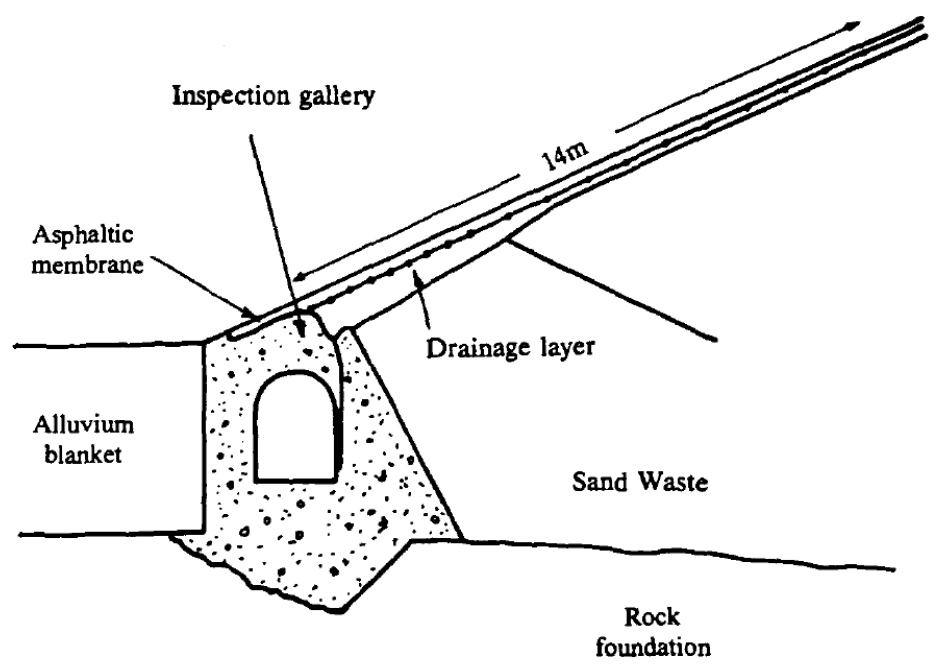

Figure 6.11: Cross-section of the Roadford dam (Kovacevic, 1994)

\subsubsection{Numerical analysis}

Kovacevic (1994) performed a two-dimensional stress-deformations analysis as well as Melo and Hart (1997). This analysis was carried out considering a non-linear elastic perfectly plastic model that incorporated a Mohr-Coulomb failure criterion as a yield surface besides of the Lade and Kim constitutive model in order to compare results regarding displacements; however, only the analysis based on the Lade and Kim constitutive model is subject of interest. Thus, based on the finite element method, Kovacevic (1994) presented the mesh shown in figure 6.12 , which consists of 215 quadrilateral elements.

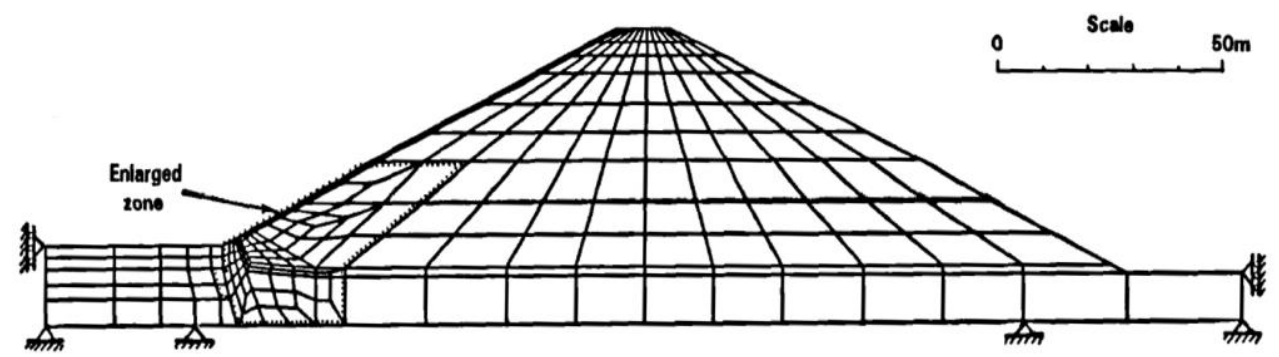

Figure 6.12: Finite element mesh - Roadford dam (Kovacevic, 1994)

Six materials were considered for this analysis: low-grade rockfill, sandwaste fill and drainage layer, rock foundation, alluvium blanket, cut-off structure and the asphaltic concrete membrane. Kovacevic (1994) modeled the lowgrade rockfill and sandwaste fill considering the Lade and Kim constitutive model and the parameters shown in table 5.2. Furthermore, low-grade rockfill was modeled considering a unit weight of $22.75 \mathrm{kN} / \mathrm{m}^{3}$ whereas the sandwaste fill was modeled considering a unit weight of $18.35 \mathrm{kN} / \mathrm{m}^{3}$. The drainage layer and the asphaltic concrete membrane were modeled considering the sandwaste fill 
parameters due to unavailability of experimental data and convenience. On the other side, the rock foundation, alluvium blanket and the cut-off structure were modeled considering a linear elastic model and the parameters shown in table 6.3. The alluvium blanket was modeled considering the same parameters of the rockfill for simplicity and due to the small influence on predicted deformations.

Table 6.3: Linear elastic constitutive model parameters used in the analysis (Kovacevic, 1994)

\begin{tabular}{|l|c|c|}
\cline { 2 - 3 } \multicolumn{1}{c|}{} & Young's modulus (MPa) & Poisson's ratio \\
\hline Rock foundation & 225 & 0.2 \\
\hline Cut-off structure & 30000 & 0.15 \\
\hline
\end{tabular}

The Roadford dam was modeled in FLAC3D, considering the implemented model when needed and the procedure applied in the case of the Beliche dam, in other words, developing a three-dimensional model with a unit thickness and corresponding boundary conditions. Thus, a model with 3212 hexahedral zones was created in order to predict the behavior of the Roadford dam, see figure 6.13 .

Considering these conditions and gravity load, the vertical displacements during the dam construction are presented in figure 6.14.

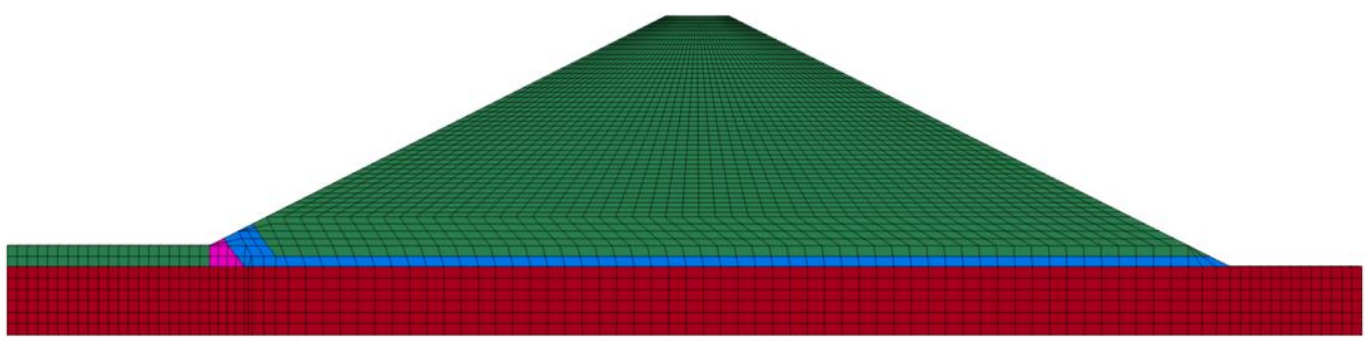

Figure 6.13: Finite volume model - Roadford dam
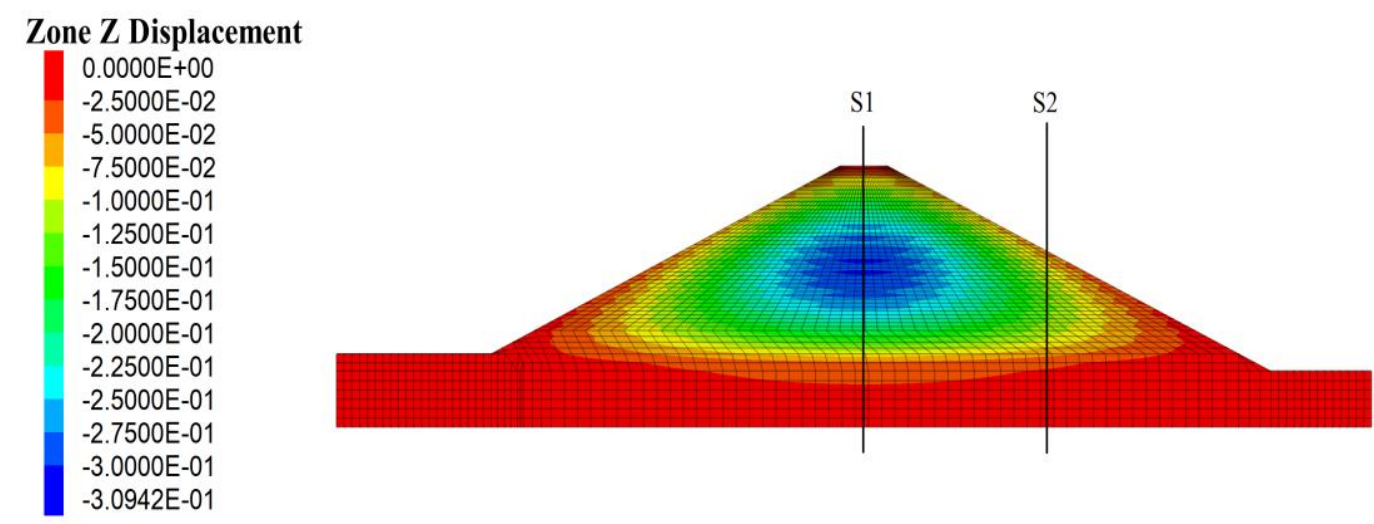

Figure 6.14: Vertical displacements (m) - Roadford dam 
The procedure was accomplished when comparing the results of both analyses regarding displacements. Vertical displacements at settlement plates $S 1$ and $S 2$ are presented in figure 6.15. Thus, it is concluded that strong agreement between the results exists. Besides, a better coincidence was found during this validation analysis than the case of the Beliche dam.

On the other side, discrepancies between the numerical and measured results rely on the assumption that the laboratory test data is representative according to Kovacevic (1994). Moreover, the measured displacements shows nonuniformity of the dam material regarding compressibility which is explained by the water content variation, allowing to deduce that the lower part of the dam is softer that the upper part. Although discrepancies exist and the uncertainty, a similar maximum vertical displacement was obtained.

Thus, is concluded that the validation procedure showed agreement when analyzing the applicability of the constitutive model for stress-strain analyses.

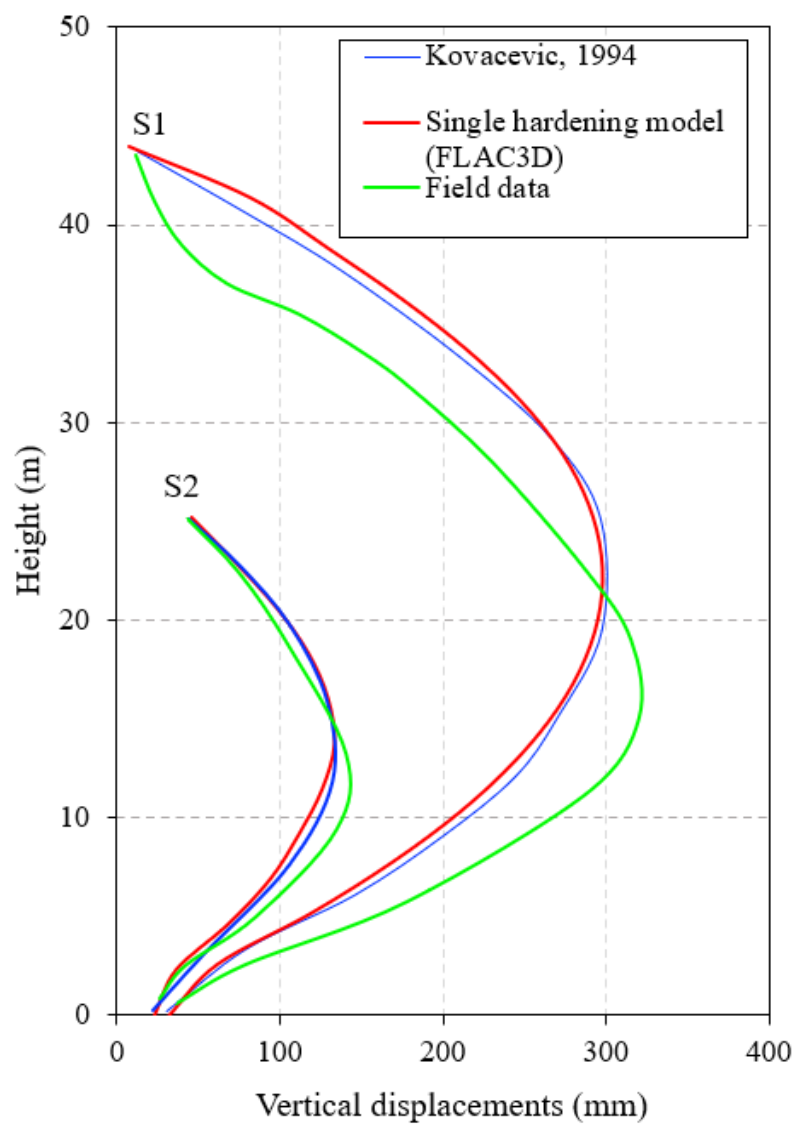

Figure 6.15: Vertical displacements at settlement plates $S 1$ and $S 2$ 


\subsection{Llancopi dam}

The Llancopi dam is a homogeneous earth dam located in Cuzco, Peru principally made of clayey sand (SC). It is partially founded on volcanic rock from the Casanuma formation, mostly involving andesite and rhyolite besides of alluvial material. Regarding its geometry, the Llancopi dam is $\mathrm{V}$-shaped with an average height of $16 m$ reaching 4396 m.a.s.l., a 2:1 (H:V) slope for both upstream and downstream, $5 \mathrm{~m}$ crest width and a $220 \mathrm{~m}$ long crest. Thus, considering the description of the dam and the site topography, a three-dimensional model is created. In figures 6.16, the longitudinal view is presented, whereas a plan view is observed in figure 6.17. Finally, a three-dimensional view is presented in figure 6.18 .
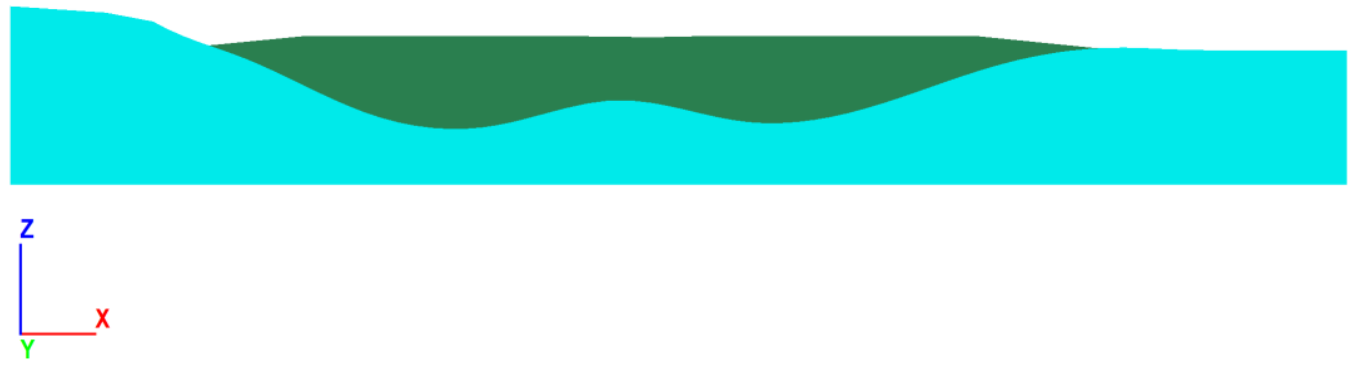

Figure 6.16: Three-dimensional model of the Llancopi dam - longitudinal view along the dam axis

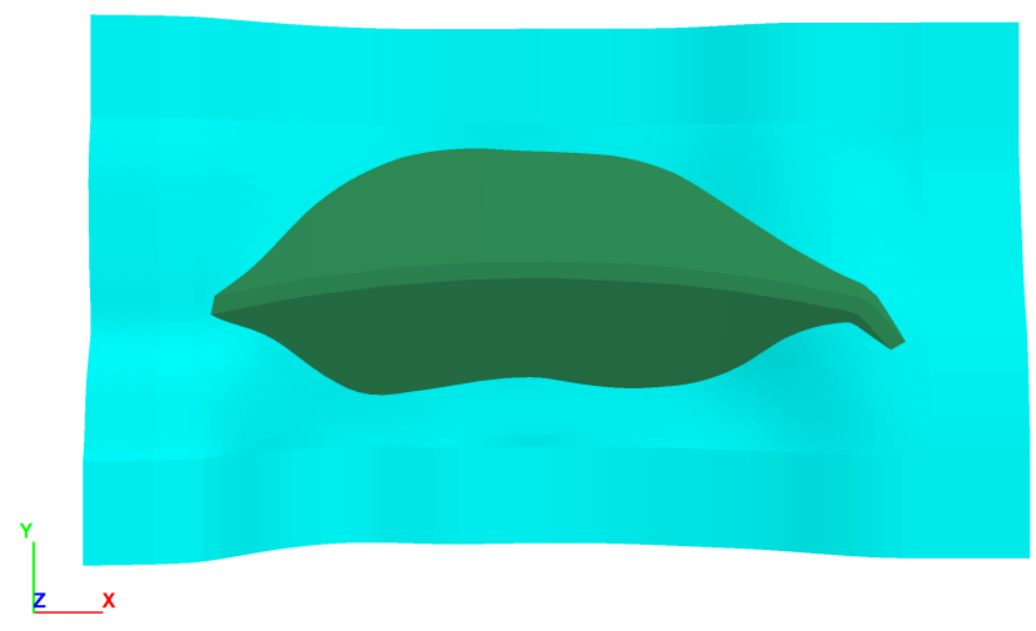

Figure 6.17: Three-dimensional model of the Llancopi dam - plan view 


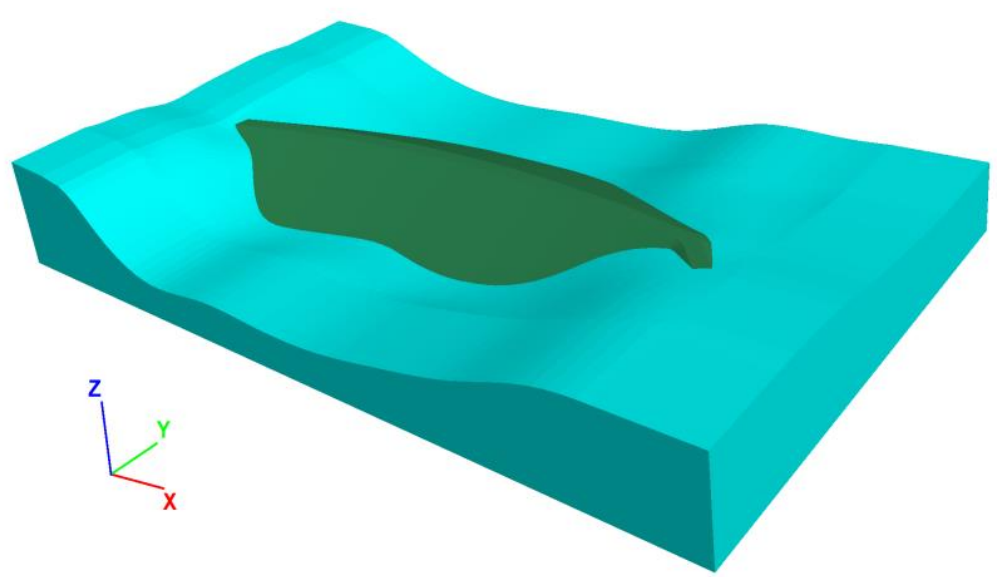

Figure 6.18: Three-dimensional model of the Llancopi dam

The dam material was obtained from different local borrow quarries and matched with the properties and parameters shown in Table 6.4. On the basis of these data, the typical Lade and Kim constitutive model parameters for Sacramento river sand shown in Table 6.5 are adopted in order to model the elastoplastic behavior of the dam material. Furthermore, Mohr-Coulomb constitutive model parameters are calibrated based on the stress-strain curve obtained from a numerical simulation of a drained triaxial compression test considering a confining pressure of $135 \mathrm{kPa}$ and the parameters shown in table 6.7. The confining pressure value was adopted by calculating an average stress value at the middle of the embankment.

Table 6.4: Properties and parameters of the Llancopi dam material

\begin{tabular}{|c|c|}
\hline Unified soil classification system (USCS) & SM-SC \\
\hline Permeability $\left(x 10^{-9} \mathrm{~m} / \mathrm{s}\right)$ & $1.36-4.95$ \\
\hline Friction angle $\left(^{\circ}\right)$ & $17-23$ \\
\hline Cohesion $(k P a)$ & $60-140$ \\
\hline
\end{tabular}

Table 6.5: Typical parameters for dense Sacramento river sand - dam material (Lade, 2005)

\begin{tabular}{|c|c|c|c|c|}
\hline Model component & Parameter names & \multicolumn{3}{|c|}{ Parameter values } \\
\hline Elastic properties & $M, \lambda, v$ & 900 & 0.28 & 0.20 \\
\hline Failure criterion & $m, \eta_{1}$ & 0.23 & 80 & - \\
\hline Plastic potential & $\psi_{2}, \mu$ & -3.09 & 2.01 & - \\
\hline Yield criterion & $h, \alpha$ & 0.765 & 0.229 & - \\
\hline Hardening/Softening law & $C, p$ & 0.0000396 & 1.92 & - \\
\hline
\end{tabular}


The implemented calibration criteria consisted of adopting parameters that matched with the borrow quarry characteristics and that allowed to simulate the failure criterion represented by the Lade and Kim constitutive model. Thus, considering stress-curves shown in figure 6.19, Mohr-Coulomb are listed in Table 6.6 .

Table 6.6: Mohr-Coulomb model parameters for the dam material

\begin{tabular}{|c|c|}
\hline Young's modulus $(k P a)$ & 112270 \\
\hline Poisson's ratio & 0.20 \\
\hline Friction angle $\left(^{\circ}\right)$ & 23 \\
\hline Cohesion $(k P a)$ & 138 \\
\hline
\end{tabular}

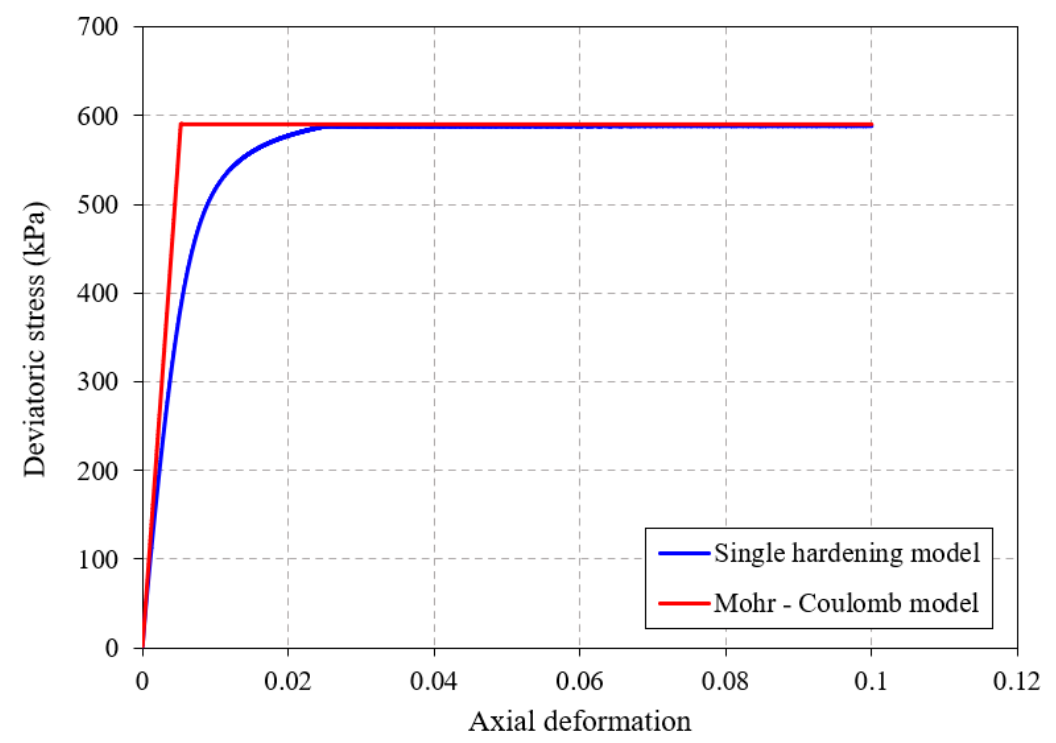

Figure 6.19: Stress-strain curves obtained from simulating triaxial compression tests

Geotechnical site investigations provided information about the local geology, which involved a $0.8 \mathrm{~m}$ layer of silty sand and clayey sand (SM-SC) that covers volcanic rock. Further analyses revealed andesite and rhyolite underneath the top layer, which presented a RQD index that varies from $40 \%$ to $90 \%$ and is classified as a class II rock according to the rock mass rating developed by Bieniawski (1989). Thus, a similar procedure to the applied in the Roadford dam case was applied during this analysis. The foundation is modeled as homogeneous material, neglecting the thin soil layer on the top due to the small influence it has in the stress-deformation analysis. Besides, a linear elastic constitutive model is used by considering the parameters shown in Table 6.7 . 
Table 6.7: Linear elastic model parameters of the Llancopi dam foundation

\begin{tabular}{|c|c|}
\hline Young's modulus (GPa) & 2.98 \\
\hline Poisson's ratio & 0.33 \\
\hline
\end{tabular}

\subsection{Numerical analysis}

\subsubsection{Three-dimensional analysis}

A three-dimensional finite volume model is created in order to represent the foundation and the Llancopi dam. The model is based on a tetrahedral discretization resulting in 130900 zones, see figure 6.20. Regarding boundary conditions, the bottom of the model is fixed in $x_{-}^{-}, y-$ and $\mathrm{z}$ - directions whereas the lateral faces are fixed in their respective normal vector direction. On the other hand, gravity loading is applied considering a unit weight of $22.51 \mathrm{kN} / \mathrm{m}^{3}$ for the dam material, whereas a unit weight of $27 \mathrm{kN} / \mathrm{m}^{3}$ is considered for the foundation material.

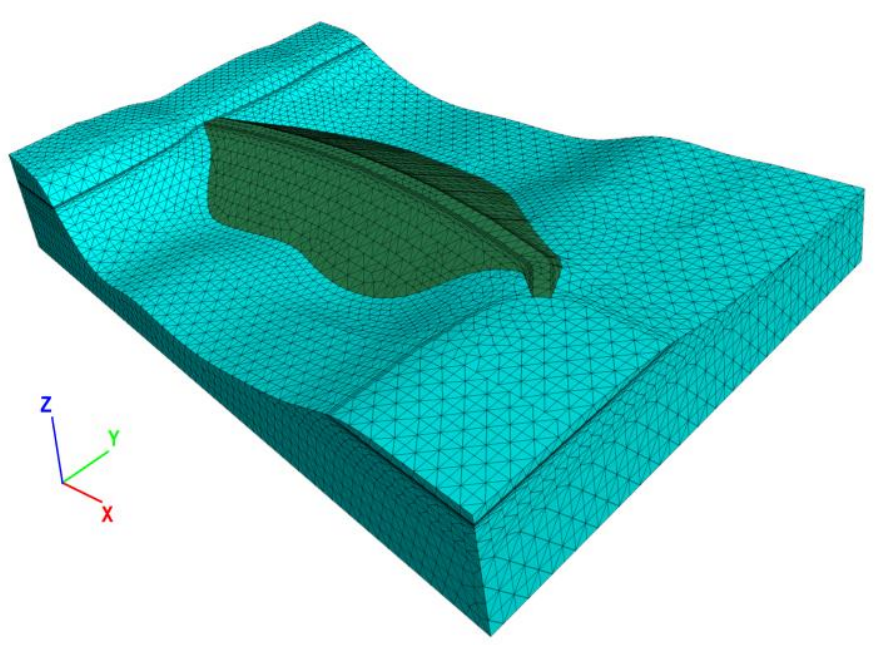

Figure 6.20: Three-dimensional finite volume model

The numerical simulation of the dam construction is carried out performing a sequential modeling in order to represent construction layers. Modeling the foundation is considered an initial stage where boundary conditions are applied and initial stresses calculated. Then, a first construction layer is modeled by adding the respective zones and reaching equilibrium after the gravity load is applied. After that, a similar process is performed for a second construction layer. This process is carried out until the dam is constructed. Thus, final vertical displacements are calculated and shown in figure 6.21 whereas final vertical stresses are shown in 
figure 6.22 .
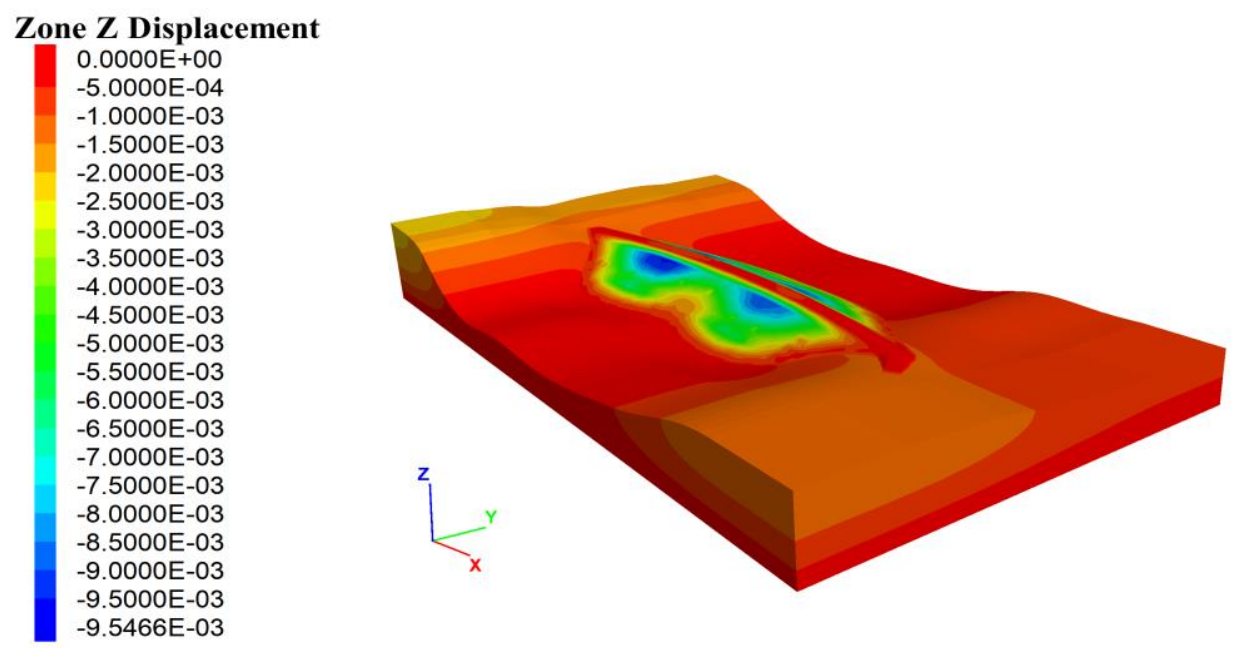

Figure 6.21: Vertical displacements $(m)$ - Llancopi dam

Zone ZZ Stress

Calculated by: Volumetric Averaging
$0.0000 \mathrm{E}+00$
$-5.0000 \mathrm{E}+01$
$-1.0000 \mathrm{E}+02$
$-1.5000 \mathrm{E}+02$
$-2.0000 \mathrm{E}+02$
$-2.5000 \mathrm{E}+02$
$-3.0000 \mathrm{E}+02$
$-3.5000 \mathrm{E}+02$
$-4.0000 \mathrm{E}+02$
$-4.5000 \mathrm{E}+02$
$-5.0000 \mathrm{E}+02$
$-5.5000 \mathrm{E}+02$
$-6.0000 \mathrm{E}+02$
$-6.5000 \mathrm{E}+02$
$-7.0000 \mathrm{E}+02$
$-7.5000 \mathrm{E}+02$
$-8.0000 \mathrm{E}+02$
$-8.5000 \mathrm{E}+02$
$-8.8248 \mathrm{E}+02$

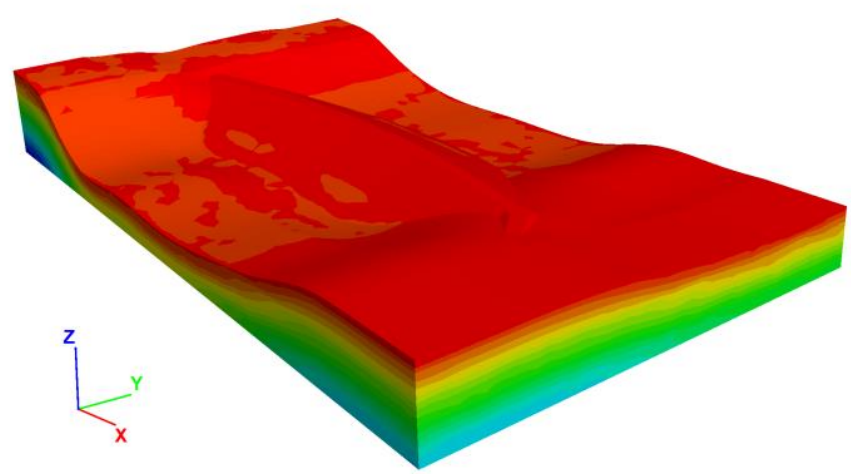

Figure 6.22: Vertical stresses $(k P a)$ - Llancopi dam

The desired results regarding displacements and stresses are obtained by using a cutting plane. In this case, two cutting planes are intended to be used since a comparison with two-dimensional analyses will be carried out. Thus, the tallest cross-section and the shortest cross-sections are analyzed as shown in figures 6.23 , $6.24,6.25$ and 6.26 . 


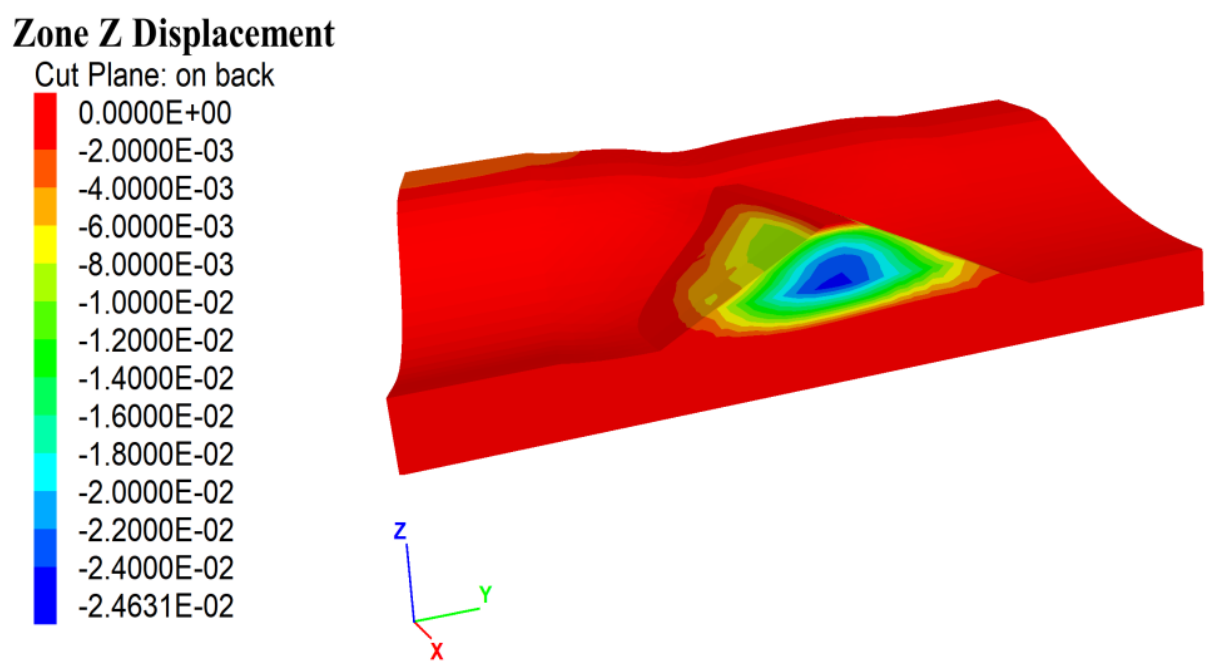

Figure 6.23: Vertical displacements $(m)$ at $\mathrm{x}=79.5 m$ - Llancopi dam

\section{Zone ZZ Stress}

Cut Plane: on back

Calculated by: Volumetric Averaging

$0.0000 \mathrm{E}+00$

$-5.0000 \mathrm{E}+01$

$-1.0000 \mathrm{E}+02$

$-1.5000 \mathrm{E}+02$

$-2.0000 \mathrm{E}+02$

$-2.5000 \mathrm{E}+02$

$-3.0000 \mathrm{E}+02$

$-3.5000 \mathrm{E}+02$

$-4.0000 \mathrm{E}+02$

$-4.5000 \mathrm{E}+02$

$-5.0000 \mathrm{E}+02$

$-5.5000 \mathrm{E}+02$

$-6.0000 E+02$

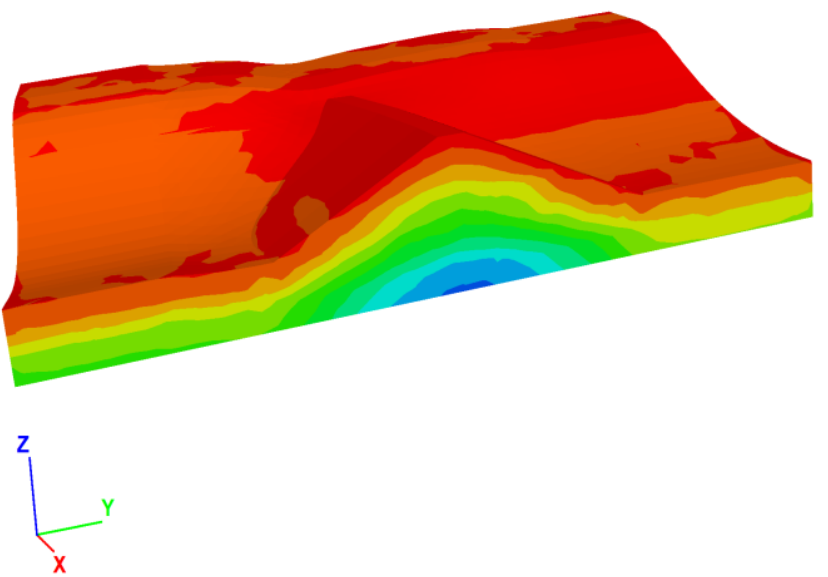

Figure 6.24: Vertical stresses $(k P a)$ at $\mathrm{x}=79.5 m$ - Llancopi dam 
Zone Z Displacement

Cut Plane: on back

$0.0000 \mathrm{E}+00$

$-1.0000 \mathrm{E}-03$

$-2.0000 \mathrm{E}-03$

$-3.0000 \mathrm{E}-03$

$-4.0000 \mathrm{E}-03$

$-5.0000 \mathrm{E}-03$

$-6.0000 \mathrm{E}-03$

$-7.0000 \mathrm{E}-03$

$-8.0000 \mathrm{E}-03$

$-9.0000 \mathrm{E}-03$

$-1.0000 \mathrm{E}-02$

$-1.1000 \mathrm{E}-02$

$-1.2000 \mathrm{E}-02$

$-1.3000 \mathrm{E}-02$

$-1.4000 \mathrm{E}-02$

$-1.4269 \mathrm{E}-02$

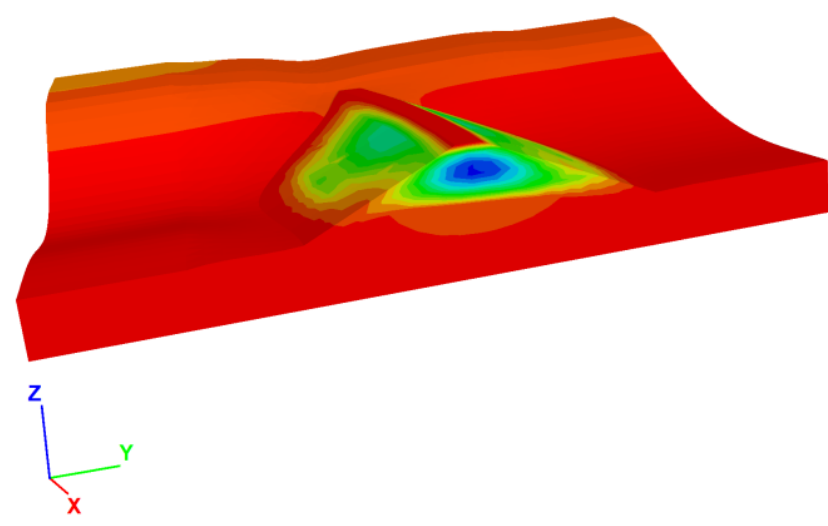

Figure 6.25: Vertical displacements $(m)$ at $\mathrm{x}=107.5 m$ - Llancopi dam

\section{Zone ZZ Stress}

Cut Plane: on back
Calculated by: Volumetric Averaging
$0.0000 \mathrm{E}+00$
$-5.0000 \mathrm{E}+01$
$-1.0000 \mathrm{E}+02$
$-1.5000 \mathrm{E}+02$
$-2.0000 \mathrm{E}+02$
$-2.5000 \mathrm{E}+02$
$-3.0000 \mathrm{E}+02$
$-3.5000 \mathrm{E}+02$
$-4.0000 \mathrm{E}+02$
$-4.5000 \mathrm{E}+02$
$-5.0000 \mathrm{E}+02$
$-5.5000 \mathrm{E}+02$
$-6.0000 \mathrm{E}+02$
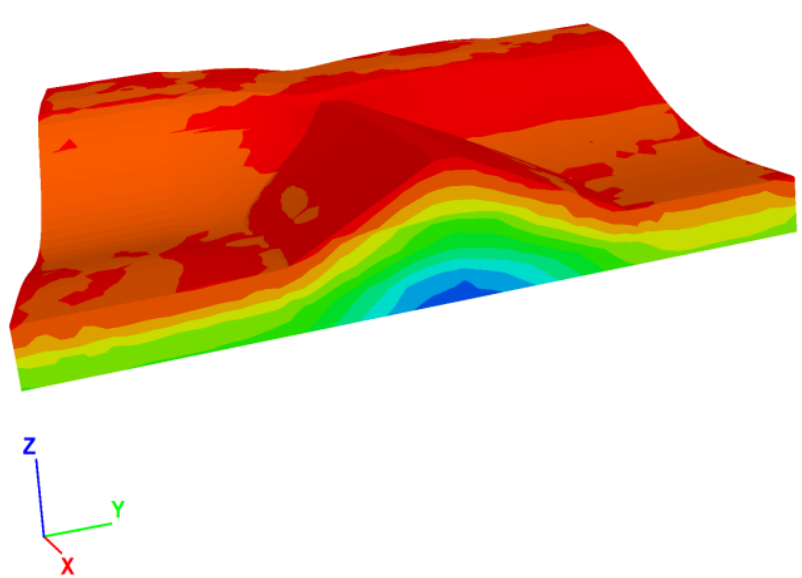

Figure 6.26: Vertical stresses $(k P a)$ at $\mathrm{x}=107.5 m$ - Llancopi dam

\subsubsection{Comparison with two-dimensional analyses}

Two-dimensional stress-deformation analyses are performed in order to study the discrepancies between the results from two- and three-dimensional analyses and the advantages or disadvantages that may exist. First, the tallest crosssection of the Llancopi dam was selected as object of study. Thus, a finite volume model is created considering the same procedure applied during the validation of the constitutive model as shown in figure 6.27. 


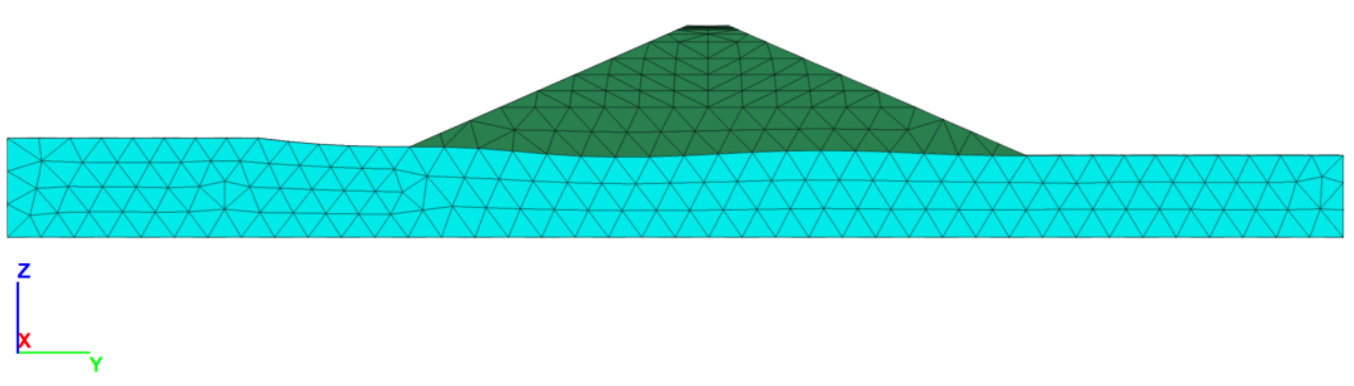

Figure 6.27: Finite volume model of the tallest cross-section of the Llancopi dam

The model corresponds to the tallest cross-section of the Llancopi dam, which is located at $\mathrm{x}=79.5 \mathrm{~m}$ in the three-dimensional model and consists of 1393 tetrahedral zones. The applied boundary conditions include restricted displacements of the bottom of the model in both directions and in $y$ - direction of the lateral faces of the foundation. After simulating the dam construction, vertical displacements due to gravity loading are obtained and showed in figure 6.28 whereas vertical stresses are shown in figure 6.29.

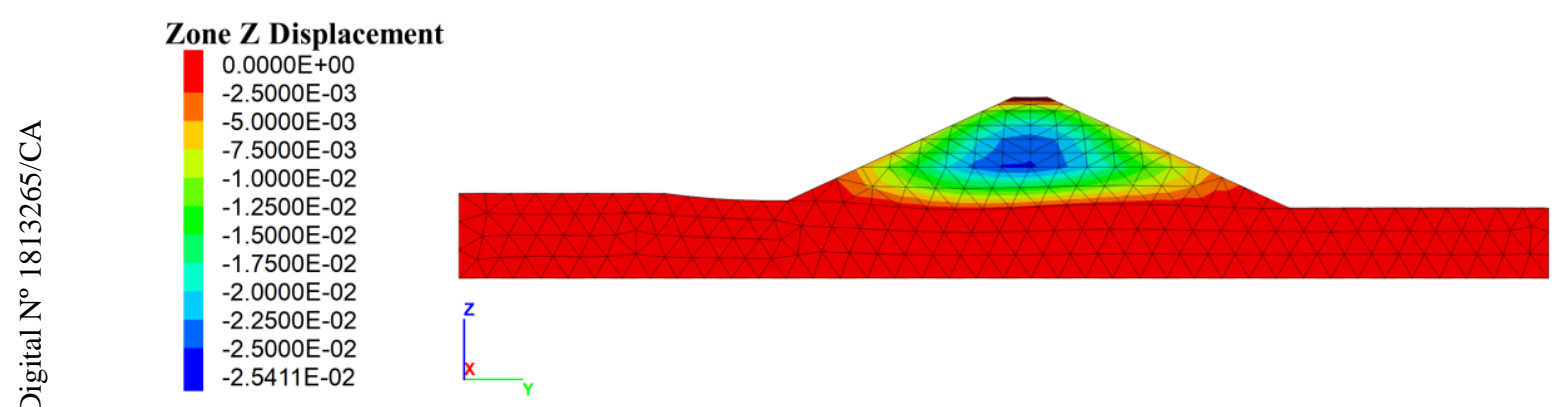

Figure 6.28: Two-dimensional vertical displacements $(m)$ at $x=79.5 m$ Llancopi dam

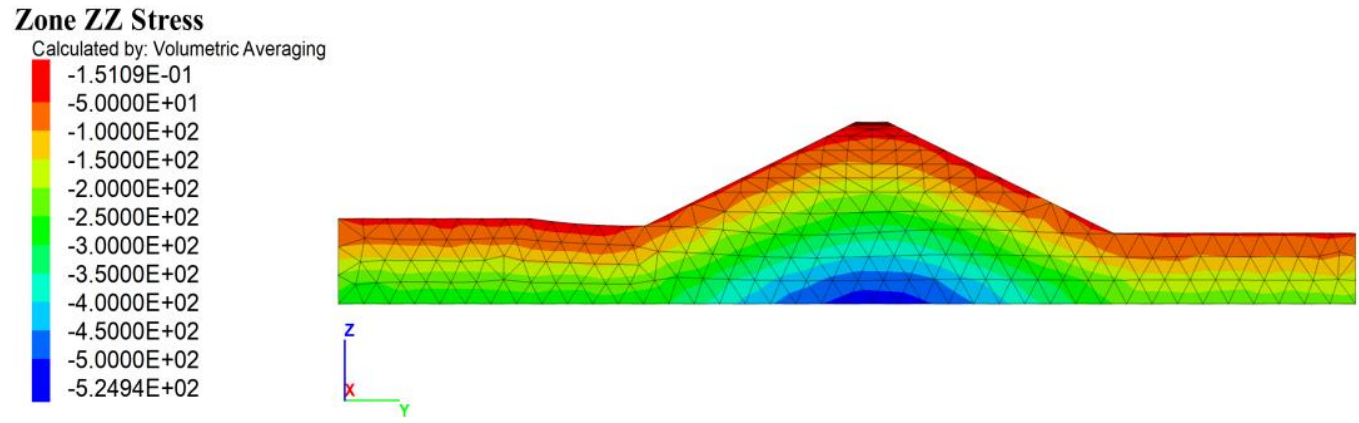

Figure 6.29: Two-dimensional vertical stresses $(k P a)$ at $\mathrm{x}=79.5 m$ - Llancopi dam

A second model that consists of 1313 tetrahedral zones is created in order to perform another stress-deformation analysis considering the shortest crosssection of the Llancopi dam, which is located at $\mathrm{x}=107.5 \mathrm{~m}$ in the three- 
dimensional model, see figure 6.30. Considering the same boundary conditions as the adopted during the analysis of the tallest cross-section, vertical displacements and stresses are obtained and shown in figures 6.31 and 6.32 .
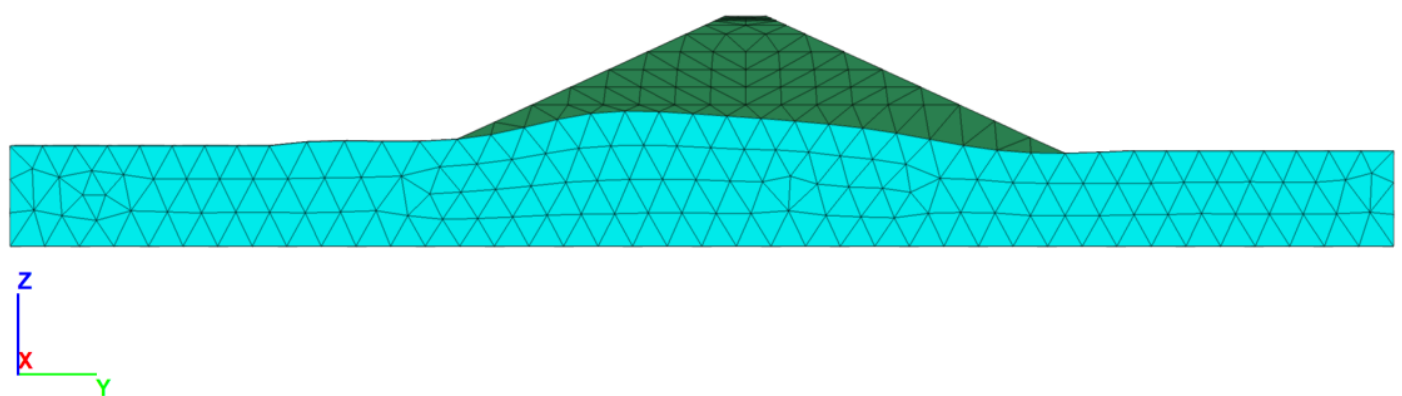

Figure 6.30: Finite volume model of the shortest cross-section of the Llancopi dam

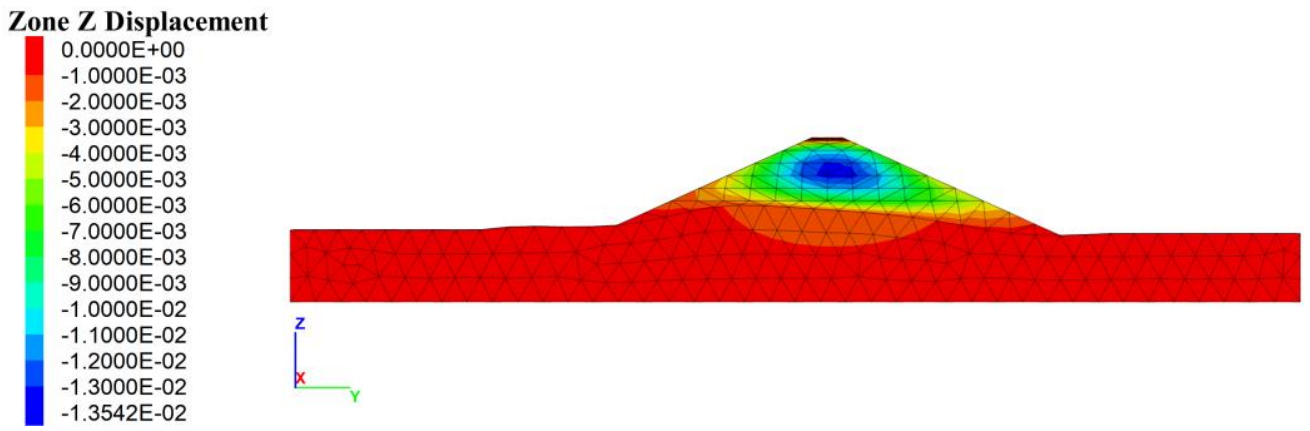

Figure 6.31: Two-dimensional vertical displacements $(m)$ at $\mathrm{x}=107.5 m$ Llancopi dam
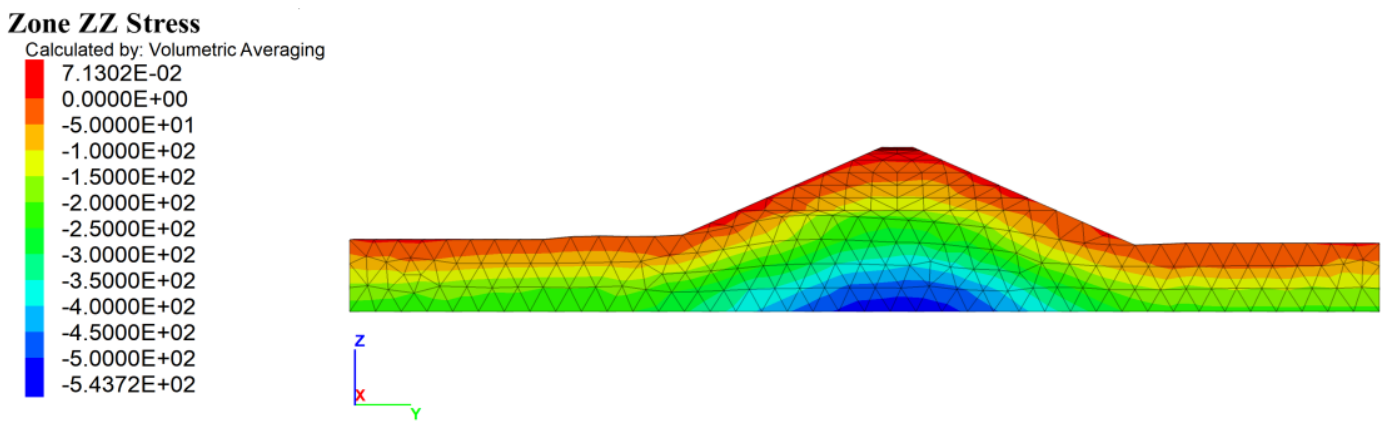

Figure 6.32: Two-dimensional vertical stresses $(k P a)$ at $\mathrm{x}=107.5 m$ - Llancopi dam

As observed in the presented figures, result differences can be addressed due to the type of analysis carried out. A more specific comparison regarding vertical displacements along the center of the dam section is shown in figure 6.33. In the case of the tallest section, greater displacements are obtained in the twodimensional analysis whereas; in the other case, greater displacements are obtained 
in the three-dimensional case. The reason behind this discrepancy relies on the dam geometry. Due to the fact that in the three-dimensional analysis, displacements along the longitudinal axis of the dam are not restricted and that the cross-sections are located as shown in figure 6.34, greater vertical displacements at cross-section at $\mathrm{x}=107.5 \mathrm{~m}$ are expected during a three-dimensional analysis.

On the other hand, the opposite situation is expected for cross-section located at $x=79.5 \mathrm{~m}$. Thus, the expected results match with the obtained results for both types of analysis. Regarding vertical stresses, small discrepancies are presented when comparing the two types of analysis due to the fact that vertical displacements are relatively small; however, differences are noted when comparing the two cross-sections due to the different material distribution between these.

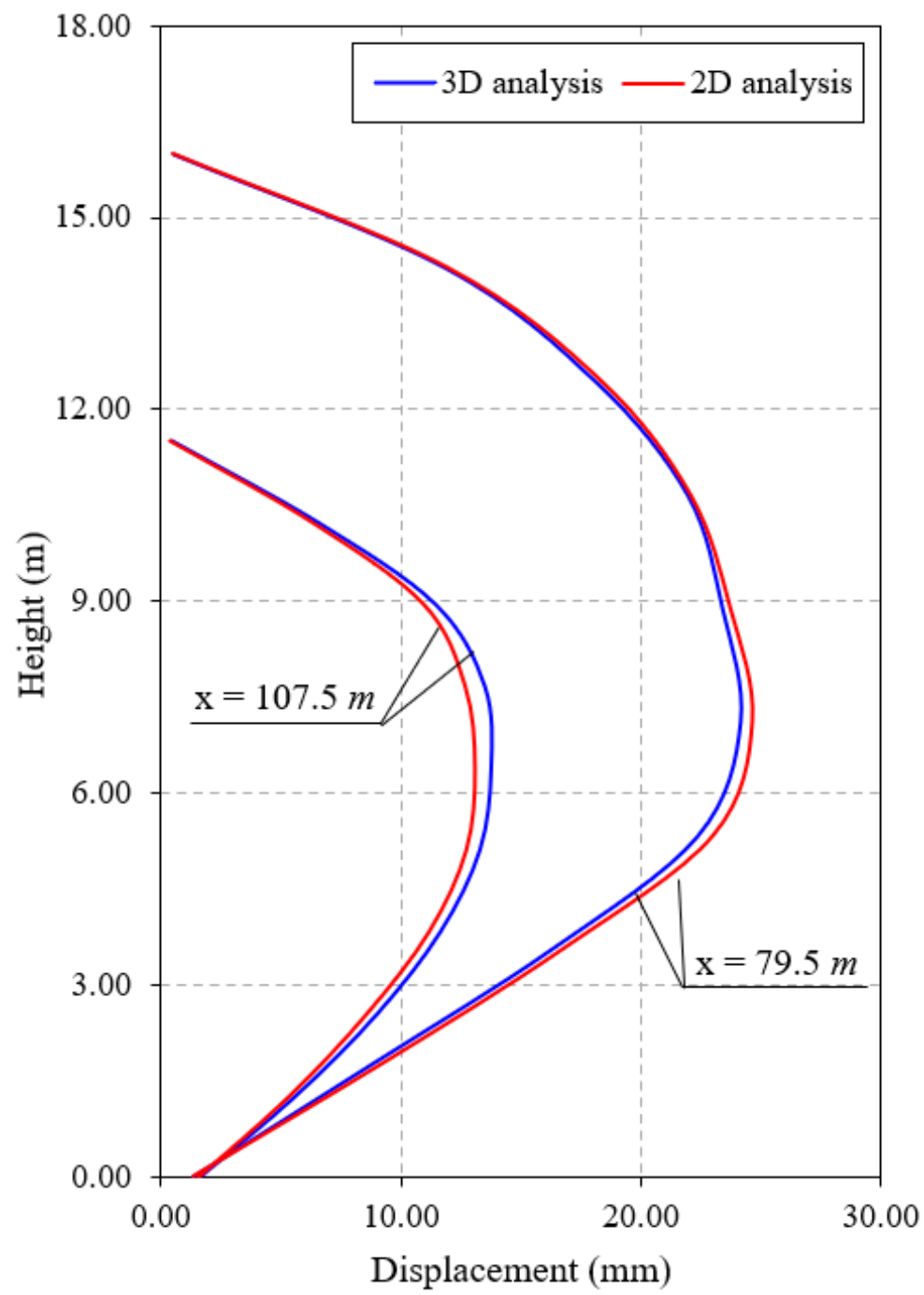

Figure 6.33: Comparison of vertical displacement profiles obtained in 2D and $3 \mathrm{D}$ analyses 


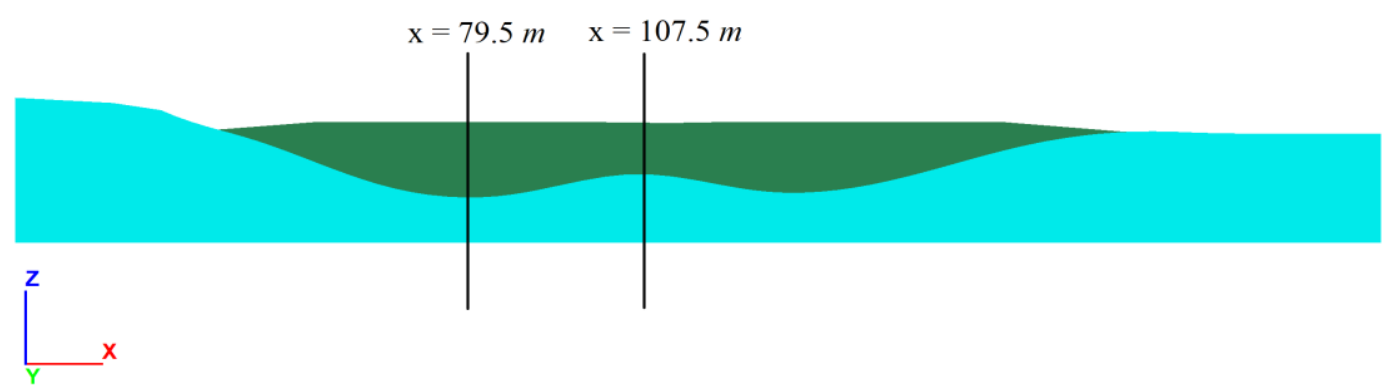

Figure 6.34: Studied cross-sections - longitudinal view along the dam axis

\subsubsection{Comparison with analyses carried out using the Mohr-Coulomb constitutive model}

During the validation procedure, drained triaxial compression tests and twodimensional analyses were simulated considering the Lade and Kim constitutive model and was concluded that the model is capable of describing the elastoplastic behavior of soil effectively under different stress conditions. Nevertheless, in order to analyze the advantages of this model, a comparison between constitutive models is needed. Thus, the same analysis regarding the Llancopi dam are performed considering the Mohr-Coulomb constitutive model in order to compare results regarding stresses and displacements.

Initially, the three-dimensional analysis is carried out considering the same boundary conditions and modeling procedure previously applied. The results regarding vertical stresses and displacements are presented in figures 6.35 and 6.36. However, as the case involving the Lade and Kim constitutive model, sections at $\mathrm{x}$ $=79.5 \mathrm{~m}$ and $\mathrm{x}=107.5 \mathrm{~m}$ are studied to obtain a better comparison. Thus, vertical displacements and stresses for the cross-section at $\mathrm{x}=79.5 \mathrm{~m}$ are presented in figures 6.37 and 6.38 respectively. Furthermore, the same type of results for the cross-section at $\mathrm{x}=107.5 \mathrm{~m}$ are presented in figures 6.39 and 6.40 .
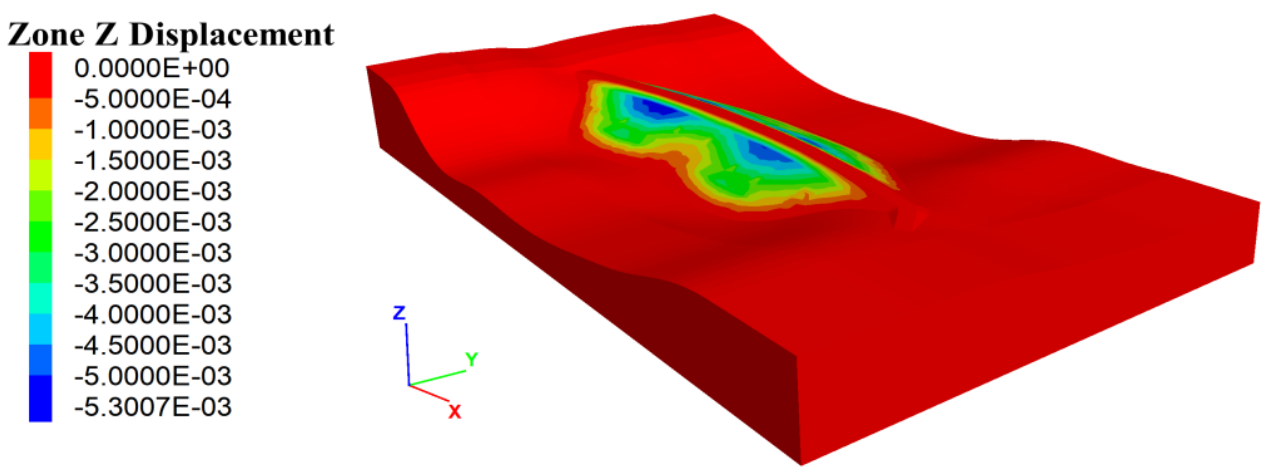

Figure 6.35: Vertical displacements $(m)$ - Llancopi dam, Mohr - Coulomb model 
Zone ZZ Stress

Calculated by: Volumetric Averaging

$0.0000 \mathrm{E}+00$

$-5.0000 \mathrm{E}+01$

$-1.0000 \mathrm{E}+02$

$-1.5000 E+02$

$-2.0000 E+02$

$-2.5000 E+02$

$-3.0000 \mathrm{E}+02$

$-3.5000 E+02$

$-4.0000 E+02$

$-4.5000 E+02$

$-5.0000 E+02$

$-5.5000 \mathrm{E}+02$

$-6.0000 E+02$

$-6.5000 \mathrm{E}+02$

$-7.0000 E+02$

$-7.5000 \mathrm{E}+02$

$-8.0000 E+02$

$-8.5000 \mathrm{E}+02$

$-8.9140 \mathrm{E}+02$

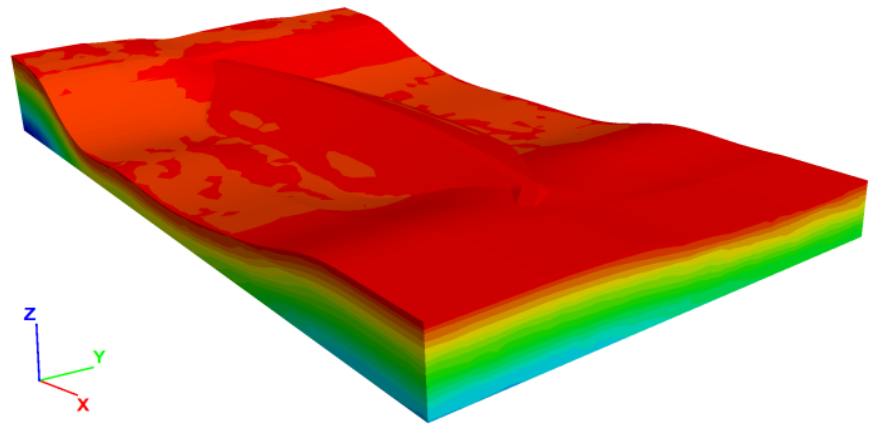

Figure 6.36: Vertical stresses $(k P a)$ - Llancopi dam, Mohr - Coulomb model

\section{Zone Z Displacement}

Cut Plane: on back

$0.0000 \mathrm{E}+00$

$-1.0000 \mathrm{E}-03$

$-2.0000 \mathrm{E}-03$

$-3.0000 \mathrm{E}-03$

$-4.0000 \mathrm{E}-03$

$-5.0000 \mathrm{E}-03$

$-6.0000 \mathrm{E}-03$

$-7.0000 \mathrm{E}-03$

$-8.0000 \mathrm{E}-03$

$-9.0000 \mathrm{E}-03$

-1.0000E-02

$-1.1000 \mathrm{E}-02$

$-1.2000 \mathrm{E}-02$

$-1.2880 \mathrm{E}-02$
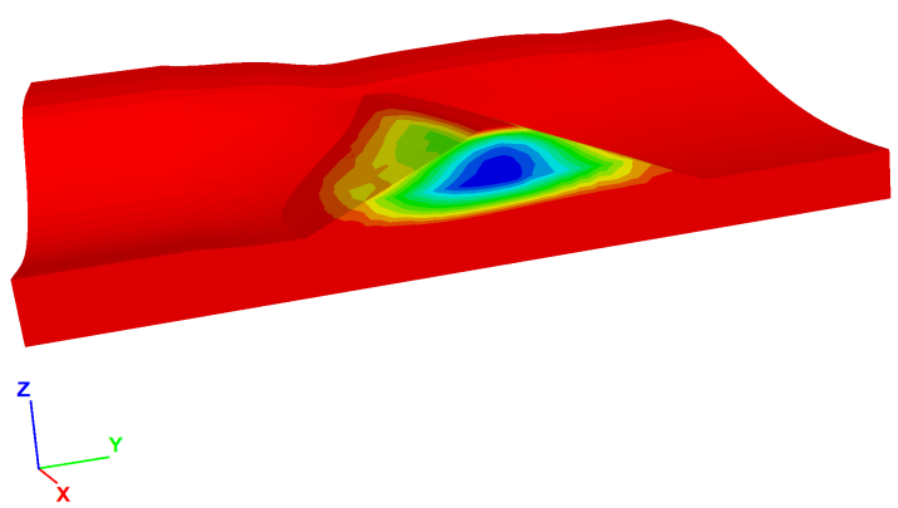

Figure 6.37: Vertical displacements $(m)$ at $\mathrm{x}=79.5 m$ - Llancopi dam, Mohr Coulomb model 


\section{Zone ZZ Stress}

Cut Plane: on back

Calculated by: Volumetric Averaging

$0.0000 \mathrm{E}+00$

$-5.0000 \mathrm{E}+01$

$-1.0000 \mathrm{E}+02$

$-1.5000 \mathrm{E}+02$

$-2.0000 \mathrm{E}+02$

$-2.5000 \mathrm{E}+02$

$-3.0000 \mathrm{E}+02$

$-3.5000 \mathrm{E}+02$

$-4.0000 \mathrm{E}+02$

$-4.5000 \mathrm{E}+02$

$-5.0000 \mathrm{E}+02$

$-5.5000 \mathrm{E}+02$

$-6.0000 \mathrm{E}+02$

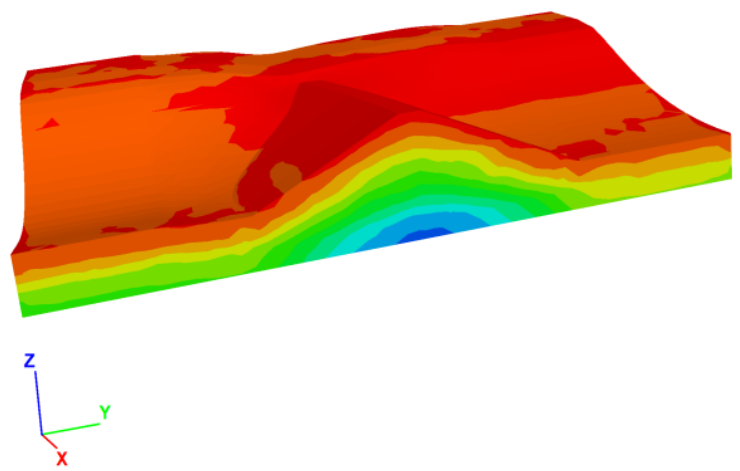

Figure 6.38: Vertical stresses $(k P a)$ at $\mathrm{x}=79.5 m$ - Llancopi dam, Mohr -

Coulomb model

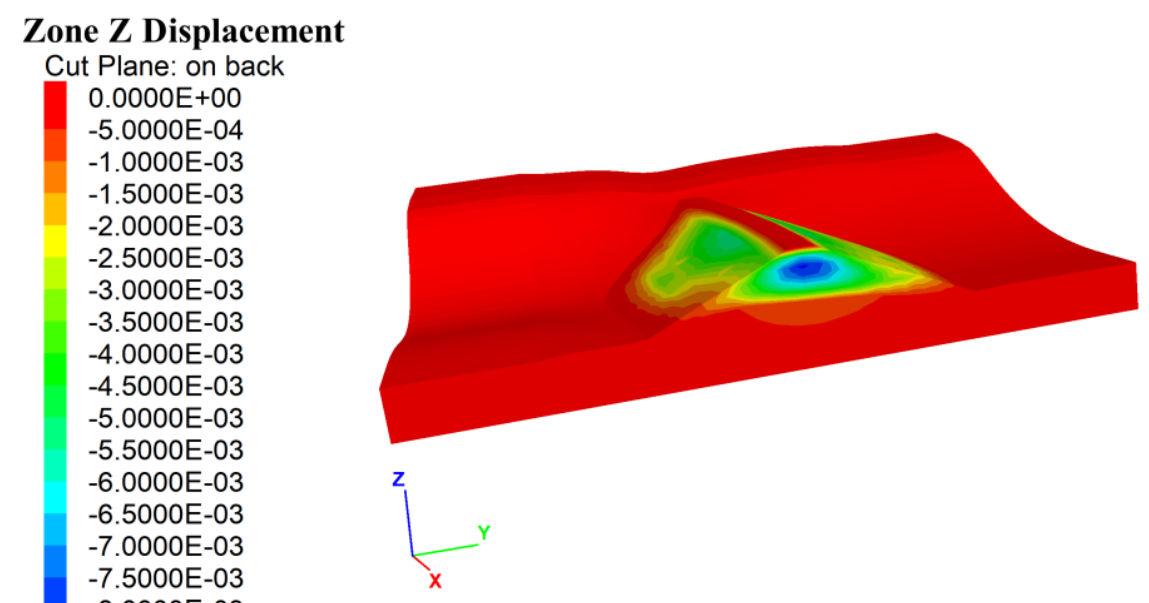

Figure 6.39: Vertical displacements $(m)$ at $\mathrm{x}=107.5 m$ - Llancopi dam, Mohr Coulomb model

\section{Zone ZZ Stress}

Cut Plane: on back

Calculated by: Volumetric Averaging
$0.0000 \mathrm{E}+00$
$-5.0000 \mathrm{E}+01$
$-1.0000 \mathrm{E}+02$
$-1.5000 \mathrm{E}+02$
$-2.0000 \mathrm{E}+02$
$-2.5000 \mathrm{E}+02$
$-3.0000 \mathrm{E}+02$
$-3.5000 \mathrm{E}+02$
$-4.0000 \mathrm{E}+02$
$-4.5000 \mathrm{E}+02$
$-5.0000 \mathrm{E}+02$
$-5.5000 \mathrm{E}+02$
$-6.0000 \mathrm{E}+02$

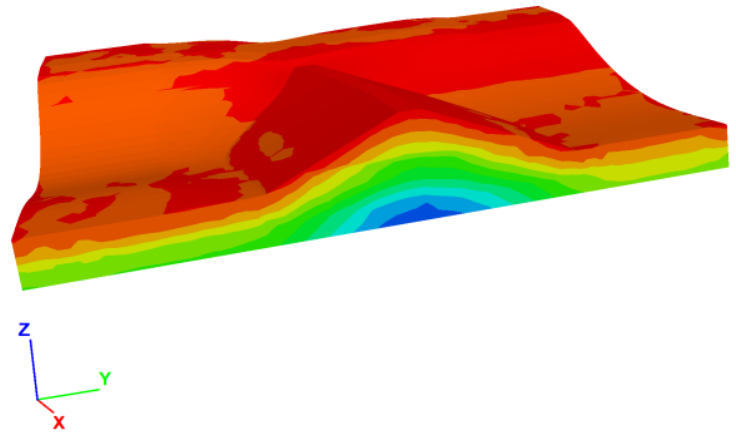

Figure 6.40: Vertical stresses $(k P a)$ at $\mathrm{x}=107.5 m$ - Llancopi dam, Mohr -

Coulomb model 
Lower vertical displacements and higher vertical stresses are obtained from the analysis involving the Mohr - Coulomb constitutive model. The reason behind this elastoplastic behavior can be observed during the numerical simulations of drained triaxial compression tests. The stress-strain curves obtained by these simulations are showed in figure 6.19 and allow to deduce that a higher stress level is required by the Mohr - Coulomb constitutive model in order to generate the same axial deformation as the Lade and Kim constitutive model. This deduction shows agreement with the numerical results from the stress-strain analyses, where larger vertical displacements and lower vertical stresses are obtained for the Lade and Kim model-based analysis.

A better comparison is obtained when comparing vertical displacements as shown in figure 6.41. Since a successful application of the constitutive model for stress-strain analyses was showed in the validation procedure, it is considered that the obtained vertical displacements show consistency. Thus, it is deduced that Mohr - Coulomb model-based results show inefficiency regarding displacement predictions.

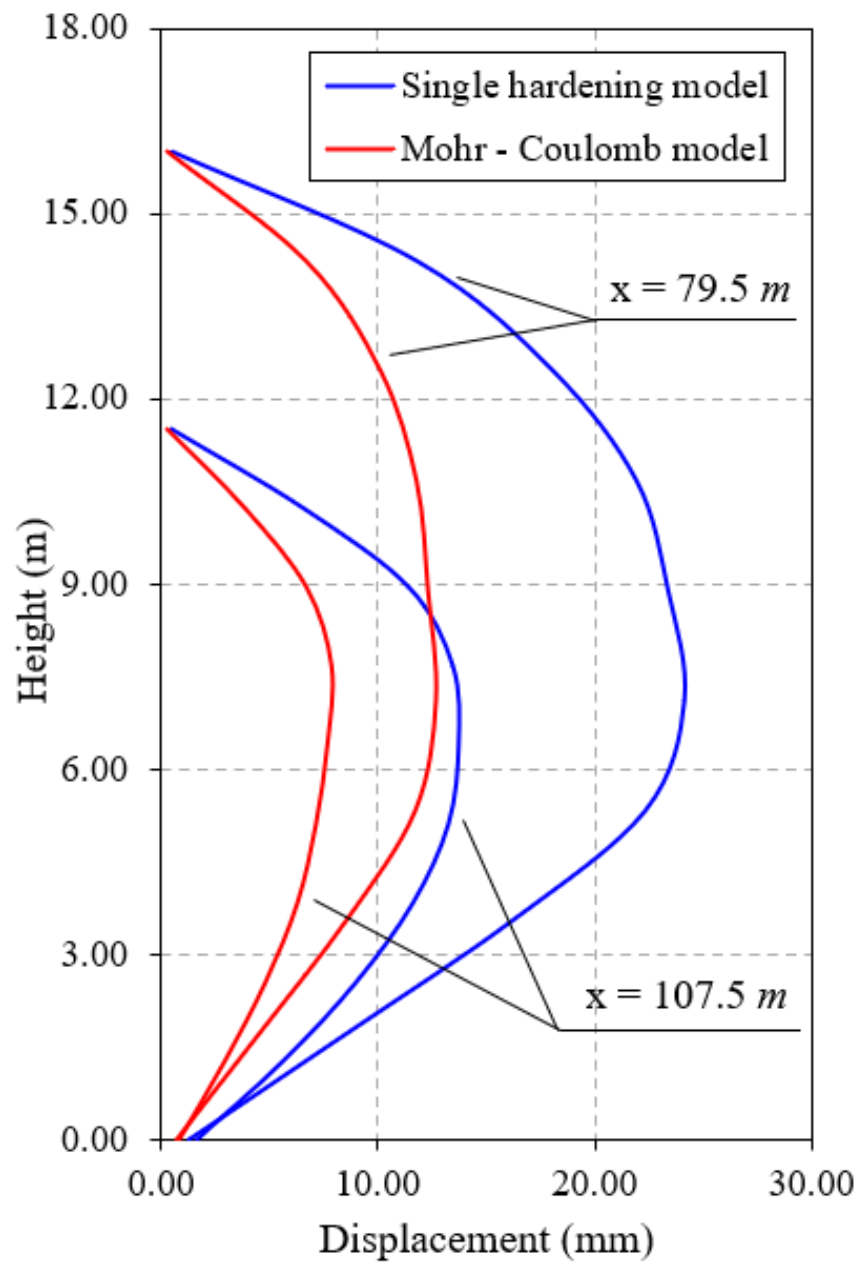

Figure 6.41: Comparison of constitutive models 


\section{Conclusions and suggestions}

This research aims to study the geomechanical behavior of an embankment based on the explicit finite volume method and the Lade-Kim constitutive model. The numerical formulation of this method as well as the discretization procedure is presented in order to understand the solution method of the computational program FLAC3D. The governing functions and the incremental form of the Lade-Kim model as well as stress integration algorithms such as the forward Euler scheme and its variations are presented.

The implementation of the model was successfully validated and finally, the model was applied in different cases of deformation analyses. In this chapter, conclusions and suggestions based on the research work in this dissertation are presented in order to provide other authors with a background regarding constitutive model implementation and its application in geotechnical projects.

\subsection{Conclusions}

Based on the results obtained in this dissertation, the following main conclusions are presented:

(a) The FLAC3D code adopts a discrete-model approach where the medium is represented by a discrete representative model that is formed by constant strain-rate elements. Due to this fact, the grid adopted in FLAC3D tends to be finer than grids adopted in a finite element code in order to obtain results with acceptable accuracy.

(b) The two types of grid (hexahedral and tetrahedral) are used for different validation cases. However, thinner layers are needed in the case of the hexahedral grid in order to obtain smooth results due to the discretization technique used.

(c) Regarding layered analysis, different authors provided observations that were taken into account during the numerical model of the dam. However, results were more similar to the measured on field ones after adopting thinner layers at the top of the dam.

(d) The implemented constitutive model was initially validated through numerical simulations of drained compression triaxial tests. Although this type of tests is performed on cylindrical samples in laboratory, a hexahedral zone was considered in order to represent the sample since applying the boundary conditions was relatively simpler.

(e) The adopted stress integration scheme for the implementation procedure 
provided satisfactory results in the validation cases and the analysis of the earth dam. The explicit scheme was adopted considering that FLAC3D uses small timesteps when finding a numerical solution.

(f) The Lade-Kim model showed efficiency regarding modeling geomechanical behavior through numerical simulation of laboratory tests and construction of dams since it provided numerical results similar to the measured data. This allows to confirm that the Lade-Kim model is capable of modeling soil response under different combinations of effective stress.

(g) A three-dimensional analysis takes into account the influence of the intermediate stress. Therefore, the provided results represent reality in a more efficient way than those obtained through a two-dimensional analysis. Although the discrepancies were relatively small, the intermediate stress influence was noticed in the comparison between the two- and threedimensional analyses of the Llancopi dam. It is important to note that for a greater gravity load, greater discrepancies may be obtained from these analyses.

(h) The implementation of the Lade-Kim model on a finite volume code (FLAC3D) that takes into account the intermediate stress influence constitutes a powerful tool to be used when analyzing geotechnical engineering projects in which modeling soil response is crucial.

\subsection{Suggestions}

The following suggestions are meant to be taken into account in future research work:

(a) Implement a variation of the Lade-Kim model that takes into account the creep behavior of granular materials.

(b) Perform a three-dimensional analysis of other types of construction in order to analyze the efficiency of the implemented model.

(c) Perform parametric analyses regarding the parameters involved in the LadeKim model. 


\section{Bibliography}

[1] ABBO, A.; SLOAN, S.. Backward euler and subincrementation schemes in computational plasticity. Computational Plasticity, Val-liapan et al.(eds). Balkema: Rotterdam, 1993.

[2] BIENIAWSKI, Z. T.. Engineering rock mass classifications: a com-plete manual for engineers and geologists in mining, civil, and petroleum engineering. John Wiley \& Sons, 1989.

[3] BORJA, R. I.. Plasticity, volumen 2. Springer, 2013.

[4] CHARLES, J. A.. The use of one-dimensional compression tests and elastic theory in predicting deformations of rockfill embank-ments. Canadian Geotechnical Journal, 13(3):189-200, 1976.

[5] CHEN, W.-F.; MIZUNO, E. ; OTHERS. Nonlinear analysis in soil mechanics. Número BOOK. Elsevier Amsterdam, 1990.

[6] CLOUGH, R. W.; WOODWARD, R. J.. Analysis of embankment stresses and deformations. Journal of Soil Mechanics \& Foundations Div, 1967.

[7] CRISFIELD, M.. Basic plasticity. Non-linear finite element analysis of solids and structures Vol, 1:152-200, 1991.

[8] DE MELO, L.; HARTL, H.. Lade and kim elasto-plastic constitutive model: Implementation into a fem code.

[9] DE SAINT-VENANT, B.. Memóire sur l'établissement des équations di eréntielles des mouvements intérieurs opérés dans les corps solides ductiles au delá des limites oú l'élasticité pourrait les ramener á leur premier état. Compt. Rend, 70:473-480, 1870.

[10] DUNCAN, J. M.; CHANG, C.-Y.. Nonlinear analysis of stress and strain in soils. Journal of Soil Mechanics \& Foundations Div, 1970.

[11] EGGING, D. E.; KO, H.-Y.. Constitutive relations of randomly ori-ented steel fiber reinforced concrete under multiaxial compres-sive loadings. Technical report, COLORADO UNIV AT BOULDER DEPT OF CIVIL ENVIRONMENTAL AND ARCHITECTURAL . . , 1981.

[12] FREIBERGER, W.. (1960), the international dictionary of applied mathematics.

[13] HAMZA, M. M. A. F.. The analysis of embankment dams by nonlinear finite element method. 1976.

[14] JAKOBSEN, K. P.. Application of the single hardening model in the finite 
element program ABAQUS. Geotechnical Engineering Group, Department of Civil Engineering, Aalborg . . , 1999.

[15] JAKOBSEN, K.; LADE, P. V.. Implementation algorithm for a single hardening constitutive model for frictional materials. International Journal for Numerical and Analytical Methods in Geomechanics, 26(7):661-681, 2002.

[16] KIM, M. K.; LADE, P. V.. Single hardening constitutive model for frictional materials: I. plastic potential function. Computers and Geotechnics, 5(4):307-324, 1988.

[17] KOVACEVIC, N.. Numerical analyses of rockfill dams, cut slopes and road embankments. 1994.

[18] LADE, P. V.. The stress-strain and strength characteristics of cohesionless soils. Thesis Doctoral, Universidad de California, 1972.

[19] LADE, P. V.. Elasto-plastic stress-strain theory for cohesionless soil with curved yield surfaces. International Journal of Solids and Structures, 13(11):1019-1035, 1977.

[20] LADE, P.. Stress-strain theory for normally consolidated clay. In: 3RD INT. CONF. ON NUMERICAL METHODS IN GEOMECHANICS, p. 13251337, 1979.

[21] LADE, P. V.. Modeling creep behaviour of granular materials. Computer Methods and Advances in Geomechanics, 2001.

[22] LADE, P. V.. Single hardening model for soils: parameter determi-nation and typical values. In: SOIL CONSTITUTIVE MODELS: EVALUATION, SELECTION, AND CALIBRATION, p. 290-309. 2005.

[23] LADE, P. V.; DUNCAN, J. M.. Cubical triaxial tests on cohesionless soil. Journal of Soil Mechanics \& Foundations Div, 99(Proc Paper 10057), 1973.

[24] LADE, P. V.; DUNCAN, J. M.. Elastoplastic stress-strain theory for cohesionless soil. Journal of Geotechnical and Geoenvironmental Engineering, 101(ASCE\# 11670 Proceeding), 1975.

[25] LADE, P. V.; JAKOBSEN, K.. Incrementalization of a single harden-ing constitutive model for frictional materials. International Journal for Numerical and Analytical Methods in Geomechanics, 26(7):647-659, 2002.

[26] LADE, P.; KIM, M.. Single hardening constitutive model for fric-tional materials ii. yield criterion and plastic work contours. Com-puters and geotechnics, 6(1):13-29, 1988.

[27] LADE, P.; KIM, M. K.. Single hardening constitutive model for frictional 
materials iii. comparisons with experimental data. Computers and Geotechnics, 6(1):31-47, 1988.

[28] LADE, P. V.; LIU, C.-T.. Experimental study of drained creep behavior of sand. Journal of Engineering Mechanics, 124(8):912-920, 1998.

[29] LADE, P. V.; NELSON, R. B.. Incrementalization procedure for elastoplastic constitutive model with multiple, intersecting yield surfaces. International Journal for Numerical and Analytical Methods in Geomechanics, 8(4):311-323, 1984.

[30] MANUAL, F.-U.. Itasca consulting group inc. Minnesota, USA, 2007.

[31] MARTI, J.; CUNDALL, P.. Mixed discretization procedure for accurate modelling of plastic collapse. International Journal for Numerical and Analytical Methods in Geomechanics, 6(1):129-139, 1982.

[32] MELAN, E.. Zur plastizität des räumlichen kontinuums. Archive of Applied Mechanics, 9(2):116-126, 1938.

[33] NAYLOR, D.. Finite element methods for fills and embankment dams. In: ADVANCES IN ROCKFILL STRUCTURES, p. 291-340. Springer, 1991.

[34] NAYLOR, D.; JONES, D.. The prediction of settlement within broad layered fills. Géotechnique, 23(4):589-594, 1973.

[35] NAYLOR, D.; MARANHA DAS NEVES, E.; MATTAR, D. ; VEIGA PINTO, A.. Prediction of construction performance of beliche dam. Geotechnique, 36(3):359-376, 1986.

[36] NAYLOR, D.; MATTAR JR, D.. Layered analysis of embankment dams. In: NUMERICAL METHODS IN GEOMECHANICS, INNSBRUCK 1988. PROCEEDINGS OF THE SIXTH INTERNATIONAL CONFERENCE ON NUMERICAL METHODS IN GEOMECHANICS, INNSBRUCK, AUS-TRIA, p. 11-15, 1988.

[37] NOGUEIRA, C.. Análise não linear de escavações e aterros. DSc thesis, Pontifícia Universidade Católica do Rio de Janeiro, Rio de Janeiro, Brazil in Portuguese, 1998.

[38] ORTIZ, M.; SIMO, J.. An analysis of a new class of integration algorithms for elastoplastic constitutive relations. International Journal for Numerical Methods in Engineering, 23(3):353-366, 1986.

[39] POTTS, D.; GENS, A.. A critical assessment of methods of correct-ing for drift from the yield surface in elasto-plastic finite element analysis. International Journal for Numerical and Analytical Methods in Geomechanics, 9(2):149-159, 1985. 
[40] PRAGER, W.. Recent developments in the mathematical theory of plasticity. Journal of applied physics, 20(3):235-241, 1949.

[41] SCHICKERT, G.; WINKLER, H.. Results of test concerning strength and strain of concrete subjected to multi-axial compressive stress. 1977.

[42] SLOAN, S. W.. Substepping schemes for the numerical integra-tion of elastoplastic stress-strain relations. International journal for numerical methods in engineering, 24(5):893-911, 1987.

[43] SMITH, I.; GRIFFITHS, D.. Programming the finite element method. Chichester: Wiley, 1988, 2nd ed., 1988.

[44] VALVERDE, N.. Análise Elasto-plástica 3D de fundações superfi-ciais e aterros pelo Método dos Elementos Finitos. $\mathrm{PhD}$ thesis, Masters dissertation, PUC Rio/UFOP, 2010.

[45] VEIGA PINTO, A.; MARANHA DAS NEVES, E.. Prediction of beliche dam behaviour during reservoir filling. In: INTERNATIONAL CONFERENCE ON SOIL MECHANICS AND FOUNDATION ENGINEERING. 11,p. 2021-2024, 1985.

[46] WILSON, A.; EVANS, J.. The use of low grade rockfill at roadford dam. In: THE EMBANKMENT DAM: PROCEEDINGS OF THE SIXTH CONFERENCE OF THE BRITISH DAM SOCIETY HELD IN NOTTING-HAM ON 12-15 SEPTEMBER 1990, p. 21-27. Thomas Telford Publishing, 1991.

[47] ZIENKIEWICZ, O.. The finite element method. vol. 2, solid and fluid mechanics. 1991. 